\title{
Article
}

\section{Probiotics for maintenance of remission in ulcerative colitis}

Iheozor-Ejiofor, Zipporah, Kaur, Lakhbir, Gordon, Morris, Baines, Patricia Anne, Sinopoulou, Vasiliki and Akobeng, Anthony K

Available at http://clok.uclan.ac.uk/32070/

Iheozor-Ejiofor, Zipporah, Kaur, Lakhbir, Gordon, Morris ORCID: 0000-00021216-5158, Baines, Patricia Anne, Sinopoulou, Vasiliki ORCID: 0000-00022831-9406 and Akobeng, Anthony K (2020) Probiotics for maintenance of remission in ulcerative colitis. Cochrane Database of Systematic Reviews .

It is advisable to refer to the publisher's version if you intend to cite from the work. http://dx.doi.org/10.1002/14651858.cd007443.pub3

For more information about UCLan's research in this area go to http://www.uclan.ac.uk/researchgroups/ and search for <name of research Group>.

For information about Research generally at UCLan please go to http://www.uclan.ac.uk/research/

All outputs in CLoK are protected by Intellectual Property Rights law, including Copyright law. Copyright, IPR and Moral Rights for the works on this site are retained by the individual authors and/or other copyright owners. Terms and conditions for use of this material are defined in the policies page.

\section{CLoK}

Central Lancashire online Knowledge www.clok.uclan.ac.uk

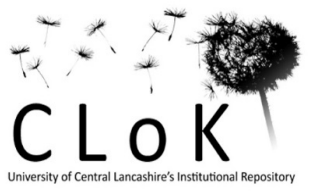


Cochrane Database of Systematic Reviews

\section{Probiotics for maintenance of remission in ulcerative colitis} (Review)

Iheozor-Ejiofor Z, Kaur L, Gordon M, Baines PA, Sinopoulou V, Akobeng AK

Iheozor-Ejiofor Z, Kaur L, Gordon M, Baines PA, Sinopoulou V, Akobeng AK. Probiotics for maintenance of remission in ulcerative colitis.

Cochrane Database of Systematic Reviews 2020, Issue 3. Art. No.: CD007443. DOI: 10.1002/14651858.CD007443.pub3. 
TABLE OF CONTENTS

HEADER 1

ABSTRACT

PLAIN LANGUAGE SUMMARY

SUMMARY OF FINDINGS

BACKGROUND

OBJECTIVES

METHODS

Figure 1.

RESULTS

Figure 2.

Figure 3.

Figure 4.

Figure 5.

DISCUSSION

AUTHORS' CONCLUSIONS

ACKNOWLEDGEMENTS

REFERENCES

CHARACTERISTICS OF STUDIES

DATA AND ANALYSES

Analysis 1.1. Comparison 1 Probiotics versus placebo, Outcome 1 Clinical relapse.

Analysis 1.2. Comparison 1 Probiotics versus placebo, Outcome 2 Maintenance of clinical remission.

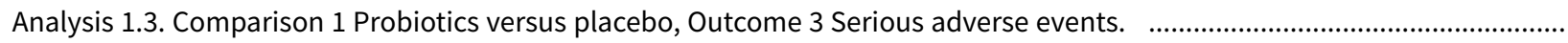

Analysis 1.4. Comparison 1 Probiotics versus placebo, Outcome 4 Withdrawal due to adverse events. ...................................

Analysis 1.5. Comparison 1 Probiotics versus placebo, Outcome 5 Health-related quality of life.

Analysis 2.1. Comparison 2 Probiotics versus 5-aminosalicylic acid (5-ASA) (mesalazine), Outcome 1 Clinical relapse. .............

Analysis 2.2. Comparison 2 Probiotics versus 5-aminosalicylic acid (5-ASA) (mesalazine), Outcome 2 Maintenance of clinical remission.

Analysis 2.3. Comparison 2 Probiotics versus 5-aminosalicylic acid (5-ASA) (mesalazine), Outcome 3 Serious adverse events. ... Analysis 2.4. Comparison 2 Probiotics versus 5-aminosalicylic acid (5-ASA) (mesalazine), Outcome 4 Withdrawal due to adverse events.

Analysis 2.5. Comparison 2 Probiotics versus 5-aminosalicylic acid (5-ASA) (mesalazine), Outcome 5 Health-related quality of life.

Analysis 3.1. Comparison 3 Probiotic + 5-aminosalicylic acid (5-ASA) (mesalazine) versus 5-ASA (mesalazine), Outcome 1 Clinical relapse.

Analysis 3.2. Comparison 3 Probiotic + 5-aminosalicylic acid (5-ASA) (mesalazine) versus 5-ASA (mesalazine), Outcome 2 Maintenance of clinical remission.

Analysis 3.3. Comparison 3 Probiotic + 5-aminosalicylic acid (5-ASA) (mesalazine) versus 5-ASA (mesalazine), Outcome 3 Withdrawal due to serious adverse events.

ADDITIONAL TABLES

APPENDICES

WHAT'S NEW

HISTORY

CONTRIBUTIONS OF AUTHORS

DECLARATIONS OF INTEREST

SOURCES OF SUPPORT

DIFFERENCES BETWEEN PROTOCOL AND REVIEW

INDEX TERMS 
[Intervention Review]

\title{
Probiotics for maintenance of remission in ulcerative colitis
}

\author{
Zipporah Iheozor-Ejiofor ${ }^{1}$, Lakhbir Kaur ${ }^{1}$, Morris Gordon1,2, Patricia Anne Baines 3 , Vasiliki Sinopoulou ${ }^{1}$, Anthony K Akobeng4 \\ 1School of Medicine, University of Central Lancashire, Preston, UK. ${ }^{2}$ Families Division, Blackpool Victoria Hospital, Blackpool, UK. \\ 3Preston, UK. ${ }^{4}$ Sidra Medicine, Doha, Qatar
}

Contact address: Anthony K Akobeng, Sidra Medicine, PO Box 26999, Doha, Qatar. aakobeng@sidra.org, akobeng@aol.com.

Editorial group: Cochrane IBD Group

Publication status and date: New search for studies and content updated (no change to conclusions), published in Issue 3, 2020.

Citation: Iheozor-Ejiofor Z, Kaur L, Gordon M, Baines PA, Sinopoulou V, Akobeng AK. Probiotics for maintenance of remission in ulcerative colitis. Cochrane Database of Systematic Reviews 2020, Issue 3. Art. No.: CD007443. DOI: 10.1002/14651858.CD007443.pub3.

Copyright $(2020$ The Cochrane Collaboration. Published by John Wiley \& Sons, Ltd.

\begin{abstract}
A B S T R A C T

\section{Background}

Ulcerative colitis is an inflammatory condition affecting the colon, with an annual incidence of approximately 10 to 20 per 100,000 people. The majority of people with ulcerative colitis can be put into remission, leaving a group who do not respond to first- or secondline therapies. There is a significant proportion of people who experience adverse effects with current therapies. Consequently, new alternatives for the treatment of ulcerative colitis are constantly being sought. Probiotics are live microbial feed supplements that may beneficially affect the host by improving intestinal microbial balance, enhancing gut barrier function and improving local immune response.
\end{abstract}

\section{Objectives}

The primary objective was to determine the efficacy of probiotics compared to placebo, no treatment, or any other intervention for the maintenance of remission in people with ulcerative colitis. The secondary objective was to assess the occurrence of adverse events associated with the use of probiotics.

\section{Search methods}

We searched CENTRAL, MEDLINE, Embase, and two other databases on 31 October 2019. We contacted authors of relevant studies and manufacturers of probiotics regarding ongoing or unpublished trials that may be relevant to the review, and we searched ClinicalTrials.gov. We also searched references of trials for any additional trials.

\section{Selection criteria}

Randomised controlled trials (RCTs) that compared probiotics against placebo or any other intervention, in both adults and children, for the maintenance of remission in ulcerative colitis were eligible for inclusion. Maintenance therapy had to be for a minimum of three months when remission has been established by any clinical, endoscopic, histological or radiological relapse as defined by study authors.

\section{Data collection and analysis}

Two review authors independently conducted data extraction and 'Risk of bias' assessment of included studies. We analysed data using Review Manager 5. We expressed dichotomous and continuous outcomes as risk ratios (RRs) and mean differences (MDs) with 95\% confidence intervals $(\mathrm{Cls})$. We assessed the certainty of the evidence using the GRADE methodology.

\section{Main results}

In this review, we included 12 studies (1473 randomised participants) that met the inclusion criteria. Participants were mostly adults. The studies compared probiotics to placebo, probiotics to 5-aminosalicylic acid (5-ASA) and a combination of probiotics and 5-ASA to 5-ASA. The studies ranged in length from 12 to 52 weeks. The average age of participants was between 32 and 51 , with a range between 18 and 88 years. Seven studies investigated a single bacterial strain, and five studies considered mixed preparations of multiple strains. The risk 
of bias was high in all except three studies due to selective reporting, incomplete outcome data and lack of blinding. This resulted in lowto very low-certainty of evidence.

It is uncertain if there is any difference in occurrence of clinical relapse when probiotics are compared with placebo $(\mathrm{RR} 0.87,95 \% \mathrm{Cl} 0.63$ to 1.18; 4 studies, 361 participants; very low-certainty evidence (downgraded for risk of bias, imbalance in baseline characteristics and imprecision)). It is also uncertain whether probiotics lead to a difference in the number of people who maintain clinical remission compared with placebo (RR 1.16, 95\% Cl 0.98 to $1.37 ; 2$ studies, 141 participants; very low-certainty evidence (downgraded for risk of bias, imbalance in baseline characteristics and imprecision)).

When probiotics are compared with 5-ASA, there may be little or no difference in clinical relapse (RR $1.01,95 \% \mathrm{Cl} 0.84$ to $1.22 ; 2$ studies, 452 participants; low-certainty evidence) and maintenance of clinical remission (RR 1.06, 95\% Cl 0.90 to $1.25 ; 1$ study, 125 participants; low-certainty evidence). It is uncertain if there is any difference in clinical relapse when probiotics, combined with 5-ASA are compared with 5-ASA alone (RR 1.11, 95\% Cl 0.66 to 1.87 ; 2 studies, 242 participants; very low-certainty evidence (downgraded due to risk of bias and imprecision)). There may be little or no difference in maintenance of remission when probiotics, combined with 5-ASA, are compared with 5-ASA alone (RR 1.05, 95\% Cl 0.89 to 1.24; 1 study, 122 participants; low-certainty evidence).

Where reported, most of the studies which compared probiotics with placebo recorded no serious adverse events or withdrawals due to adverse events. For the comparison of probiotics and 5-ASA, one trial reported 11/110 withdrawals due to adverse events with probiotics and $11 / 112$ with 5-ASA (RR 1.02, 95\% Cl 0.46 to 2.25; 222 participants; very low-certainty evidence). Discontinuation of therapy was due to gastrointestinal symptoms. One study (24 participants) comparing probiotics combined with 5-ASA with 5-ASA alone, reported no withdrawals due to adverse events; and two studies reported two withdrawals in the probiotic arm, due to avascular necrosis of bilateral femoral head and pulmonary thromboembolism (RR 5.29, 95\% Cl 0.26 to 107.63 ; 127 participants; very low-certainty evidence).

Health-related quality of life and need for additional therapy were reported infrequently.

\section{Authors' conclusions}

The effectiveness of probiotics for the maintenance of remission in ulcerative colitis remains unclear. This is due to low- to very lowcertainty evidence from poorly conducted studies, which contribute limited amounts of data from a small number of participants. Future trials comparing probiotics with 5-ASA rather than placebo will better reflect conventional care given to people with ulcerative colitis. Appropriately powered studies with a minimum length of 12 months are needed.

\section{PLAIN LANGUAGE SUMMARY}

\section{Probiotics for maintenance of remission in ulcerative colitis}

\section{What is the aim of this review?}

The aim of this Cochrane Review was to find out whether probiotics can maintain remission in people with ulcerative colitis. We collected and analysed data from 12 studies with a total of 1473 people to answer this question.

\section{Key messages}

The question on whether probiotics can maintain remission in people with ulcerative colitis remains unanswered. There were no serious adverse events when probiotics were compared with placebo. However, one study reported similar numbers of serious adverse events in people who had probiotics and those who received 5-aminosalicylic acid (5-ASA, an anti-inflammatory medicine used to treat ulcerative colitis and other conditions. . More information as to what these serious adverse events are, was not provided.

\section{What was studied in the review?}

Ulcerative colitis is a chronic disease of the large bowel, which causes inflammation (swelling). Some of the symptoms include tummy pain, diarrhoea and tiredness. Probiotics are living microscopic organisms that are thought to change the growth of bacteria in the bowel and reduce inflammation.

\section{What are the main results of the review?}

We searched for randomised controlled trials (RCTs; clinical studies where people are randomly put into one of two or more treatment groups) comparing probiotics with placebo (dummy treatment), probiotics with 5-ASA and a combination of probiotics and 5-ASA with 5ASA. There were 12 RCTs involving 1473 participants. The trials looked at adult males and females. Only three studies clearly stated that participants were not allowed to take other medication outside of those being compared.

1) There was no clear difference in the number of people who had a clinical relapse when probiotics were compared with placebo.

2) There was also no clear difference in the number of people who had a clinical relapse when probiotics were compared with 5-ASA. 
3) It is uncertain whether probiotics lead to a difference in the number of people who remain in clinical remission compared with placebo because the quality of evidence is very low.

4) There was no clear difference in the number of people who remained in clinical remission when probiotics were compared to 5-ASA.

5) When probiotics combined with 5-ASA was compared to 5-ASA alone, there was no clear difference in the number of people who remained in clinical remission.

6) It is uncertain whether probiotics combined with 5-ASA lead to a difference in the number of people who have a clinical relapse when compared with 5-ASA alone.

7) No serious adverse events were reported in the trials which compared probiotics with placebo. One study which compared probiotics with 5-ASA reported similar numbers of serious adverse events with both treatments. Discontinuation of therapy was due to gastrointestinal disorders, such as bloody stools, nausea, diarrhoea and abdominal pain.

8) There was not enough information from the studies on how probiotics affect people's quality of life and the need for additional therapy when compared to other treatments.

\section{Conclusion}

We are uncertain as to whether probiotics can maintain remission in people with ulcerative colitis. This is because the studies had very few participants and were not conducted using reliable methods. With the evidence presented in these studies, we are unable to make strong conclusions into the effectiveness of probiotics; better designed studies with more participants are needed.

\section{How up-to-date is this review?}

This review is up-to-date as of October 2019. 


\begin{tabular}{|c|c|c|c|c|c|c|}
\hline \multicolumn{7}{|c|}{ Summary of findings for the main comparison. Probiotics compared to placebo for maintenance of remission in ulcerative colitis } \\
\hline \multicolumn{7}{|c|}{ Probiotics compared to placebo for maintenance of remission in ulcerative colitis } \\
\hline \multicolumn{7}{|c|}{$\begin{array}{l}\text { Patient or population: people with ulcerative colitis in remission } \\
\text { Setting: hospitals } \\
\text { Intervention: probiotics } \\
\text { Comparison: placebo }\end{array}$} \\
\hline \multirow[t]{2}{*}{ Outcomes } & \multicolumn{2}{|c|}{$\begin{array}{l}\text { Anticipated absolute effects }{ }^{*} \\
(95 \% \mathrm{Cl})\end{array}$} & \multirow[t]{2}{*}{$\begin{array}{l}\text { Relative ef- } \\
\text { fect } \\
(95 \% \mathrm{CI})\end{array}$} & \multirow{2}{*}{$\begin{array}{l}\text { No of partici- } \\
\text { pants } \\
\text { (studies) }\end{array}$} & \multirow{2}{*}{$\begin{array}{l}\text { Certainty of } \\
\text { the evidence } \\
\text { (GRADE) }\end{array}$} & \multirow[t]{2}{*}{ Comments } \\
\hline & $\begin{array}{l}\text { Risk with } \\
\text { placebo }\end{array}$ & $\begin{array}{l}\text { Risk with probi- } \\
\text { otics }\end{array}$ & & & & \\
\hline \multirow{2}{*}{$\begin{array}{l}\text { Clinical relapse } \\
\text { (12 to } 52 \text { weeks) }\end{array}$} & \multicolumn{2}{|c|}{ Study population } & \multirow{2}{*}{$\begin{array}{l}\text { RR } 0.87 \\
\text { (0.63 to } 1.18 \text { ) }\end{array}$} & \multirow{2}{*}{$\begin{array}{l}361 \\
\text { (4 RCTs) }\end{array}$} & \multirow{2}{*}{$\begin{array}{l}\oplus \odot \ominus \ominus \\
\text { Very low } a\end{array}$} & \multirow{2}{*}{$\begin{array}{l}\text { Clinical relapse was defined as a flare-up } \\
\text { (NCT02361957), CAI } \leq 5 \text { (Yasushi 2015) and persistence } \\
\text { of a rectal bleeding score of } \leq 2 \text { on Sutherland DAI } \\
\text { score for } 3 \text { consecutive days and/or initiation of remis- } \\
\text { sion induction therapy for worsening of ulcerative col- } \\
\text { itis (Matsuoka 2018), respectively }\end{array}$} \\
\hline & 554 per 1000 & $\begin{array}{l}493 \text { per } 1000 \\
\text { (399 to } 609)\end{array}$ & & & & \\
\hline \multirow{2}{*}{$\begin{array}{l}\text { Maintenance of clinical } \\
\text { remission } \\
\text { (52 weeks) }\end{array}$} & \multicolumn{2}{|c|}{ Study population } & \multirow{2}{*}{$\begin{array}{l}\text { RR } 1.16 \\
\text { (0.98 to } 1.37)\end{array}$} & \multirow{2}{*}{$\begin{array}{l}141 \\
(2 \mathrm{RCTs})\end{array}$} & \multirow{2}{*}{$\begin{array}{l}\oplus \odot \odot \odot \\
\text { Very low } a\end{array}$} & \multirow{2}{*}{$\begin{array}{l}\text { Maintenance of remission is the number of partici- } \\
\text { pants who did not relapse. One additional study re- } \\
\text { ported insufficient data for inclusion in the meta- } \\
\text { analysis, therefore, we did not further analyse the re- } \\
\text { sults (reported } P=0.643 \text { ). }\end{array}$} \\
\hline & 400 per 1000 & $\begin{array}{l}532 \text { per } 1000 \\
\text { (308 to } 924)\end{array}$ & & & & \\
\hline $\begin{array}{l}\text { Serious adverse events } \\
\text { ( } 48 \text { to } 52 \text { weeks) }\end{array}$ & See comment & See comment & - & $\begin{array}{l}351 \\
(4 \mathrm{RCTs})\end{array}$ & - & $\begin{array}{l}\text { Four studies reported that no serious adverse events } \\
\text { occurred. }\end{array}$ \\
\hline $\begin{array}{l}\text { Withdrawal due to ad- } \\
\text { verse events }\end{array}$ & See comment & See comment & - & $\begin{array}{l}113 \\
(2 \mathrm{RCTs})\end{array}$ & - & $\begin{array}{l}\text { Two studies reported there were no withdrawals due } \\
\text { to adverse events. }\end{array}$ \\
\hline $\begin{array}{l}\text { Need for additional } \\
\text { therapy }\end{array}$ & \multicolumn{6}{|c|}{ Not reported in any of the studies } \\
\hline $\begin{array}{l}\text { Health-related quality } \\
\text { of life } \\
\text { (12 weeks) }\end{array}$ & $\begin{array}{l}\text { Mean IBD-Q } \\
\text { score with } \\
\text { placebo was } \\
3.5\end{array}$ & $\begin{array}{l}\text { MD } 0.70 \text { points } \\
\text { lower } \\
\text { (1.63 lower to } \\
0.23 \text { higher) }\end{array}$ & - & $\begin{array}{l}25 \\
(1 \mathrm{RCT})\end{array}$ & $\begin{array}{l}\oplus \oplus \ominus \ominus \\
\text { Lowb }\end{array}$ & $\begin{array}{l}\text { Scale: IBD-Q, range } 1-7 \text {, higher score = better quality } \\
\text { of life }\end{array}$ \\
\hline
\end{tabular}


*The risk in the intervention group (and its $95 \%$ confidence interval) is based on the mean risk in the comparison group and the relative effect of the intervention (and its $95 \% \mathrm{Cl})$.

CAI: colitis activity index CI: confidence interval; DAI: disease activity index; IBD-Q: inflammatory bowel disease questionnaire; MD: mean difference; RCT: randomised controlled trial; RR: risk ratio

\section{GRADE Working Group grades of evidence}

High certainty: we are very confident that the true effect lies close to that of the estimate of the effect.

Moderate certainty: we are moderately confident in the effect estimate; the true effect is likely to be close to the estimate of the effect, but there is a possibility that it is

substantially different.

Low certainty: our confidence in the effect estimate is limited; the true effect may be substantially different from the estimate of the effect.

Very low certainty: we have very little confidence in the effect estimate; the true effect is likely to be substantially different from the estimate of effect.

aDowngraded three times: risk of reporting bias and other bias due to imbalance in baseline characteristics, imprecision due to small sample size.

bDowngraded two times: imprecision due to small sample size from a single study resulting in wide confidence interval.

Summary of findings 2. Probiotics compared to 5-aminosalicylic acid (5-ASA) (mesalazine) for maintenance of remission in ulcerative colitis

\section{Probiotics compared to 5-ASA (mesalazine) for maintenance of remission in ulcerative colitis}

Patient or population: people with ulcerative colitis in remission

Setting: hospitals

Intervention: probiotics

Comparison: 5-ASA

\begin{tabular}{|c|c|c|c|c|c|c|}
\hline \multirow[t]{2}{*}{ Outcomes } & \multicolumn{2}{|c|}{$\begin{array}{l}\text { Anticipated absolute effects* }(95 \% \\
\mathrm{Cl} \text { ) }\end{array}$} & \multirow[t]{2}{*}{$\begin{array}{l}\text { Relative ef- } \\
\text { fect } \\
(95 \% \mathrm{Cl})\end{array}$} & \multirow[t]{2}{*}{$\begin{array}{l}\text { № of partici- } \\
\text { pants } \\
\text { (studies) }\end{array}$} & \multirow[t]{2}{*}{$\begin{array}{l}\text { Certainty of } \\
\text { the evidence } \\
\text { (GRADE) }\end{array}$} & \multirow[t]{2}{*}{ Comments } \\
\hline & $\begin{array}{l}\text { Risk with 5- } \\
\text { ASA }\end{array}$ & Risk with probiotics & & & & \\
\hline \multirow{2}{*}{$\begin{array}{l}\text { Clinical relapse } \\
\text { (52 weeks) }\end{array}$} & \multicolumn{2}{|c|}{ Study population } & \multirow{2}{*}{$\begin{array}{l}\text { RR } 1.01 \\
\text { (0.84 to } 1.22)\end{array}$} & \multirow{2}{*}{$\begin{array}{l}452 \\
(2 \mathrm{RCTs})\end{array}$} & \multirow{2}{*}{$\begin{array}{l}\oplus \oplus \odot \odot \\
\mathbf{L o w}^{a}\end{array}$} & \multirow{2}{*}{$\begin{array}{l}\text { Clinical relapse was based on the presence of all the } \\
\text { following: CAI > } 6 \text { (or an increase in CAl of at least } \\
3 \text { points with CAI = } 4 \text { being exceeded at the same } \\
\text { time); endoscopic index }>4 \text {; histological signs of } \\
\text { acute inflammation (Kruis 2004) and appearance of } \\
\text { ulcerative colitis symptoms or an increase in CAI to } \\
\text { more than } 4 \text { points (Zocco 2006) }\end{array}$} \\
\hline & 458 per 1000 & $\begin{array}{l}458 \text { per } 1000 \\
\text { ( } 380 \text { to } 554)\end{array}$ & & & & \\
\hline \multirow{2}{*}{$\begin{array}{l}\text { Maintenance of clini- } \\
\text { cal remission } \\
\text { (52 weeks) }\end{array}$} & \multicolumn{2}{|c|}{ Study population } & \multirow{2}{*}{$\begin{array}{l}\text { RR } 1.06 \\
(0.90 \text { to } 1.25)\end{array}$} & \multirow{2}{*}{$\begin{array}{l}125 \\
(1 \mathrm{RCT})\end{array}$} & \multirow{2}{*}{$\begin{array}{l}\oplus \oplus \ominus \ominus \\
\text { Low }^{b}\end{array}$} & \multirow{2}{*}{$\begin{array}{l}\text { Maintenance of remission is the number of partici- } \\
\text { pants who did not relapse. }\end{array}$} \\
\hline & 800 per 1000 & 848 per 1000 & & & & \\
\hline
\end{tabular}




\begin{tabular}{|c|c|c|c|c|c|c|}
\hline \multirow{3}{*}{ 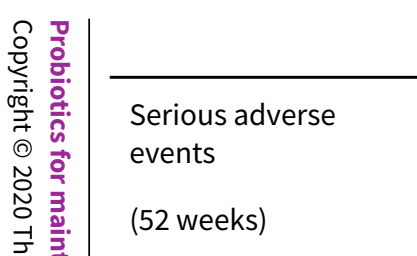 } & \multicolumn{2}{|r|}{ (720 to 1000 ) } & & & & \\
\hline & \multicolumn{2}{|c|}{ Study population } & \multirow{2}{*}{$\begin{array}{l}\text { RR } 1.19 \\
\text { (0.41 to } 3.46)\end{array}$} & \multirow{2}{*}{$\begin{array}{l}327 \\
(1 \mathrm{RCT})\end{array}$} & \multirow{2}{*}{$\begin{array}{l}\oplus \ominus \odot \odot \\
\text { Very lowd }\end{array}$} & \multirow[t]{2}{*}{ Serious adverse events were not reported in detail } \\
\hline & 36 per 1000 & $\begin{array}{l}43 \text { per } 1000 \\
(15 \text { to } 126)\end{array}$ & & & & \\
\hline Withdrawal due to & \multicolumn{2}{|c|}{ Study population } & \multirow{2}{*}{$\begin{array}{l}\text { RR } 1.02 \\
\text { (0.46 to } 2.25)\end{array}$} & \multirow{2}{*}{$\begin{array}{l}222 \\
\text { (1 study) }\end{array}$} & \multirow{2}{*}{$\begin{array}{l}\oplus \ominus \odot \odot \\
\text { Very lowe }\end{array}$} & \multirow{2}{*}{$\begin{array}{l}\text { Discontinuation of therapy was due to gastrointesti- } \\
\text { nal disorders, such as bloody stools, nausea, diar- } \\
\text { rhoea, mucous secretion and abdominal pain }\end{array}$} \\
\hline (52 weeks) & 98 per 1000 & $\begin{array}{l}100 \text { per } 1000 \\
\text { ( } 45 \text { to } 221)\end{array}$ & & & & \\
\hline $\begin{array}{l}\text { Need for additional } \\
\text { therapy }\end{array}$ & \multicolumn{2}{|c|}{ Not reported in any of the studies } & & & & \\
\hline $\begin{array}{l}\text { Health-related quali- } \\
\text { ty of life } \\
\text { (52 weeks) }\end{array}$ & $\begin{array}{l}\text { Mean IBD-Q } \\
\text { score with 5- } \\
\text { ASA was } 24.3 \\
\text { points }\end{array}$ & $\begin{array}{l}\text { MD } 0.80 \text { points low- } \\
\text { er ( } 2.01 \text { lower to } 0.41 \\
\text { higher) }\end{array}$ & & $\begin{array}{l}222 \\
(1 \mathrm{RCT})\end{array}$ & $\begin{array}{l}\oplus \oplus \ominus \ominus \\
\text { Lowc }\end{array}$ & $\begin{array}{l}\text { Scale: IBD-Q, range } 1-32 \text {, higher score = better quali- } \\
\text { ty of life }\end{array}$ \\
\hline
\end{tabular}

${ }^{\star}$ The risk in the intervention group (and its 95\% confidence interval) is based on the mean risk in the comparison group and the relative effect of the intervention (and its $95 \% \mathrm{Cl}$.

5-ASA: 5-aminosalicylic acid; CAI: colitis activity index CI: confidence interval; IBD-Q: inflammatory bowel disease questionnaire; RCT: randomised controlled trial; RR: risk ratio

\section{GRADE Working Group grades of evidence}

High certainty: we are very confident that the true effect lies close to that of the estimate of the effect.

Moderate certainty: we are moderately confident in the effect estimate; the true effect is likely to be close to the estimate of the effect, but there is a possibility that it is substantially different.

Low certainty: our confidence in the effect estimate is limited; the true effect may be substantially different from the estimate of the effect.

Very low certainty: we have very little confidence in the effect estimate; the true effect is likely to be substantially different from the estimate of effect.

aDowngraded two times: risk of attrition bias and other bias due to imbalance in baseline characteristics, imprecision due to sample size not meeting the optimal information size. bDowngraded two times: risk of performance and detection bias from an open-label study and small number of events.

cDowngraded two times: risk of attrition bias and imprecision due to small sample size.

dDowngraded three times: risk of attrition bias, imprecision due to small number of events from a single study resulting in wide confidence interval which includes appreciable

harm. Serious adverse events were not described in detail. eDowngraded three times: risk of attrition bias, imprecision due to small number of events from a single study resulting in wide confidence interval which includes appreciable harm. 


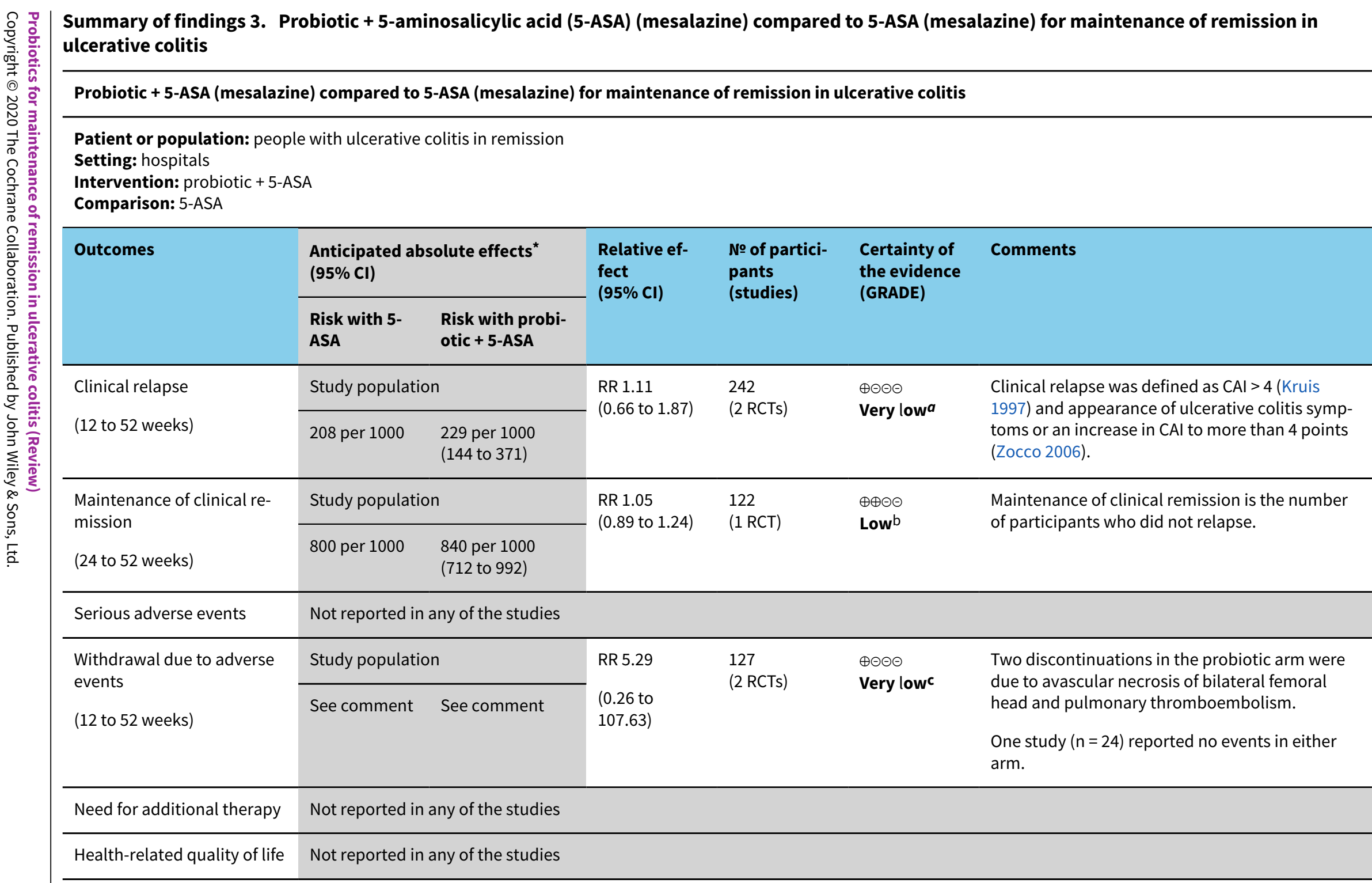

${ }^{\star}$ The risk in the intervention group (and its $95 \%$ confidence interval) is based on the mean risk in the comparison group and the relative effect of the intervention (and its $95 \% \mathrm{Cl})$.

5-ASA: 5-aminosalicylic acid; CAl: Colitis activity index CI: confidence interval; $\mathbf{R C T}$ : randomised controlled trial; RR: risk ratio 
High certainty: we are very confident that the true effect lies close to that of the estimate of the effect.

Moderate certainty: we are moderately confident in the effect estimate; the true effect is likely to be close to the estimate of the effect, but there is a possibility that it is substantially different.

Low certainty: our confidence in the effect estimate is limited; the true effect may be substantially different from the estimate of the effect.

Very low certainty: we have very little confidence in the effect estimate; the true effect is likely to be substantially different from the estimate of effect.

aDowngraded three times: risk of attrition bias, imprecision due to small number of events and confidence interval which includes appreciable harm.

bDowngraded two times: risk of performance and detection bias from an open-label study, imprecision due to small number of events.

cDowngraded three times: unclear risk of selection bias (lack of information on sequence generation), imprecision due to small number of events in a single study and confidence interval which include appreciable harm. 


\section{B A C K G R O U N D}

\section{Description of the condition}

Ulcerative colitis is a chronic relapsing disease, with the greatest reported incidence in mainland Europe and Scandinavia of 9.2 to 20.3 per 100,000 people (Loftus 2004), totalling approximately 2.2 million sufferers in Europe alone. The peak incidence of the disease occurs between 15 and 25 years of age, and there is another smaller prevalence at ages 55 to 65 . The disease is characterised by abdominal pain, bloody diarrhoea and faecal urgency. The diagnosis of ulcerative colitis is based on medical history, signs and symptoms, and any endoscopic or histopathological findings.

The disease is caused by diffuse inflammation, which starts at the rectum, spreads proximally, and is limited to the colon. The aetiology behind the disease is unknown, but is likely to be multifactorial; consisting of a genetic predisposition, dysregulation of the mucosal and epithelial barrier and lastly dysbiosis, although whether dysbiosis causes or is a result of the disease remains unclear (Ungaro 2016). The genetic component was further evaluated by Cleynen 2016 and a strong association between HLA DRB1 and ulcerative colitis was found. The genetic predisposition creates a four-fold risk for first-degree relatives.

\section{Description of the intervention}

Probiotics are live micro-organisms, that when consumed, may provide multiple health benefits. They produce their benefits by altering the gut microbiome through either enhancing the activity, volume or both, of the normal flora. Lactobacillus spp, for example, is one of the more popular probiotics and is thought to secrete bacteriocin, blocking the adherence of translocation of harmful bacteria (Panigrahi 2014).

Lactobacillus rhamnosus GG (L rhamnosus) produced mixed responses in animal models of colitis (Dieleman 2003; Shibolet 2002), as did Lactobacillus plantarum (L plantarum) 299V (Dieleman 2003; Kennedy 2000; Schultz 2002). Studies investigating combinations of probiotic species incorporated within VSL\#3 have demonstrated a partial reduction of colitis in animal models (Madsen 2001; Shibolet 2002). There has been increasing interest in the use of probiotics, as they are considered safe and easily accessible (Ong 2019). It is worth noting that there are a huge number of different preparations available, varying in the specific strains isolated, the use of mixed strains in a single preparation, the form of the preparation and finally the licensing arrangements surrounding the preparations (medicinal versus food products).

\section{How the intervention might work}

There is growing evidence looking at the effects of probiotics in the use of inducing remission in ulcerative colitis since a previous Cochrane review (Mallon 2007). Due to the part that dysbiosis plays in ulcerative colitis, there is potential benefit in trying to restore the endogenous flora. Several observations, both on humans and animal models, emphasised the importance of bacterial flora in inflammatory bowel disease pathogenesis, justifying the current interest in antibiotic and probiotic therapies aimed at the manipulation of enteric flora (Cui 2004). The therapeutic efficacy of probiotics has been demonstrated in various models of experimental colitis, including interleukin-10 deficient mice (Madsen 1999; Schultz 2002), and acetic acid-induced colitis in rats (Fabia 1993).

\section{Why it is important to do this review}

In the UK, National Institute for Health and Care Excellence (NICE) and USA guidelines state that first-line therapy for maintenance of remission in ulcerative colitis is 5-aminosalicylic acid (5-ASA) (NICE 2019). 5-ASA works by binding to PPAR-\# and reducing cytokine production. Some of the adverse effects associated with 5-ASA include headache, rash, nausea (common), pancreatitis (uncommon), and agranulocytosis (rare). Due to these side effects, some people are unable to tolerate the drug. If 5-ASA fails to work then other therapies to maintain remission include immune suppressants, such as anti-tumour necrosis factor (TNF) monoclonals, vedolizumab and tofacitinib may be used. These drugs work by blocking leukocyte recruitment at the molecular and vascular level (Fiorino 2016), some of the side effects include headache, dizziness and arthralgia.

The relapsing and remitting nature of the disease means that people can be in and out of hospital, experimenting with different drug regimes. The treatment costs Europe between GBP 11 to 26 billion pounds annually, with per patient costs approximately GBP 8011 to 9306 (Cohen 2010). If an alternative, cheaper treatment can be found for ulcerative colitis, then it would greatly benefit not only a budget stricken National Health Service (NHS), but also improve patients' quality of life. Whilst some studies have suggested that probiotics may be useful for maintenance of remission in mild to moderate ulcerative colitis (Kruis 2004; Zocco 2006), others have failed to show any benefit (Kruis 1997; Rembacken 1999). In this review we investigate the available evidence on the use of probiotics for the maintenance of remission in ulcerative colitis.

\section{O B JECT IVES}

The primary objective was to determine the efficacy of probiotics compared to placebo, no treatment, or any other intervention for the maintenance of remission in people with ulcerative colitis. The secondary objective was to assess the occurrence of adverse events associated with the use of probiotics.

\section{METHODS}

\section{Criteria for considering studies for this review}

\section{Types of studies}

We considered randomised controlled trials (RCTs), with a minimum duration of three months, for inclusion in the review.

\section{Types of participants}

People of any age with ulcerative colitis in remission, defined as clinical, endoscopic, histological or radiological relapse by study authors.

\section{Types of interventions}

Probiotics administered in any form (drink, powder, capsule), orally as a single species, or as a cocktail of multiple species compared to no treatment, placebo or any other intervention.

\section{Types of outcome measures}

\section{Primary outcomes}

- Relapse (clinical, endoscopic, histopathological or radiological), as defined by the authors of the primary studies. 
Where studies reported on the number of participants who did not experience a relapse, i.e. those who remained in remission, this was noted under 'maintenance of clinical remission'.

\section{Secondary outcomes}

- Serious adverse events

- Withdrawal due to adverse events

- Need for additional therapy

- Health-related quality of life, as measured by a validated quality of life tool

\section{Search methods for identification of studies}

\section{Electronic searches}

We conducted a comprehensive and systematic search to identify RCTs from inception to 31 October 2019 using the following databases.

- Cochrane Inflammatory Bowel Disease (IBD) Specialized Trials Register

- Cochrane Central Register of Controlled Trials (CENTRAL)

- MEDLINE

- Embase

- CINAHL

We did not place any restrictions on publication dates (after 1966) or language. See Appendix 1 for the detailed search strategies.

\section{Searching other resources}

We inspected the reference lists of all identified studies for more trials. We also contacted leaders in the field and manufacturers of probiotics to identify potentially relevant studies. We also searched ClinicalTrials.gov (clinicaltrials.gov) for ongoing trials (Appendix 1).

\section{Data collection and analysis}

We conducted data collection and analysis according to methods stipulated in the Cochrane Handbook for Systematic Reviews of Interventions (Higgins 2011).

\section{Selection of studies}

We undertook study selection in Covidence. Using the above search strategy, two review authors (LK, ZIE) identified titles that appeared to be potentially relevant. These were independently screened and in circumstances of disagreement, a third review author (AA) was involved to reach consensus.

There is some evidence that data from abstract publications can be inconsistent with data from published articles (Pitkin 1999), therefore we considered abstract publications, but only if sufficient data were presented to judge inclusion criteria fully and reports of the primary and secondary outcomes were given. If these were not available, we contacted authors directly, and if data were not provided, we excluded such studies.

The review authors, after reading the full texts, independently assessed the eligibility of all trials identified using ad hoc eligibility, based on the inclusion criteria above. Disagreement among review authors was again discussed, and agreement was reached by consensus after involvement of a third review author. We contacted authors of multiple publications, which appeared to report on the same study, for clarification. A flow chart was included (Figure 1). 
Figure 1. Study flow diagram.

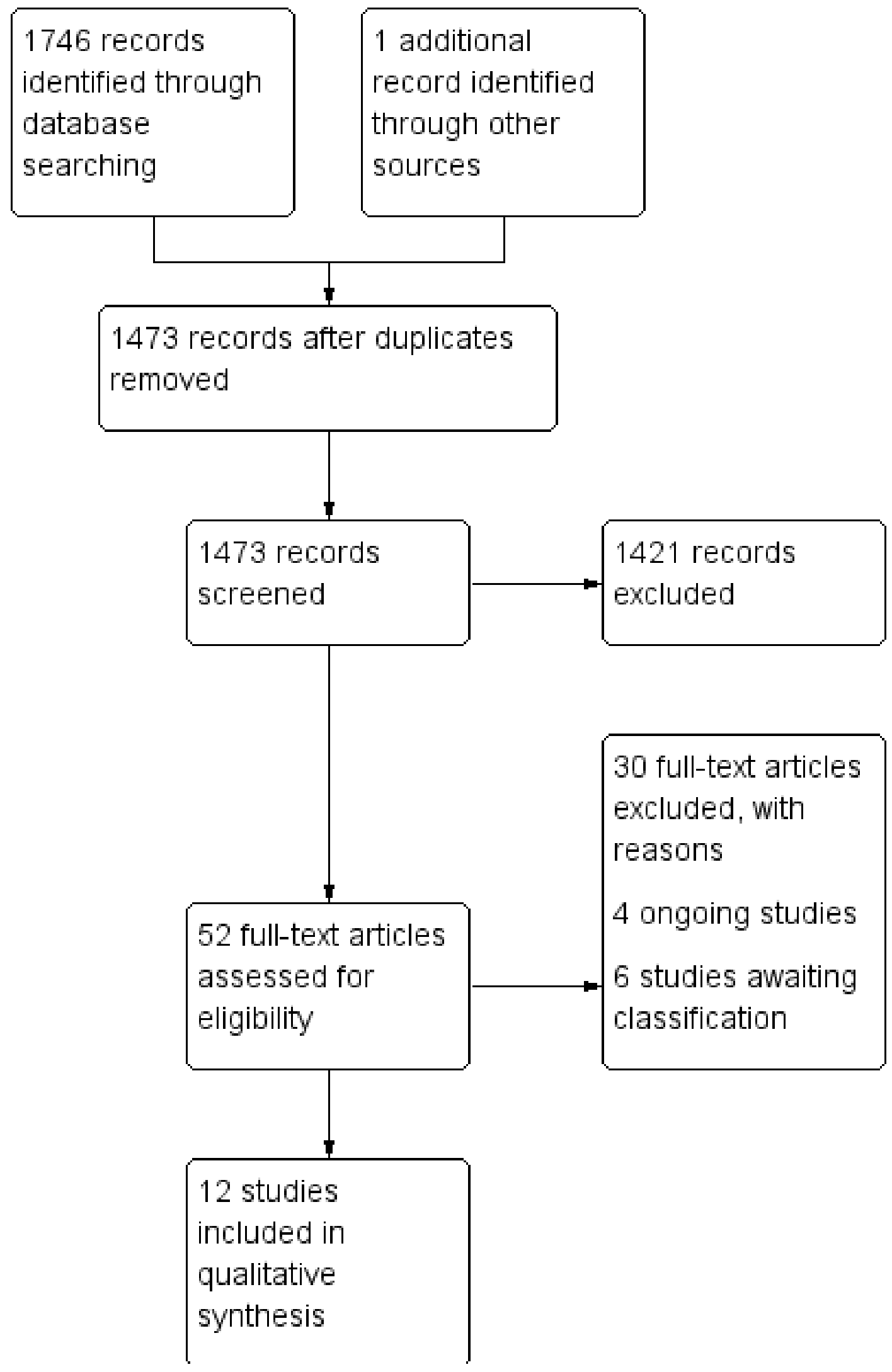


Figure 1. (Continued)

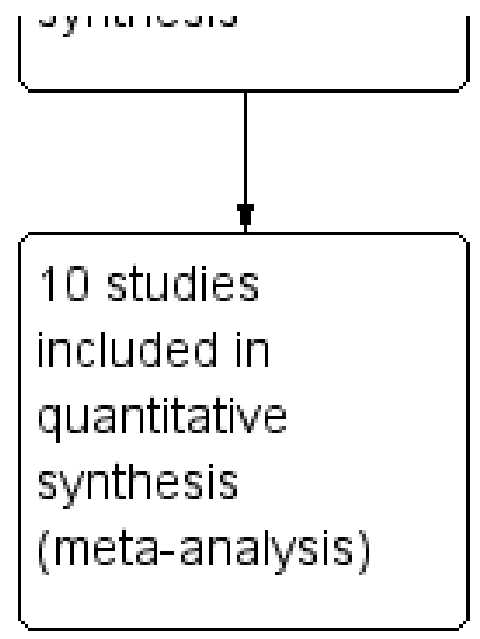

\section{Data extraction and management}

We developed a data extraction form and used it to extract information on relevant features and results of included studies. Two review authors (LK, ZIE) independently extracted and recorded data on a predefined checklist. Again, when disagreements occurred, a third review author (AA) was involved and consensus was reached. Extracted data included the following items.

- Characteristics of participants: age, sex, disease distribution, disease duration, disease activity index

- Total number of participants originally assigned to each intervention group

- Intervention: type and dose of probiotic(s)

- Control: no intervention, placebo or other interventions

- Concurrent medications

- Outcomes: time of assessment, length of follow-up, type of symptom score used or ulcerative colitis activity index, definition of remission and relapse, relapse rates, time to relapse, quality of life assessment, and adverse events

We resolved inconsistencies in data extraction, and transferred the information above into the Characteristics of included studies table.

\section{Assessment of risk of bias in included studies}

Two review authors (LK, ZIE) independently assessed risk of bias using the Cochrane 'Risk of bias' tool (Higgins 2011). We assessed the following domains.

- Selection bias

* Sequence generation (i.e. was the allocation sequence adequately generated?)

* Allocation sequence concealment (i.e. was allocation adequately concealed?)

- Performance bias (i.e. was knowledge of the allocated intervention adequately prevented during the study towards the participants?)

- Detection bias (i.e. were outcome assessors blinded adequately?)
- Attrition bias (were attritions and exclusions adequately reported?)

- Reporting bias: selective outcome reporting (i.e. are reports of the study free of suggestion of selective outcome reporting?)

- Other potential sources of bias (i.e. was the study apparently free of other problems that could put it at a high risk of bias?)

We considered subjective outcomes separately in our assessment of blinding and incompleteness of data. We judged studies to be at 'high', 'low' or 'unclear' risk of bias for each domain assessed. We judged the risk of bias across studies as follows.

- Low risk of bias (plausible bias unlikely to seriously alter the results) if all domains are at low risk of bias.

- Unclear risk of bias (plausible bias that raises some doubt about the results) if one or more domains are at unclear risk of bias.

- High risk of bias (plausible bias that seriously weakens confidence in the results) if one or more domains are at high risk of bias.

Disagreements were resolved by consensus. We contacted study authors when insufficient information was provided to determine the risk of bias. Where we obtained information supporting our judgement on risk of bias through correspondence with study authors, we indicated this in the 'Risk of bias' table.

\section{Measures of treatment effect}

The measure of treatment effect for dichotomous outcomes was risk ratios (RRs). Where continuous outcomes reported with the same scale, we used mean differences (MDs).

\section{Unit of analysis issues}

The unit of analysis was the participant. Where studies assessed more than two interventions which are relevant to the review, we made multiple pair wise comparisons and analysed just the groups of interest. We did not include the same group of participants twice in the same meta-analysis. We were alert to the unit of analysis issues relating to outcome reporting at different follow-up times and only reported outcomes at final follow-up. 


\section{Dealing with missing data}

We contacted study authors to request missing data. Where authors reported both intention-to-treat (ITT) and per protocol analysis, we preferred the former. However, where ITT analysis was not conducted or reported in the studies, we regarded withdrawals as failures. We undertook sensitivity analyses to exclude studies with missing data. We did not impute missing standard deviations (SDs). However, we noted any instances where data were extracted from graphs.

\section{Assessment of heterogeneity}

We assessed heterogeneity among trial results by inspection of graphical presentations and by calculating the $\mathrm{Chi}^{2}$ test of heterogeneity; we regarded $\mathrm{P}=0.10$ as statistically significant. We used the $\mathrm{I}^{2}$ statistic to quantity the effect of heterogeneity (Higgins 2003).

We based our interpretation of the $1^{2}$ statistic results on those suggested by Higgins 2011 (Section 9.5.2):

- $0 \%$ to $40 \%$ : might not be important;

- $30 \%$ to $60 \%$ : may represent moderate heterogeneity;

- $50 \%$ to $90 \%$; may represent substantial heterogeneity;

- $75 \%$ to $100 \%$ : considerable heterogeneity.

\section{Assessment of reporting biases}

We avoided different reporting biases by conducting an extensive literature search. It was not necessary to generate a funnel plot to investigate publication bias, as there were an insufficient number of studies contributing to the analysis.

\section{Data synthesis}

We pooled studies with the same population, intervention, comparator and outcomes; we did not pool studies which were clinically heterogenous. We used Review Manager 5 for data analysis (Review Manager 2014). For dichotomous variables, we calculated RRs and 95\% confidence intervals (Cls) based on a random-effects model. For continuous variables, we calculated the MD and $95 \% \mathrm{Cls}$ when continuous outcomes were measured using the same units. We used the fixed-effect model, as $1^{2}=0$. We had planned to use the random-effects model if $\mathrm{l} 2 \mathrm{had}$ been $>0$.

\section{Subgroup analysis and investigation of heterogeneity}

Had we included a sufficient number of studies, we would have carried out subgroup analyses based on:

- age (below 18 years and above 18 years); and

- species of probiotic.

\section{Sensitivity analysis}

We carried out the following sensitivity analyses, apart from the exclusion of studies at high risk of bias; this was not possible due to the paucity of data.

- Only including participants whose outcome is known (i.e. number of participants who completed the study used as denominator)

- Study quality (removing those at highest risk of bias)

- Random-effects versus fixed-effect models
Summary of findings and assessment of the certainty of the evidence

We used the GRADE approach to assess the certainty of evidence related to all outcomes listed in the Types of outcome measures (Schünemann 2011). The four levels of evidence certainty are 'high', 'moderate', 'low' or 'very low'. Certainty may be downgraded due to study limitations (risk of bias), imprecision, inconsistency, indirectness or publication bias. We derived the optimal information size for the primary outcomes from the included studies.

Two review authors (MG, ZIE) independently produced 'Summary of findings' tables using the GRADEpro GDT software for our main comparisons (GRADEpro GDT 2015). We presented the results for clinical relapse, maintenance of clinical remission, health-related quality of life, need for additional therapy, serious adverse events, and withdrawal due to serious adverse events.

\section{RESULTS}

\section{Description of studies}

\section{Results of the search}

The literature search returned 1473 unique records after duplicates were removed; we also identified an additional study from another source. After screening 1474 titles and abstracts, we found 52 studies that met our inclusion criteria. We obtained and screened the full-text copies of these 52 studies. We included 12 studies and excluded 30 studies with reasons. We contacted authors of eight studies for additional information (Bjarnason 2019; Copaci 2014; Shanahan 2006; Wildt 2011; Yasushi 2015; Zocco 2003; Zocco 2006; NCT02361957); we received responses from three authors (NCT02361957; Bjarnason 2019; Wildt 2011). We identified four ongoing studies and six studies are awaiting classification (Characteristics of ongoing studies; Characteristics of studies awaiting classification). The results of the search are presented in the PRISMA flow diagram Figure 1. Full details of the included and excluded studies are available in the Characteristics of included studies and Characteristics of excluded studies tables and are summarised below.

\section{Included studies}

\section{Study design and setting}

We included 12 studies (Bjarnason 2019; Copaci 2014; Kruis 1997; Kruis 2004; Matsuoka 2018; NCT02361957; Shanahan 2006; Vejdani 2017; Wildt 2011; Yasushi 2015; Zocco 2003; Zocco 2006). These studies were either single centre (Bjarnason 2019; Copaci 2014; NCT02361957; Shanahan 2006; Yasushi 2015; Zocco 2006), or multicentre (Kruis 1997; Kruis 2004; Matsuoka 2018; Vejdani 2017; Wildt 2011) parallel group RCTs. The studies were conducted in hospitals in Italy (Zocco 2003; Zocco 2006), Iran (Vejdani 2017), Ireland (Shanahan 2006), Japan (Yasushi 2015), the Netherlands (NCT02361957), Romania (Copaci 2014), the UK (Bjarnason 2019); multiple centres in Denmark (Wildt 2011) and Japan (Matsuoka 2018); multiple centres across Germany, the Czech Republic, Austria (Kruis 1997) and Germany, the Czech Republic, Austria, Estonia, Latvia, Lithuania, Slovak Republic, Sweden, Switzerland and the UK (Kruis 2004). In two studies (Copaci 2014; Shanahan 2006), where the setting was not explicitly stated, we have assumed this to be the authors' affiliation. 


\section{Participants}

In five studies reporting mean age, the average age of participants was between 32 years in Zocco 2003 and 51 years in NCT02361957). In five studies reporting on age range, included participants were between 18 in Copaci 2014 and 88 years in Kruis 1997. Only one study (Yasushi 2015), which based on its inclusion criteria may have included paediatric patients ( $>13$ years). This study had an overall mean age of $43.9+/-14.8$ years, therefore, it is unclear whether children were recruited. Ten out of 11 studies randomised 25 (NCT02361957) to 327 (Kruis 2004) participants. Copaci 2014 included 36 participants, some (number not stated) of which received interventions that are outside the scope of this review. The studies included male and female participants with ulcerative colitis who may or may not have been receiving medication at the time of recruitment, except for Vejdani 2017 who did not report on age and sex, making it unclear whether the study was conducted on adult and/or paediatric female and/or male patients. In 10 studies, participants had the following forms of ulcerative colitis: pancolitis, left-sided, total colitis, proctitis, proctosigmoiditis, total colitis, subtotal colitis, distal, left colon. However, three studies did not provide any information on the extent of disease (Vejdani 2017; Wildt 2011; Zocco 2003). The length of time participants had been in remission at the point of study entry was not stated in six studies (Bjarnason 2019; Copaci 2014; NCT02361957; Shanahan 2006; Vejdani 2017; Zocco 2003), and unclear in one study (Yasushi 2015). Three studies reported at recruitment, that participants had been in remission between one month in Kruis 1997 and Matsuoka 2018 and 12 years in Kruis 1997.

\section{Intervention}

All the included studies had two trial arms, except three studies (Shanahan 2006; Zocco 2003; Zocco 2006), which had three trial arms. Copaci 2014 had three trial arms, however, one arm was excluded for assessing an intervention (prebiotic) that is not relevant to the review. The studies investigated the following comparisons.

- Probiotics versus placebo (Bjarnason 2019; Matsuoka 2018; NCT02361957; Vejdani 2017; Wildt 2011; Yasushi 2015)

- Probiotics versus 5-aminosalicylic acid (5-ASA) (mesalazine) (Kruis 2004)

- Probiotics plus 5-ASA versus 5-ASA (Copaci 2014)

- Probiotics plus 5-ASA versus 5-ASA plus placebo (Kruis 1997)

- Probiotics versus probiotics versus placebo (Shanahan 2006)

- Probiotics versus probiotics plus 5-ASA versus 5-ASA (Zocco 2003; Zocco 2006)

In seven studies (Copaci 2014; Kruis 1997; Kruis 2004; Shanahan 2006; Vejdani 2017; Zocco 2003; Zocco 2006), the probiotics contained single bacterial strains and probiotics in five studies contained multiple strains (Bjarnason 2019; Matsuoka 2018; NCT02361957; Wildt 2011; Yasushi 2015). These single bacterial strains include Bifidobacterium longum (B longum) W11 (Copaci 2014), Echerichia coli (E coli) Nissle 1917 (Kruis 1997; Kruis 2004), Lactobacillus salivarius (L salivarius) UCC118 (Shanahan 2006), Bifidobacterium infantis (B infantis) 35624 (Shanahan 2006), Lactobacillus casei (L casei) strain ATCC PTA-3945 (Vejdani 2017), and Lactobacillus GG $18 \times 10^{9}$ (Zocco 2003; Zocco 2006).
In studies with multiple strain probiotics, the following combinations were studied.

- Lactobacillus rhamnosus (L rhamnosus) NCIMB 30174, Lactobacillus plantarum (L plantarum) NCIMB 30173, Lactobacillus acidophilus (L acidophilus) NCIMB 30175 and Enterococcus faecium (E faecium) NCIMB 30176 (Bjarnason 2019).

- Bifidobacterium bifidum (B bifidum) W23, Bifidobacterium lactis (B lactis) W51, Bifidobacterium lactis (B lactis) W52, L acidophilus W22, L casei W56, Lactobacillus paracasei (L paracasei) W20, Lactobacillus plantarum (L plantarum) W62, L salivarius W24 and Lactococcus lactis (L lactis) W19 (NCT02361957).

- Bifidobacterium breve (B breve) and L acidophilus (Matsuoka 2018).

- L acidophilus strain La-5 + Bifidobacterium animalis (B animalis) subsp. lactis strain BB-12 (Wildt 2011).

- Streptococcus faecalis (S faecalis) T-110 (lactomin) + Clostridium butyricum TO-A + Bacillus mesentericus (Yasushi 2015).

Interventions were administered daily for four weeks in Bjarnason 2019 to 52 weeks (Kruis 2004; Shanahan 2006; Wildt 2011; Yasushi 2015; Zocco 2003; Zocco 2006). Concomittant treatments were not allowed in three studies (Kruis 2004; Wildt 2011; Zocco 2006), and in five studies it was not explicitly stated whether concomitant treatments were used or not. In four studies different concomitant treatments were used, such as 5-aminosalycilic preparation, lowdose azathioprine $(1 \mathrm{mg} / \mathrm{kg})$ and prednisolone $<4 \mathrm{mg} /$ day (Bjarnason 2019), $2.4 \mathrm{~g}$ per day of mesalazine (NCT02361957), aminosalicylate (Shanahan 2006), unrestricted mesalazine and salazosulfapyridine plus topical antibiotics were not restricted (Yasushi 2015).

\section{Outcomes}

The studies reported data on all outcomes of interest except 'need for withdrawal of therapy'. We summarised outcome data in Table 1.

- Relapse was reported in all studies (Bjarnason 2019; Copaci 2014; Kruis 1997; Kruis 2004; Matsuoka 2018; NCT02361957; Shanahan 2006; Vejdani 2017; Wildt 2011; Yasushi 2015; Zocco 2003; Zocco 2006). Clinical relapse was reported in six studies (Bjarnason 2019; Kruis 1997; Kruis 2004; Matsuoka 2018; Yasushi 2015; Zocco 2006). In three studies, endoscopic and clinical relapse were not separated out (Vejdani 2017; Wildt 2011; Zocco 2003).

- Maintenance of remission (the number of participants who did not have a relapse) was reported in five studies (Copaci 2014; Matsuoka 2018; Wildt 2011; Yasushi 2015; Zocco 2006). Maintenance of clinical remission was reported in three studies (Bjarnason 2019; Yasushi 2015; Zocco 2006).

- Health related quality of life was reported in three studies (Bjarnason 2019; Kruis 2004; NCT02361957).

- Serious adverse events were reported in seven studies (Bjarnason 2019; Kruis 2004; Matsuoka 2018; Vejdani 2017; Wildt 2011; Yasushi 2015; Zocco 2006), although no full description was provided. Therefore, we were unable to ascertain the severity of the adverse events.

- Withdrawal due to adverse events was reported in five studies (Bjarnason 2019; Kruis 1997; Kruis 2004; Wildt 2011; Zocco 2003). 


\section{Funding and declaration of interest}

The studies were government funded (Yasushi 2015), funded by manufacturing companies (Bjarnason 2019; Kruis 1997; Matsuoka 2018), part funded by industry and a charity (Wildt 2011), and part funded by government and industry (NCT02361957). The funding source was not reported in six studies (Copaci 2014; Kruis 2004; Shanahan 2006; Vejdani 2017; Zocco 2003; Zocco 2006).

Conflict of interest was not fully reported in any of the studies except Copaci 2014, in which the authors reported that they had none. Three studies reported that one author had no conflict of interest (Yasushi 2015), and two authors were funded by manufacturing companies (Bjarnason 2019; Matsuoka 2018). Two studies reported that authors were employed by a manufacturing company (NCT02361957; Wildt 2011). Conflicts of interest were not reported in five studies (Kruis 1997; Kruis 2004; Shanahan 2006; Zocco 2003; Zocco 2006).

\section{Excluded studies}

Thirty studies failed to meet the inclusion criteria and we excluded them for the following reasons.
- Wrong study design: review (Do 2010), commentary piece (Faubion 2000; Folwaczny 2000), not a RCT (Henker 2008; Venturi 1999).

- Wrong population: participants were not in remission at study entry (Fujimori 2009; IRCT20120415009475N5; Li 2013; Liu 2014; Miele 2009; NCT01772615; Rembacken 1999; SanchezMorales 2019; Zhang 2018a), a mixed population of active and inactive ulcerative colitis (Ishikawa 2011), mixed population of ulcerative colitis and Crohn's disease (Ballini 2019; Shadnoush 2013), participants had active ulcerative colitis (NCT00951548; Palumbo 2016; Solovyeva 2014; Tursi 2010), microscopic colitis (Rohatgi 2015).

- Wrong intervention (Bamba 2002).

- Short duration of follow-up (Ahmed 2013; Cui 2004).

- Insufficient information on study details and no response when authors were contacted (Ishikawa 2002; NCT00268164; NCT00374725; NCT00803829; Pelech 1998).

\section{Risk of bias in included studies}

The studies were either at high or unclear risk of bias. The risk of bias for the studies is summarised in Figure 2 and Figure 3. Further details are available in the Characteristics of included studies table. 
Figure 2. Risk of bias summary: review authors' judgements about each risk of bias item for each included study.

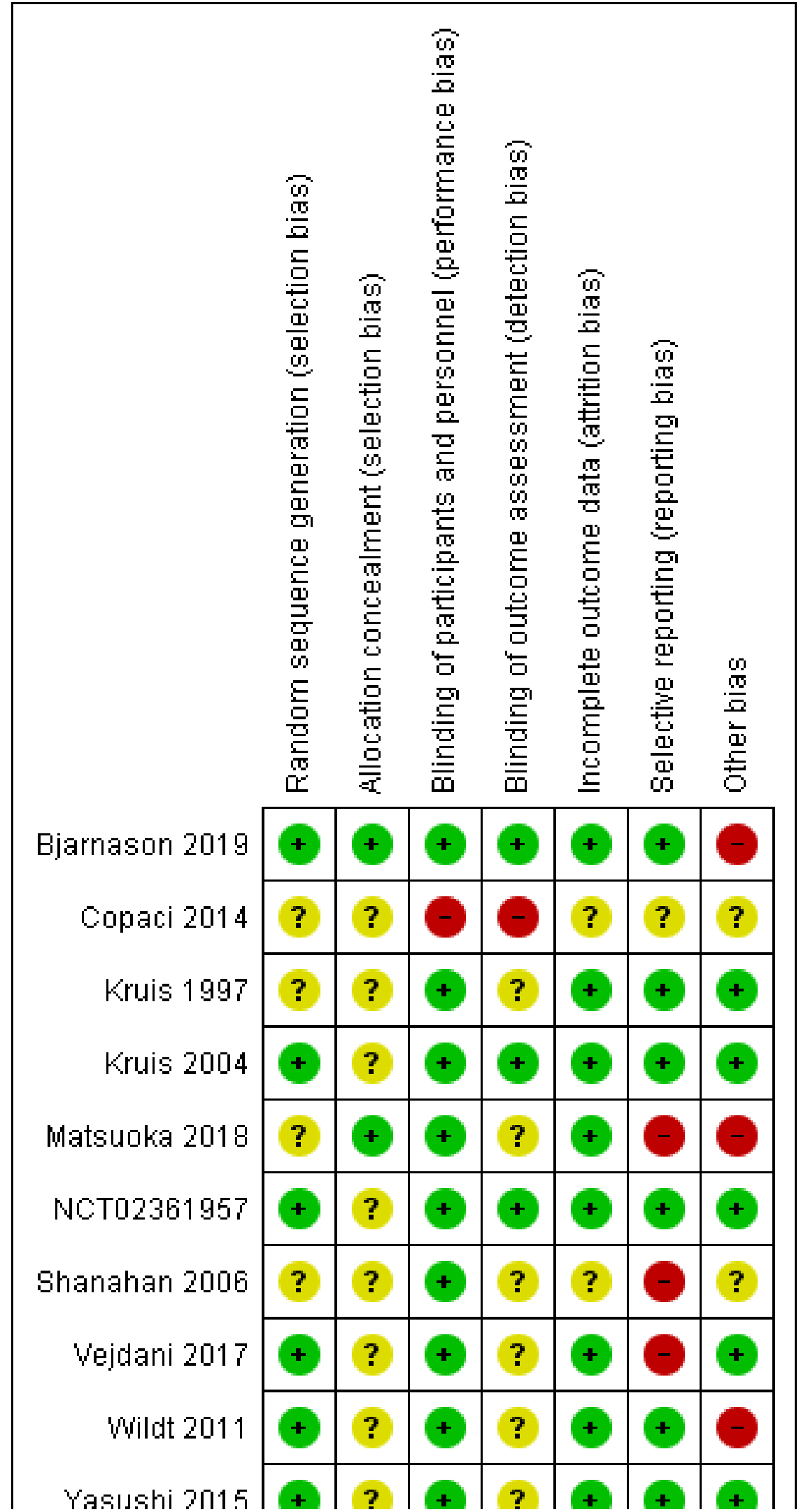


Figure 2. (Continued)

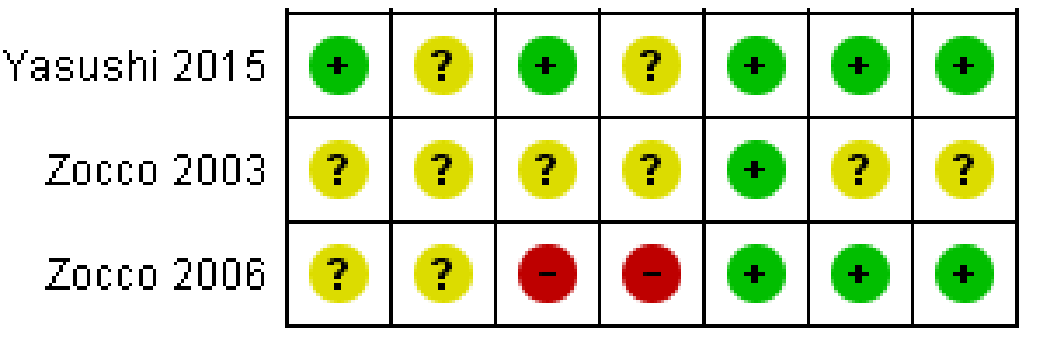

Figure 3. Risk of bias graph: review authors' judgements about each risk of bias item presented as percentages across all included studies.

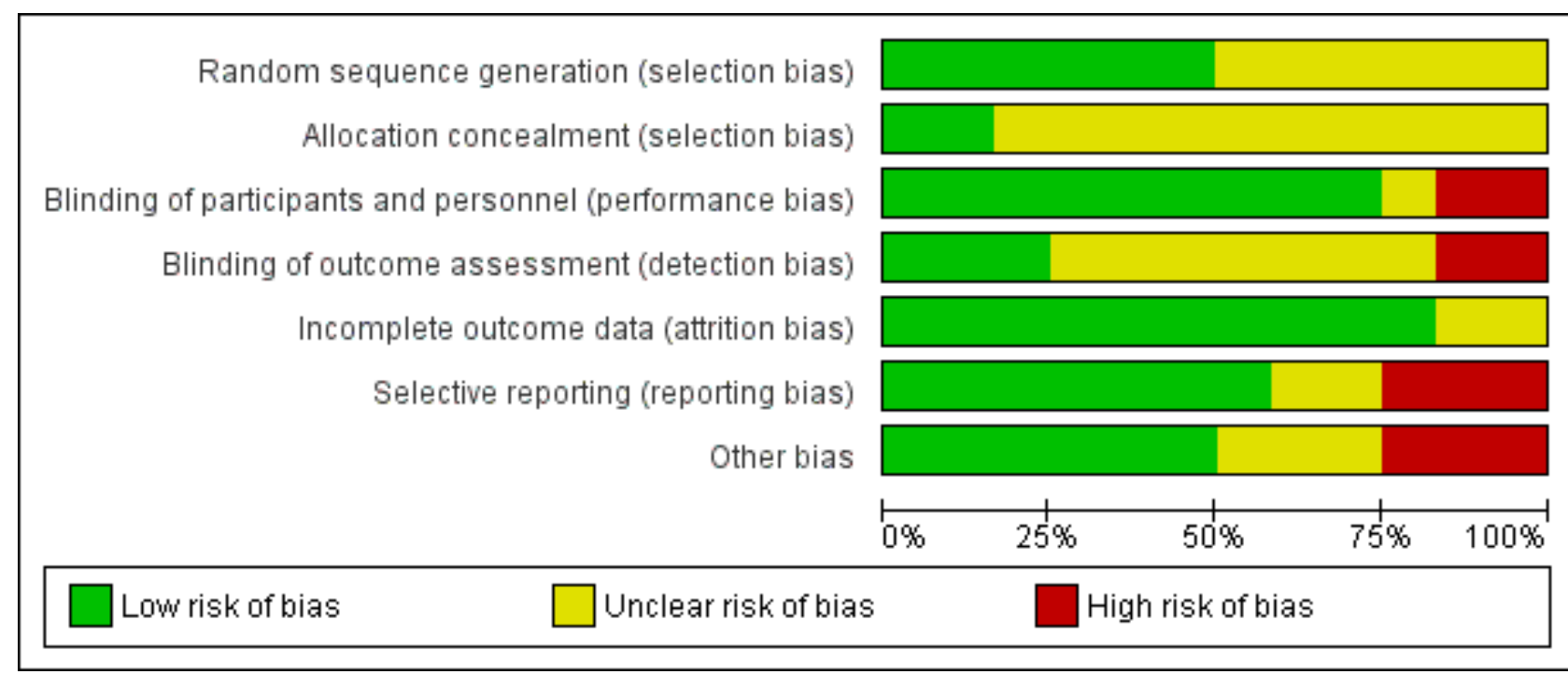

\section{Allocation}

\section{Random sequence generation}

In all the included studies, allocation of participants to intervention or placebo was described as random. The method of randomisation was adequately described in six studies (Bjarnason 2019; Kruis 2004; NCT02361957; Vejdani 2017; Wildt 2011; Yasushi 2015), and not described in six studies (Copaci 2014; Kruis 1997; Matsuoka 2018; Shanahan 2006; Zocco 2003; Zocco 2006). We contacted the authors of these six studies to clarify the method of randomisation, but did not receive further information. We rated these studies as unclear risk of bias for sequence generation.

\section{Allocation concealment}

We rated allocation concealment as unclear for all except two studies (Bjarnason 2019; Matsuoka 2018). We contacted the authors to clarify allocation concealment, but did not receive a response. The interventions in Matsuoka 2018 were delivered in identical containers from the central pharmacy, therefore we rated this study as low risk of bias.

\section{Blinding}

Nine of the studies were described as double-blinded (Bjarnason 2019; Kruis 1997; Kruis 2004; Matsuoka 2018; NCT02361957; Shanahan 2006; Vejdani 2017; Wildt 2011; Yasushi 2015), and we rated them at low risk of performance bias. However, only three of these studies provided information (Bjarnason 2019; Kruis 2004; NCT02361957), which suggests that blinding was maintained until after outcome assessment. We rated all three studies at low risk of detection bias, and the remaining as unclear. Copaci 2014 and Zocco 2006 were open-label studies and we rated them at high risk of bias. There was insufficient information in Zocco 2003 to make a decision, therefore it we rated it at unclear risk of performance and detection bias.

\section{Incomplete outcome data}

Ten studies were at low risk of bias for reporting data for all participants (Bjarnason 2019; Zocco 2003; Zocco 2006), conducting full ITT analysis (NCT02361957; Vejdani 2017; Wildt 2011), a combination of low attrition rates and partial ITT analysis (Kruis 1997; Matsuoka 2018), and two studies had attrition rates of $>20 \%$ (Kruis 2004; Yasushi 2015), but balanced between both groups. Two studies were at unclear risk of bias (Copaci 2014; Shanahan 2006).

\section{Selective reporting}

Trial registrations were available for only three studies (Matsuoka 2018; NCT02361957; Wildt 2011).

Of the seven trials which we rated at low risk of reporting bias, two reported all outcomes which were prespecified in the trial 
registration (NCT02361957; Wildt 2011), and five had no trial registration, but reported all expected outcomes (Bjarnason 2019; Kruis 1997; Kruis 2004; Yasushi 2015; Zocco 2006). We rated three studies at high risk of bias for reporting more outcomes than specified in the protocol (Matsuoka 2018), failing to report adverse events (Shanahan 2006), and results of biochemical tests (Vejdani 2017), Copaci 2014 and Zocco 2003 failed to provide sufficient information for a judgement to be made (unclear).

\section{Other potential sources of bias}

We rated six studies at low risk of bias for not having other apparent biases (Kruis 1997; Kruis 2004; NCT02361957; Vejdani 2017; Yasushi 2015; Zocco 2006). We rated three studies at high risk of bias due to an imbalance in baseline characteristics (Wildt 2011), a posthoc decision to discontinue the trial (Matsuoka 2018), and for being funded by the manufacturer of the probiotic product studied with no justification of the limits or level of involvement (Bjarnason 2019)

\section{Effects of interventions}

See: Summary of findings for the main comparison Probiotics compared to placebo for maintenance of remission in ulcerative colitis; Summary of findings 2 Probiotics compared to 5aminosalicylic acid (5-ASA) (mesalazine) for maintenance of remission in ulcerative colitis; Summary of findings 3 Probiotic + 5-aminosalicylic acid (5-ASA) (mesalazine) compared to 5-ASA (mesalazine) for maintenance of remission in ulcerative colitis

\section{Probiotics versus placebo}

Seven studies compared probiotics with placebo (Bjarnason 2019; Matsuoka 2018; NCT02361957; Shanahan 2006; Vejdani 2017; Wildt 2011; Yasushi 2015). See Summary of findings for the main comparison.

\section{Primary outcome}

\section{Clinical relapse}

We found very low-certainty evidence that, on average, there was no clear difference in the incidence of clinical relapse between probiotics and placebo (risk ratio (RR) $0.87,95 \%$ confidence interval (CI) 0.63 to 1.18 ; 4 studies, 361 participants; very low-certainty evidence; Analysis 1.1, Figure 4). We downgraded the evidence three times for high risk of reporting and other bias due to imbalance in baseline characteristics, and imprecision due to small sample size.

Figure 4. Forest plot of comparison: 1 Probiotics versus placebo, outcome: 1.1 Clinical relapse.

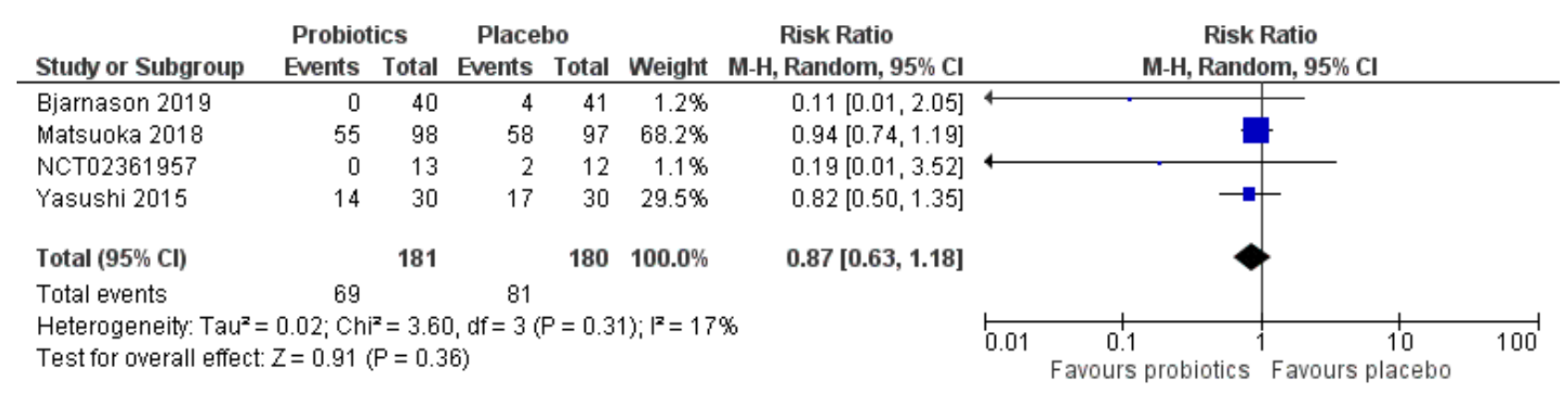

Two other studies also reported on relapse (Vejdani 2017; Wildt 2011). In these studies, relapse data appear to have included a mix of endoscopic and clinical relapse. Vejdani 2017 defines relapse as: an increase in bowel frequency with blood for at least one week and a colonoscopy and biopsies to confirm relapse. Wildt 2011 defines relapse as: simple clinical colitis activity index (SCCAI) score $>4$ and/ or endoscopic changes grade 2 to 3 . Due to concerns about clinical heterogeneity, we did not analyse the data. Number of relapses in the probiotics compared to the placebo group were $4 / 14(28.6 \%)$ versus $7 / 15(46.7 \%)$ in Vejdani 2017 and 15/20 (75\%) versus 11/12 (91.7\%) in Wildt 2011.

\section{Maintenance of clinical remission}

The number of participants who remained in clinical remission, i.e. did not have a relapse, was reported in three studies. It is uncertain whether probiotics lead to a difference in maintenance of remission when compared with placebo (RR 1.16, 95\% Cl 0.98 to $1.37 ; 2$ studies, 141 participants; very low-certainty of evidence;
Analysis 1.2). We downgraded the evidence three times for high risk of bias and imprecision due to wide $\mathrm{Cls}$, which includes appreciable harm. One additional study with 205 participants (Matsuoka 2018), reported insufficient data for inclusion in the meta-analysis; we did not analyse the results further.

Wildt 2011 reported on the number of participants who remained in remission, however, the definition of the relapse suggests that the data potentially includes participants in endoscopic and clinical remission. The number of people on probiotics who remained in remission compared to those on placebo were 5/20 (25\%) versus $1 / 12(8.3 \%)$, respectively.

\section{Secondary outcomes}

\section{Serious adverse events}

In four studies with 351 participants which reported on serious adverse events, no events were recorded (Analysis 1.3, Figure 5). 
Figure 5. Forest plot of comparison: 1 Probiotics versus placebo, outcome: 1.3 Serious adverse events.

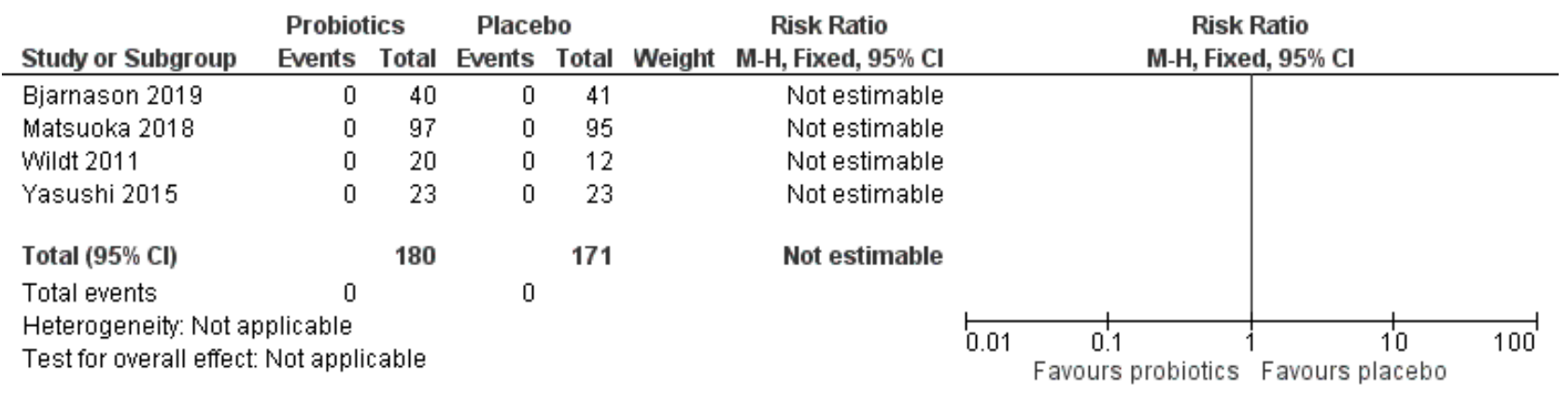

\section{Withdrawal due to adverse events}

Two studies with 113 participants indicated that there were no withdrawals as a result of adverse events (Bjarnason 2019; Wildt 2011).

\section{Need for additional therapy}

This outcome was not reported.

\section{Health-related quality of life}

Health-related quality of life was reported in two studies and measured using the inflammatory bowel disease questionnaire (IBD-Q) scale in one of them (NCT02361957), and the UK IBD-Q in the other one (Bjarnason 2019). The IBD-Q scale ranges from 1 to 7 , with a higher score representing better quality of life. We found low-certainty evidence that, on average, probiotics made no clear difference in health-related quality of life compared with placebo (mean difference (MD) $-0.70,95 \% \mathrm{Cl}-1.63$ to $0.23 ; 1$ study, 25 participants; low-certainty evidence; Analysis 1.5). We downgraded the evidence twice for imprecision due to inadequate sample size from a single study with wide CIs. The UK IBD-Q is similar, however, the authors that used it reported separately on the five overall parameters of the questionnaire (emotional symptoms, bowel function-1, social function, bowel function-2, systemic function). As there was no overall score reported, we could not include a quality of life value in our meta-analysis.

\section{Probiotics versus 5-aminosalicylic acid (5-ASA) (mesalazine)}

Three trials compared probiotics with 5-ASA (Kruis 2004; Zocco 2003; Zocco 2006). See Summary of findings 2.

\section{Primary outcome}

\section{Clinical relapse}

We found low-certainty evidence that, on average, there was no clear difference in the incidence of relapse between probiotics and 5-ASA (RR 1.01, 95\% Cl 0.84 to 1.22; 2 studies, 452 participants; low-certainty evidence; Analysis 2.1). We downgraded the evidence twice for high risk of bias and imprecision due to the inadequate sample size.

In Zocco 2003, relapse was defined "by clinical and endoscopic features". Due to the heterogeneity, we decided not to analyse the data. The number of relapses in the probiotics versus placebo group were $2 / 12(16.7 \%)$ versus $2 / 10(20 \%)$, respectively.

\section{Maintenance of clinical remission}

We found low-certainty evidence that, on average, probiotics showed no clear difference in maintenance of clinical remission when compared with 5-ASA (RR $1.06,95 \% \mathrm{Cl} 0.90$ to 1.25; 1 study, 125 participants; low-certainty evidence; Analysis 2.2). We downgraded the evidence twice for high risk of bias and imprecision due to a small number of events.

\section{Secondary outcomes}

\section{Serious adverse events}

It is uncertain whether probiotics lead to a difference in serious adverse events when compared with 5-ASA (RR 1.19, 95\% Cl 0.41 to 3.46; 1 study, 327 participants; very low-certainty evidence; Analysis 2.3). We downgraded the evidence three times for high risk of bias and imprecision due to the small number of events and wide confidence interval, which includes appreciable harm.

\section{Withdrawal due to adverse events}

It is uncertain whether probiotics lead to a difference in serious adverse events when compared with 5-ASA (RR 1.02, 95\% Cl 0.46 to 2.25; 1 study, 222 participants; very low-certainty evidence; Analysis 2.4). We downgraded the evidence three times for high risk of bias and imprecision due to the small number of events in a single study and wide confidence interval, which includes appreciable harm.

\section{Need for additional therapy}

This outcome was not reported.

\section{Health-related quality of life}

One study reported quality of life scores at 12 months based on the IBDQ scale, ranging from 0 to 32 , with a higher score representing a better quality of life (Kruis 2004). We found lowcertainty evidence that there was no clear difference in healthrelated quality of life between probiotics and 5-ASA (MD -0.80, 95\% $\mathrm{Cl}-2.01$ to 0.41 ; 1 study, 222 participants; low-certainty evidence Analysis 2.5). We downgraded the evidence twice for high risk of bias and imprecision due to small sample size.

\section{Probiotic + 5-ASA (mesalazine) versus 5-ASA (mesalazine)}

Four trials compared a probiotic plus 5-ASA with 5-ASA alone (Copaci 2014; Kruis 1997; Zocco 2003; Zocco 2006). See Summary of findings 3. 


\section{Primary outcome}

\section{Clinical relapse}

It is uncertain whether probiotics combined with 5-ASA leads to a difference in the incidence of relapse when compared with 5-ASA alone (RR 1.11, 95\% Cl 0.66 to 1.87; 2 studies, 242 participants; very low-certainty evidence; Analysis 3.1). We downgraded the evidence three times for high risk of bias and imprecision due to the small number of events and confidence interval, which includes appreciable benefit or harm.

In Zocco 2003, relapse was defined "by clinical and endoscopic features". Due to the heterogeneity, we were unable to analyse the data. The number of relapses which occurred in the probiotics and 5-ASA group compared to 5-ASA alone was 4/14 (28.6\%) versus 2/10 (20\%).

\section{Maintenance of clinical remission}

The number of participants who remained in remission, i.e. did not have a relapse, was reported in two studies. We found lowcertainty evidence that, on average, probiotics combined with and 5-ASA showed no clear difference in maintenance of remission compared with 5-ASA alone (RR 1.05, 95\% Cl 0.89 to 1.24; 1 study, 122 participants; Analysis 3.2). We downgraded the evidence twice for high risk of bias and imprecision due to the small number of events.

\section{Secondary outcomes}

\section{Serious adverse events}

This outcome was not reported.

\section{Withdrawal due to adverse events}

It is uncertain whether probiotics combined with 5-ASA leads to a difference in withdrawal due to adverse events compared with 5-ASA alone because the certainty of the evidence is very low. One study reported there were no withdrawals due to adverse events and one study reported two withdrawals in the probiotics combined with 5-ASA group (RR 5.29, $95 \% \mathrm{Cl} 0.26$ to $107.63 ; 2$ studies, 127 participants; very low-certainty evidence; Analysis 3.3). We downgraded the evidence three times for unclear risk of selection bias, small number of events and wide confidence interval, which includes appreciable harm.

\section{Need for additional therapy}

This outcome was not reported.

\section{Health-related quality of life}

This outcome was not reported.

\section{Sensitivity analysis}

We carried out sensitivity analyses using an available case analysis versus intention-to-treat (ITT) analysis as well as fixed-effect versus random-effects models. We did not find any differences between either set of analyses. See full data in Table 2.

\section{DISCUSSION}

\section{Summary of main results}

This review included 11 parallel group randomised controlled trials (RCTs) assessing the effectiveness of probiotics for the maintenance of remission in ulcerative colitis. All the studies, except two (Copaci 2014; Shanahan 2006), provided sufficient data for inclusion in a meta-analysis. The comparisons assessed by the studies were probiotics versus placebo, probiotics versus 5 -aminosalicylic acid (5-ASA) and probiotic plus 5-ASA versus 5-ASA . We analysed and summarised data from nine studies (1031 participants): Summary of findings for the main comparison; Summary of findings 2; Summary of findings 3. It is uncertain if there is any difference in occurrence of clinical relapse when probiotics are compared with placebo (very low-certainty evidence). When probiotics were compared with 5-ASA, there was no clear difference in relapse (low-certainty evidence). It is uncertain whether probiotics lead to a difference in maintenance of remission when compared with placebo because the certainty of the evidence is very low. There is no clear difference in maintenance of remission when probiotics are compared with 5-ASA, neither is there a difference when probiotics combined with 5-ASA is compared with 5-ASA alone (low-certainty evidence). It is uncertain whether probiotics combined with 5-ASA leads to a difference in the incidence of relapse when compared with 5-ASA alone because the certainty of the evidence is very low.

The studies comparing probiotics with placebo reported that no serious adverse events occurred. One study comparing probiotics and 5-ASA reported on similar numbers of serious adverse events in both groups. Further details were not provided on these serious adverse events.

No difference in efficacy was found between probiotics and placebo, which could reflect the clinical truth of no efficacy regarding these agents. However, no difference was found between probiotics and 5-ASA either. This is key, as 5-ASA are generally used as standard first-line interventional therapy, with their efficacy well demonstrated in previous systematic reviews (Wang 2016). As such, given the lack of efficacy of probiotics compared with placebo, it would be expected that they would be inferior to 5-ASA as standard therapy, which has not been demonstrated. We do not have enough evidence in this current synthesis to demonstrate the efficacy of probiotics, but feel these inconsistencies raise genuine questions for clinicians, researchers and users in the field.

\section{Overall completeness and applicability of evidence}

The capricious body of evidence synthesised in this review is highly heterogenous in terms of population and intervention, and as such, significantly limits its applicability to guide decision making. In considering application of the evidence, clinicians and patients require not just statistically significant results; the results need to reflect specific clinical contexts and problems for which they can apply these solutions. It is particularly striking that on updating this review after almost 10 years, the body of evidence has grown but is still far from complete and unable to be applied to practice.

The studies involved a wide range of people who had been in remission for various lengths (> 1 month to 12 years), but as recruiting studies ubiquitously made such judgements on clinical grounds, with the addition of activity scores, consideration of concepts, such as 'deep remission', which are key in practice, is completely absent from the discourse in these trials. The weaknesses of the primary studies have not allowed exploration of such wide ranging participant characteristics through subgroup analysis, which would be key for implementation of any findings from such a review. 
There was minimal consideration of children in included studies, with all except Yasushi 2015 recruiting only adults. Based on its inclusion criteria, Yasushi 2015 attempted to recruit both adult and paediatric patients, but it is not clear if they actually achieved this, treating them as one population. As such, the applicability of this evidence to paediatric patients is a significant concern. Furthermore, almost half of the studies excluded participants who were receiving immunosuppressants at the point of recruitment, suggesting a preference for people with mild disease severity. This should be considered in applying the evidence in practice.

Study participants received probiotics which had either single or multiple strains for a maximum period of 12 to 52 weeks. Whilst it is common for reviews within Cochrane and the wider field to synthesis evidence that considers probiotics as a single interventional group, subgroup analysis is key for what are effectively a disparate family of interventional agents, and once again the limitations of the evidence in this review has not allowed this to be completed.

Relapse and maintenance of remission were reported in most of the studies. However, most of the secondary outcomes were not sufficiently reported. Serious adverse events were reported, however, this outcome was not described at all in any of the studies. Health-related quality of life and withdrawal due to adverse events were rarely reported. Need for withdrawal of therapy was not reported in any of the included studies. The effect of probiotics on these secondary outcomes remains unclear.

\section{Certainty of the evidence}

The certainty of evidence was either low or very low due to risk of bias and imprecision. Eight studies were at high risk of bias and three studies were at unclear risk of bias. Most of the studies failed to provide sufficient information on allocation concealment. Though the studies which used double-blinding had clearly included placebo or provided control which was identical to the study intervention to prevent performance bias, it was not explicitly stated whether outcome assessment was blinded or not. Indicating that a study was double-blinded without explicitly stating who (participants, caregiver, outcome assessor, etc.) the blinding was applied to is usually not helpful in 'Risk of bias' assessment. Five studies were published as abstracts and were at unclear risk of bias for most domains.

The studies had sample sizes of between 25 and 327 participants. We downgraded for imprecision as the trials either had small numbers of events or small sample sizes which were insufficient to meet the optimal information size, thus resulting in wide confidence intervals. Whilst power calculations were used, they were often based on estimates of effect, rather than previous trial data, and therefore this raises the question as to whether these studies were adequately powered. The definition of relapse reported in some of the studies suggests that people with endoscopic and clinical relapse or remission may have been lumped together. We carried out a narrative synthesis of such studies since they were dissimilar to the studies which clearly reported on clinical relapse only. This reduced the amount of data that were pooled for the outcome of clinical relapse/remission and increased imprecision.
Most of the analyses involved single studies. Where there was sufficient data for pooling, there was no heterogeneity $\left(I^{2}=0 \%\right)$. Therefore, there was no reason to downgrade for inconsistency.

There was no indirectness, as the included studies all addressed the objectives of the review and fit within the scope. The number of studies included in the meta-analysis was insufficient to assess for publication bias.

The inconsistency within results has already been discussed, with no difference between probiotics and placebo nor probiotics and 5ASA (a standard treatment with proven superiority over placebo). This point is highlighted in the context of the quality issues raised, given that all but one study comparing probiotics and placebo was at high risk of bias. It is therefore likely that this is the source of the inconsistency and is a key message for future researchers.

\section{Potential biases in the review process}

We are aware of the biases that could arise from missing data and made efforts to contact authors for additional information and clarifications. However, most of the authors we contacted failed to reply. To minimise bias, we included such studies in our narrative synthesis and carried out sensitivity analyses, where possible, to provide a conservative estimate of effect. We aim to include any data which become available from authors in future updates.

Other limitations in the review process are to do with risk of bias of individual studies. Three of the included studies are only available as abstracts. This meant that the studies had to be marked at unclear risk of bias for most of the domains. Given that we did not carry out sensitivity analyses to examine their impact on the results due to the insufficient number of studies included in each metaanalysis, the inclusion of these abstracts may further influence the validity of the data.

Finally, we are aware of the possible impact of industry funding on the validity of trial results. Funding from probiotic manufacturing companies or inclusion of company staff in the author team was noted in some of the studies and we considered the impact of this information on the 'Risk of bias' assessment of the studies and GRADE assessment of the evidence. Given that none of the studies showed a clear difference in favour of probiotics, we assumed that industry funding is unlikely to have compromised the results of this review.

\section{Agreements and disagreements with other studies or reviews}

There is currently no other known evidence-based guidance or systematic review around the use of probiotics for the maintenance of remission in ulcerative colitis, apart from the previous version of this review (Naidoo 2011). The European Crohn's and Colitis Organisation (ECCO) and European Society of Paediatric Gastroenterology, Hepatology and Nutrition (ESPHGAN) guideline briefly described the evidence on the efficacy of probiotics and made no recommendation regarding its use for the maintenance of remission (Turner 2018). The current National Institute for Health and Care Excellence (NICE) guideline does not cover probiotics either (NICE 2013). This review has found insufficient evidence on the effect of probiotics for maintenance of remission in ulcerative colitis, and therefore retains the same conclusion from Naidoo 2011. 


\section{AUTHORS' CONCLUSIONS}

\section{Implications for practice}

The effectiveness of probiotics for the maintenance of remission in ulcerative colitis remains unclear. This is due to low- to very low-certainty evidence from poorly conducted studies, which contribute limited amounts of data from a small number of participants. It is uncertain whether probiotics lead to a difference in clinical relapse and the maintenance of remission when compared with placebo (very low-certainty evidence). Probiotics were compared with 5-aminosalicylic acid (5-ASA) (conventional therapy) and there was no clear difference in relapse or maintenance of remission (low-certainty evidence). There were no serious adverse events in all but one study, which reported similar numbers across the probiotics and 5-ASA groups, however, no further details were reported. Health-related quality of life and withdrawal due to adverse events were rarely reported.

\section{Implications for research}

This review highlights the need for further well-designed randomised controlled trials (RCTs) to investigate the efficacy and safety of probiotics for the maintenance of remission in ulcerative colitis. However, we believe it is key to define contextually what the attributes of such trials should be. The majority of the trials compared probiotics with placebo. Future trials comparing probiotics with 5-ASA would reflect conventional care given to people with ulcerative colitis. Additionally, the length of followup of most studies in this review is much less than in studies assessed by other published reviews on maintenance therapy. Maintenance studies investigating treatment effects for less than
12 months are simply too short to inform clinical practice, where the attrition rates from remission are such that a minimum of one year should be considered for study. We would also strongly suggest that study investigators work to ensure the homogenous nature of their baseline populations from a disease activity standpoint, as we believe it is difficult to consider patients in remission for one month on recruitment the same as those who are 12 years into their remission. The question of sample size is also a major concern, with a minimal use of power calculations using expected effect sizes which were estimated in wide ranging ways and have led to 11 studies with a little over 1000 participants. Given other studies exhibited in other reviews in the field, particularly the high placebo response rate seen (Jairath 2017), we believe it is likely that such calculations were too optimistic in projected effect sizes, and as such, may have been underpowered to appropriately investigate the agents under study. Considering the ongoing trials, none of these appears to be of the statistical power or length of follow up to address these issues.

\section{ACKNOWLEDGEMENTS}

Partial funding for Cochrane Inflammatory Bowel Disease (IBD) (1 April 2016 to 31 March 2018) has been provided by Crohn's and Colitis Canada (CCC).

Funding for Zipporah Iheozor-Ejiofor and partial funding for Morris Gordon was provided through the National Institute for Health Research (NIHR) Cochrane Programme Grant.

Yuhong Yuan, Information Specialist, Cochrane Upper Gastrointestinal and Pancreatic Diseases (UGPD) reran the search strategies in October 2019. 


\section{RE F E R E N C E S}

\section{References to studies included in this review}

\section{Bjarnason 2019 \{published data only\}}

Bjarnason I, Sission G, Hayee B. A randomised, double-blind, placebo controlled trial of a multi-strain probiotic in patients with asymptomatic ulcerative colitis and Crohn's disease. Inflammopharmacology 2019;27:465-73.

\section{Copaci 2014 \{published data only\}}

Copaci I, Chiriac G. Maintenance of remission of ulcerative colitis: prebiotics and dietary fiber. United European Gastroenterology Journal 2014;1:A375.

\section{Kruis 1997 \{published data only\}}

Kruis W, Schutz E, Fric P, Fixa B, Judmaier G, Stolte M. Doubleblind comparison of an oral Escherichia coli preparation and mesalazine in maintaining remission of ulcerative colitis. Alimentary Pharmacology and Therapeutics 1997;11(5):853-8.

\section{Kruis 2004 \{published data only\}}

Kruis W, Fric P, Pokrotnieks J, Lukas M, Fixa B, Kascak M, et al. Maintaining remission of ulcerative colitis with the probiotic Escherichia coli Nissle 1917 is as effective as with standard mesalazine. Gut 2004;53(11):1617-23.

\section{Matsuoka 2018 \{published data only\}}

Matsuoka K, Uemura Y, Kanai T. Efficacy of Bifidobacterium breve fermented milk in maintaining remission of ulcerative colitis. Digestive Diseases and Sciences 2018;ns:1-10. [org/10.1007/s10620-018-4946-2]

\section{NCT02361957 \{unpublished data only\}}

NCT02361957. The Effect of the Multispecies Probiotic Ecologic 825 Versus Placebo in Ulcerative Colitis Patients (CUPIDO). clinicaltrials.gov/ct2/show/NCT02361957 first posted 12 February 2015.

\section{Shanahan 2006 \{published data only\}}

Shanahan F, Guarner F, Von Wright A, Vilpponen-Salmela T, O'Donoghue, D, Kiely B, et al. A one year, randomised, double-blind, placebo controlled trial of a Lactobacillus or a Bidifobacterium probiotic for maintenance of steroid-induced remission of ulcerative colitis. Gastroenterology 2006;130(4 Supp( 2):A44

\section{Vejdani 2017 \{published data only\}}

Vejdani R, Bahari A, Zadeh AM, Azmi M, Ebrahimi-Daryani N, Hashtroudi AA, et al. Effects of lactobacillus casei probiotic on mild to moderate ulcerative colitis: A placebo controlled study. Indian Journal of Medical Sciences January-March 2017;69(1):24-8

\section{Wildt 2011 \{published data only\}}

Wildt S, Nordgaard I, Hansen U, Brockmann E, Rumessen JJ. A randomised double-blind placebo-controlled trial with Lactobacillus acidophilus La- 5 and Bifidobacterium animalis subsp. lactis BB-12 for maintenance of remission in ulcerative colitis. Journal of Crohn's and Colitis 2011;5(2):115-21.
Yasushi 2015 \{published data only\}

Yasushi Y, Akihiro Y, Ryuichi F, Koji S, Aisaku O, Kentaro N, et al. Effectiveness of probiotic therapy for the prevention of relapse in patients with inactive ulcerative colitis. World Journal of Gastroenterology 2015;21(19):5985-94.

Zocco 2003 \{published data only\}

Zocco MA, dal Verme LZ, Armuzzi A, Nista EC, Papa A, Candelli M. Comparison of Lactobacillus GG and mesalazine in maintaining remission of ulcerative colitis and Crohn's disease. Gastroenterology 2003;124(4):A201.

\section{Zocco 2006 \{published data only\}}

Zocco MA, dal Verme LZ, Cremonini F, Piscaglia AC, Nista EC, Candelli M, et al. Efficacy of Lactobacillus GG in maintaining remission of ulcerative colitis. Alimentary Pharmacology and Therapeutics 2006;23(11):1567-74.

\section{References to studies excluded from this review}

Ahmed 2013 \{published data only\}

Ahmed J, Reddy BS, Molbak L, Leser TD, Macfie J. Impact of probiotic on colonic microflora in patients with colitis: A prospective double blind randomised crossover study. International Journal of Surgery 2013;11(10):1131-6.

Ballini 2019 \{published data only\}

Ballini A, Santacroce L, Cantore S, Bottalico L, Dipalma G, Tope $S$, et al. Probiotics efficacy on oxidative stress values in inflammatory bowel disease: a randomized double-blinded placebo-controlled pilot study. Endocrine, Metabolic \& Immune Disorders - Drug Targets 2019;19(3):1-8.

Bamba 2002 \{published data only\}

Bamba T, Kanauchi O, Andoh A, Fujiyama Y. A new prebiotic from germinated barley for nutraceutical treatment of ulcerative colitis. Journal of Gastroenterology and Hepatology 2002;17(8):818-24.

\section{Cui 2004 \{published data only\}}

Cui HH, Chen CL, Wang JD, Yang YJ, Cun Y, Wu JB, et al. Effects of probiotics on intestinal mucosa of patients with ulcerative colitis. World Journal of Gastroenterology 2004;10(10):1521-5.

\section{Do 2010 \{published data only\}}

Do VT, Baird BG, Kockler DR. Probiotics for maintaining remission of ulcerative colitis in adults. Annals of Pharmacotherapy 2010;44(3):565-71.

Faubion 2000 \{published data only\}

Faubion WA, Sandborn WJ. Probiotic therapy with E. Coli for ulcerative colitis: take the good with the bad. Gastroenterology 2000;118(3):630-1.

\section{Folwaczny 2000 \{published data only\}}

Folwaczny C. Probiotics for prevention of ulcerative colitis recurrence: alternative medicine added to standard treatment. Zeitschfrift de Gastroenterologie 2000;38(6):547-50. 
Fujimori 2009 \{published data only\}

Fujimori S, Gudis K, Mitsui K, Seo T, Yonezawa M, Tanaka S, et al. Randomized controlled trial on the efficacy of synbiotic versus probiotic or prebiotic treatment to improve the quality of life in patients with ulcerative colitis. Nutrition 2009;25(5):520-5.

Henker 2008 \{published data only\}

Henker J, Müller S, Laass MW, Schreiner A, Schulze J. Probiotic Escherichia coli Nissle 1917 (ECN) for successful remission maintenance of ulcerative colitis in children and adolescents: an open-label pilot study. Zeitschrift fur Gastroenterologie 2008;46(9):874-5.

\section{IRCT20120415009475N5 \{published data only\}}

IRCT20120415009475N5. Evaluation of the effects of Saccharomyces Boulardii on pain and quality of life in children with Inflammatory Bowel Disease (IBD) [Evaluation of the effects of lyophilized Saccharomyces Boulardii capsules on quality of life and clinical outcomes in children with inflammatory bowel disease (IBD)]. www.irct.ir/trial/32179 (registration date 10 October 2018). [IRCT: https://www.irct.ir/ trial/32179]

\section{Ishikawa 2002 \{published data only\}}

Ishikawa H, Akedo I, Umesaki Y, Tanaka R, Imaoka A, Otani T. Randomized controlled trial of the effect of bifidobacteriafermented milk on ulcerative colitis. Journal of the American College of Nutrition 2002;22(1):56-63.

\section{Ishikawa 2011 \{published data only\}}

Ishikawa H, Matsumoto S, Ohashi Y, Imoaka A, Setoyama H, Umesaki Y, et al. Beneficial effects of probiotic bifidobacterium and galacto-oligosaccharide in patients with ulcerative colitis: $\mathrm{A}$ randomized controlled study. Digestion 2011;84(2):128-33.

\section{Li 2013 \{published data only\}}

Li K, Zhang CF, Xia YH, Li Z J, Han Y. Efficacy of probiotics on ulcerative colitis and its mechanism. Zhonghua Weichang Waike Zazhi 2013;16(4):336-9.

\section{Liu 2014 \{published data only\}}

Liu P, Sun L, Zhang ZH, Zhang P, Zhang J. Clinical efficacy of Salofalk combined with beneficial bacteria in patients with ulcerative colitis. World Chinese Journal of Digestology 2014;22(22):3344-8

\section{Miele 2009 \{published data only\}}

Miele E, Pascarella F, Giannetti E, Quaglietta L, Baldassano RN, Staiano A. Effect of a probiotic preparation (VSL\#3) on induction and maintenance of remission in children with ulcerative colitis. American Journal of Gastroenterology 2009;104(2):437-43.

\section{NCT00268164 \{published data only\}}

NCT00268164. Lactobacilus acidophilus and Bifidobaceterium animalis subsp. Lactis maintenance treatment in ulcerative colitis. clinicaltrials.gov/show/NCT00268164 First received 22 December 2005.

\section{NCT00374725 \{published data only\}}

NCT00374725. Treatment of Ulcerative Colitis With a Combination of Lactobacillus Rhamnosus and Lactobacillus
Acidophilus. clinicaltrials.gov/show/NCT00374725 First posted 11 September 2006.

NCT00803829 \{published data only\}

NCT00803829. Sunbiotic treatment of ulcerative colitis patients. clinialtrials.gov/show/NCT00803829 First posted 8 December 2008.

\section{NCT00951548 \{published data only\}}

NCT00951548. Food Supplementation With VSL\#3 as a Support to Standard Pharmaceutical Therapy in Ulcerative Colitis. clinicaltrials.gov/show/NCT00951548 First posted 4 August 2009.

\section{NCT01772615 \{published data only\}}

NCT01772615. Treatment of ulcerative colitis with ciprofloxacin and E. Coli Nissle. clinicaltrials/gov/show/NCT01772615 First posted 21 january 2013

Palumbo 2016 \{published data only\}

Palumbo VD, Romeo M, Marino Gammazza A, Carini F, Damiani P, Damiano G, et al. The long-term effects of probiotics in the therapy of ulcerative colitis: A clinical study. Biomedical Papers of the Medical Faculty of the University Palacky, Olomouc, Czechoslovakia 2016;160(3):372-7.

Pelech 1998 \{published data only\}

Pelech T, Fric P, Fixa B, Komarkova O. Comparison of mutaflor and mesalazine in the maintenance treatment of inactive ulcerative colitis. Prakticky Lekar 1998;78(10):556-8.

Rembacken 1999 \{published data only\}

Rembacken BJ, Snelling AM, Hawkey PM, Chalmers DM, Axon AT. Non-pathogenic Escherichia coli versus mesalazine for the treatment of ulcerative colitis: a randomised trial. Lancet 1999;354(9179):635-9.

\section{Rohatgi 2015 \{published data only\}}

Rohatgi S, Ahuja V, Makharia GK, Rai T, Das P, Dattagupta S, et al. VSL\#3 induces and maintains short-term clinical response in patients with active microscopic colitis: a twophase randomised clinical trial. BMJ Open Gastroenteroilogy 2015;2(1):e000018.

\section{Sanchez-Morales 2019 \{published data only\}}

Sanchez-Morales A, Perez-Ayala MF, Cruz-Martinez M, ArenasOsuna J, Ramirez-Mendoza P, Ceniceros RA, et al. [Efectividad de probioticos sobre sintomas, histologia, y tolerancia alimentaria en colitis ulcerativa]. Revista Medica del Instituto Mexicano del Seguro Social 2019;57(1):9-14.

\section{Shadnoush 2013 \{published data only\}}

Shadnoush M, Hosseini RS, Mehrabi Y, Delpisheh A, Alipoor E, Faghfoori Z, et al. Probiotic yogurt affects pro- and antiinflammatory factors in patients with inflammatory bowel disease. Iranian Journal of Pharamceutical Research 2013;12(4):929-36.

\section{Solovyeva 2014 \{published data only\}}

Solovyeva O. Probiotics can extend remission of ulcerative colitis. Journal of Crohn's and Colitis 2014;8:221. 
Tursi 2010 \{published data only\}

Tursi A, Brandimarte G, Papa A, Giglio A, Elisei W, Giorgetti GM, et al. Treatment of relapsing mild-to-moderate ulcerative colitis with the probiotic VSL3 as adjunctive to a standard pharmaceutical treatment: A double-blind, randomized, placebo-controlled study. American Journal of Gastroenterology 2010;105(10):2218-27.

\section{Venturi 1999 \{published data only\}}

Venturi A, Gionchetti P, Rizzello F, Johansson R, Zucconi E, Brigidi P, et al. Impact on the composition of the faecal flora by a new probiotic preparation: preliminary data on maintenance treatment of patients with ulcerative colitis. Alimentary Pharmacology and Therapeutics 1999;13(8):1103-8.

\section{Zhang 2018a \{published data only\}}

Zhang J. Effects of Bifidobacterium quadruplex live bacteria tablets on Mayo score and hs-CRP, IL-4, IL-8 in patients with mild to moderate ulcerative colitis. World Chinese Journal of Digestology 2018;26(6):373-7.

\section{References to studies awaiting assessment}

\section{Fan 2019 \{published data only\}}

Fan H, Du J, Liu X, Zheng WW, Zhuang ZH, Wang CD, et al. Effects of pentasa-combined probiotics on the microflora structure and prognosis of patients with inflammatory bowel disease. Turkish Journal of Gastroenterology 2019;30(8):680-5.

Fang 2018 \{published data only\} Fang W, Cai Q. Effect of mesalazine combined with bifid on inflammatory response and rectal-anal dynamics in patients with ulcerative colitis. World Chinese Journal of Digestology 2018;26(10):594-600.

\section{Huang 2018 \{published data only\}}

Huang M, Chen Z, Lang C, Chen J, Yang B, Xue L, et al. Efficacy of mesalazine in combination with bifid triple viable capsules on ulcerative colitis and the resultant effect on the inflammatory factors. Pakistan Journal of Pharmaceutical Sciences 2018;31(6):2891-5.

\section{Shi 2018 \{published data only\}}

Shi XH, Tan FP, Jiang WH. Bacillus subtilis and Enterococcus faecium enteric-coated capsules combined with mesalazine for treatment of patients with ulcerative colitis: Efficacy and impact on serum levels of SOD, MDA, interleukins, and TNF- $\alpha$. World Chinese Journal of Digestology 2018;26(12):748-54.

\section{Yilmaz 2019 \{published data only\}}

Yilmaz I, Dolar ME, Özpinar H. Effect of administering kefir on the changes in fecal microbiota and symptoms of inflammatory bowel disease: a randomized controlled trial. Turkish Journal of Gastroenterology 2019;30(3):242-53.

\section{Zhang 2018b \{published data only\}}

Zhang Y, Wu M, Chen Y. Effects of adjuvant therapy with bifidobacterium quadruplex on lipid peroxidation injury indices, inflammatory factors and immune function in patients with ulcerative colitis. World Chinese Journal of Digestology 2018;26(22):1348-54.

\section{References to ongoing studies}

NCT03415711 \{published data only\}

NCT03415711. PRObiotic VSL\#3 ${ }^{\circledR}$ for Maintenance of Clinical and Endoscopic REMission in Ulcerative Colitis (PROREM UC). clinicaltrials.gov/ct2/show/NCT03415711 First posted 30 January 2018.

\section{NCT03565939 \{published data only\}}

NCT03565939. Probiotic Treatment of Ulcerative Colitis With Trichuris Suis Ova (TSO) (PROCTO). clinicaltrials.gov/ct2/show/ NCT03565939 First posted 21 June 2018.

\section{NCT03798210 \{published data only\}}

NCT03798210. Lactobacillus Reuteri ATCC PTA 4659 in Ulcerative Colitis (COLUS). clinicaltrials.gov/ct2/show/NCT03798210 First posted 9 January 2019.

\section{NCT04006977 \{published data only\}}

Liang J. Multistrain Probiotics Reduces UC Depression and Anxiety Scores. clinicaltrials.gov/ct2/show/NCT04006977 First posted 5 July 2019.

\section{Additional references}

\section{Baron 1964}

Baron JH, Connell AM, Lenard-Jones JE. Variation between observers in describing mucosal appearances in proctocolitis. British medical journal 1964;1:89-92.

\section{Cleynen 2016}

Cleynen I. Inherited determinants of Crohn's disease and ulcerative colitis phenotypes: a genetic association study. Lancet 2016;387(10014):156-67.

\section{Cohen 2010}

Cohen RD. Systematic review: the costs of ulcerative colitis in Western countries. Alimentary Pharmaology and Therapeutics 2010;31(7):693-707.

\section{Dieleman 2003}

Dieleman LA, Goerres MS, Arends A, Sprengers D, Torrice C, Hoentjen $F$, et al. Lactobacillus $G G$ prevents recurrence of colitis in HLA-B27 transgenic rats after antibiotic treatment. Gut 2003;52(3):370-6.

\section{Fabia 1993}

Fabia R, Ar'Rajab A, Johansson ML, Willen R, Andersson R, Molin $\mathrm{G}$, et al. The effect of exogenous administration of Lactobacillus reuteri R2LC and oat fiber on acetic-induced colitis in the rat. Scandinavian Journal of Gastroenterology 1993;28(2):155-62.

\section{Fiorino 2016}

Fiorino $\mathrm{G}$. The clinical potential of etrolizumab in ulcerative colitis: hypes and hopes. Therapeutic Advances in Gastroenerology 2016;9(4):503-12. 


\section{GRADEpro GDT 2015 [Computer program]}

McMaster University. GRADEpro GDT: GRADEpro Guideline Development Tool. McMaster University, 2015 (developed by Evidence Prime, Inc.).

\section{Higgins 2003}

Higgins JP, Thompson SG, Deeks JJ, Altman DG. Measuring inconsistency in meta-analyses. BMJ 2003;327(7414):557-60.

\section{Higgins 2011}

Higgins JP, Altman DG, Sterne JA, editor(s). Chapter 8: Assessing risk of bias in included studies. In: Higgins JP, Green S, editor(s). Cochrane Handbook for Systematic Reviews of Interventions Version 5.1.0 (updated March 2011). The Cochrane Collaboration, 2011. Available from handbook.cochrane.org. The Cochrane Collaboration.

\section{Jairath 2017}

Jairath V, Zou GY, Parker CP, MacDonald JK, AlAmeel T, Al Beshir $\mathrm{M}$, et al. Placebo response and remission rates in randomised trials of induction and maintenance therapy for ulcerative colitis. Cochrane Database of Systematic Reviews 2017, Issue 9. [DOI: 10.1002/14651858.CD011572.pub2]

\section{Kennedy 2000}

Kennedy RJ, Hoper M, Deodhar K, Kirk SJ, Gardiner KR. Probiotic therapy fails to improve gut permeability in a hapten model of colitis. Scandinavian Journal of Gastroenterology 2000;35(12):1266-71.

\section{Loftus 2004}

Loftus EV. Clinical epidemiology of inflammatory bowel disease: Incidence, prevalence, and environmental influences. Gastroenterology 2004;126(6):1504-17.

\section{Madsen 1999}

Madsen KL, Doyle JS, Jewell LD, Tavernini MM, Fedorak RN. Lactobacillus species prevents colitis in interleukin 10 genedeficient mice. Gastroenterology 1999;116(5):1107-14.

\section{Madsen 2001}

Madsen K, Cornish A, Soper P, McKaigney C, Jijon H, Yachimec $C$, et al. Probiotic bacteria enhance murine and human intestinal epithelial barrier function. Gastroenterology 2001;121(3):580-91.

\section{Mallon 2007}

Mallon P, McKay D, Kirk S, Gardiner K. Probiotics for induction of remission in ulcerative colitis. Cochrane Database of Systematic Reviews 2007, Issue 10. [DOI: 10.1002/14651858.CD005573.pub2]

\section{NICE 2019}

National Institute for Health and Care Excellence. Ulcerative Colitis Mangagement NG130. https://www.nice.org.uk/ guidance/ng130 2019

\section{Ong 2019}

Ong TG, Gordon M, Banks SS, Thomas MR, Akobeng AK. Probiotics to prevent infantile colic. Cochrane
Database of Systematic Reviews 2019, Issue 3. [DOI:

10.1002/14651858.CD012473.pub2]

\section{Panigrahi 2014}

Panigrahi P. Probiotics and prebiotics in neonatal necrotizing enterocolitis: new opportunities for translational research. Pathophysiology 2014;21(1):35-46.

\section{Pitkin 1999}

Pitkin RM, Branagan MA, Burmeister LF. Accuracy of data in abstracts of published research articles. JAMA 1999;281:1110-1.

\section{Review Manager 2014 [Computer program]}

The Nordic Centre. Copenhagen: The Cochrane Collaboration, 13th June 2014.

\section{Schultz 2002}

Schultz M, Veltkamp C, Dieleman LA, Grenther WB, Wyrick PB, Tonkonogy SL, et al. Lactobacillus plantarum 299V in the treatment and prevention of spontaneous colitis in interleukin-10-deficient mice. Inflammatory Bowel Diseases 2002;8(2):71-80.

\section{Schünemann 2011}

Schünemann HJ, Oxman AD, Higgins JP, Vist GE, Glasziou P, Guyatt GH. Chapter 11: Presenting results and 'Summary of findings' tables. In: Higgins JP, Green S, editor(s). Cochrane Handbook for Systematic Reviews of Interventions Version 5.1.0 (updated March 2011). The Cochrane Collaboration, 2011. Available from handbook.cochrane.org.

\section{Shibolet 2002}

Shibolet O, Karmeli F, Eliakim R, Swennen E, Brigidi P, Gionchetti $\mathrm{P}$, et al. Variable response to probiotics in two models of experimental colitis in rats. Inflammatory Bowel Diseases 2002;8(6):399-406.

\section{Truelove 1956}

Truelove SC, Richards WC. Biopsy studies in ulcerative colitis. British medical journal 1956;1:1315-1318.

\section{Turner 2018}

Turner D, Ruemmele FM, Orlanski-Meyer E, Griffiths AM, de Carpi JM, Bronsky J, et al. Management of paediatric ulcerative colitis, Part 1: ambulatory care-an evidencebased guideline From European Crohn's and Colitis Organization and European Society of Paediatric Gastroenterology, Hepatology and Nutrition. Journal of Pediatric Gastroenterology and Nutrition 2018;67(2):257-91. [DOI: $10.1097 / \mathrm{mpg} .0000000000002035]$

\section{Ungaro 2016}

Ungaro R, Mehandru S, Allen PB, Peyrin-Biroulet L, Colombel JF. Ulcerative colitis. Lancet 2016;389(10080):1756-70.

\section{Wang 2016}

Wang Y, Parker CE, Feagan BG, MacDonald JK. Oral 5 aminosalicylic acid for maintenance of remission in ulcerative colitis. Cochrane Database of Systematic Reviews 2016, Issue 5. [DOI: 10.1002/14651858.CD000544.pub4] 


\section{References to other published versions of this review}

Fagbemi 2008

Fagbemi AO, Thomas AG, Akobeng AK. Probiotics for maintenance of remission in ulcerative colitis. Cochrane

\section{CHARACTERISTICS OF STUDIES}

Characteristics of included studies [ordered by study ID]
Database of Systematic Reviews 2008, Issue 4. [DOI: 10.1002/14651858.CD007443]

\section{Naidoo 2011}

Naidoo K, Gordon M, Fagbemi AO, Thomas AG, Akobeng AK. Probiotics for maintenance of remission in ulcerative colitis. Cochrane Database of Systematic Reviews 2011, Issue 12. [DOI: 10.1002/14651858.CD007443.pub2]

Bjarnason 2019

Methods RCT, double-blind, single centre

Setting: King's College Hospital Gastroenterology Clinic, London

Study duration: November 2010 to October 2014

Participants
81 patients with UC, 61 patients with CD (total IBD $=142)$

Inclusion criteria: patients attending routine clinical review with established UC and CD, age 18 to 70 years, diagnosed at least 6 months prior to the trial; patients were required to have stable inactive clinical disease, as defined by $<5$ points on Harvey Bradshaw (which corresponded to a score of $\leq 4$ on the Truelove-Witts criteria for UC, without a change in medication for 4 months. Patients on no treatment, maintenance treatment with a 5-aminosalycilic preparation or low-dose azathioprine $(1 \mathrm{mg} / \mathrm{kg})$ were eligible for inclusion in the trial.

Exclusion criteria: patients on steroids (prednisolone $>4 \mathrm{mg} /$ day) and biologics were excluded from the study; patients having undergone intestinal resection, patients with serious comorbidity including neurological, rheumatological, respiratory, nephrological, cardiovascular, psychiatric disease, patients with alcohol or drug addiction or dependency problems (within the last 5 years) and pregnant or lactating women; patients with previous intolerance or adverse reactions to probiotics or the use of these products within the preceeding 3 months were excluded.

Age (mean +/- SD): probiotic UC 47.3+/- 14.4, placebo UC: 43.4 +/- 12.1; probiotic CD: $41.2+$ +- 13.0, placebo CD: $39.0+/-13.0$

Sex: not specified

Site of disease: probiotics UC: proctosigmoid 16, left-sided 9, pancolonic 12; placebo UC: proctosigmoid 21, left-sided 10, pancolonic 9

probiotics CD: small bowel 14, colon 11, small and large bowel 9; placebo CD: small bowel 14, colon 7, small and large bowel 7

Use of medication: probiotics UC: 5-ASA 31, azathioprine 2, prednisolone 1, none 7

placebo UC: 5-ASA 33, azathioprine 2, prednisolone 0 , none 6

probiotics CD: 5-ASA 15, azathioprine 4, prednisolone 1, none 13

placebo CD: 5-ASA 12, azathioprine 2, prednisolone 0, none 15

Length of time remission at study entry: not specified

Number randomised: total probiotic: 73 , total placebo: 70 ; probiotic UC: 40 , placebo UC: 41 ; probiotic CD: 33, placebo CD: 29

Number assessed: all randomised completed the study

Postrandomisation exclusion: 0 
Bjarnason 2019 (Continued)

No significant side effects were reported and the probiotic was well-tolerated by everyone
Follow-up: 4 weeks

IV: Symprove (Symprove Ltd. Farnham, Surrey UK), a dietary food supplement which contains 4 strains of bacteria (Lactobacillus rhamnosus NCIMB

30174, Lactobacillus plantarum NCIMB 30173, Lactobacillus

acidophilus NCIMB 30175 and Enterococcus faecium

NCIMB 30176), in a water-based suspension of barley extract with each $50 \mathrm{~mL} /$ dose containing about 10 billion live bacteria.

Control: patients received placebo, which was an identical liquid in appearance and taste, containing water and flavouring and was provided in identical packaging supplied by the manufacturers identified by a trial batch and code number only. Patients were asked to keep the study medication refrigerated between $2^{\circ} \mathrm{C}$ and $7{ }^{\circ} \mathrm{C}$ and to self-administer $1 \mathrm{~mL} / \mathrm{kg}$ each morning on a fasting stomach. Foods and fluids were allowed 20 min later. Missed does could be taken later during the day provided that no food had been consumed during the preceding 3 hours.
Outcomes

Primary efficacy outcome: difference in overall change in the IBD QoL questionnaire results at week 4

Secondary measures: the differences in clinical disease activity scores between active and placebo treatment and changes in laboratory measures including FCAL (Ek-CAL, Buhlmann, Switzerland)

Notes

Funding and conflict of interest: supported by an unreserved research grant from Symprove Limited, the manufacturers of the probiotic Symprove to King's College Hospital. They also provided the probiotic used in the trial and a matching placebo free of charge. Prof Bjarnason has received financial support from Symprove Ltd for travel expenses to scientific meetings.

\section{Risk of bias}

\begin{tabular}{lll}
\hline Bias & Authors' judgement & Support for judgement \\
\hline $\begin{array}{l}\text { Random sequence genera- } \\
\text { tion (selection bias) }\end{array}$ & Low risk & $\begin{array}{l}\text { Quote: "Study participants were randomised using a two-stage computerised } \\
\text { randomisation protocol provided by the Department of Pharmacy at King's } \\
\text { College Hospital" }\end{array}$
\end{tabular}

\begin{tabular}{ll}
\hline $\begin{array}{l}\text { Allocation concealment } \\
\text { (selection bias) }\end{array}$ & Low risk \\
& It is explained that preparations were identical liquids in appearance and \\
& taste, provided in identical packaging supplied by the manufacturers, identi- \\
& allocation concealment are provided
\end{tabular}

Blinding of participants Low risk and personnel (performance bias)

All outcomes
Quote: "Blinding of allocation to treatment was maintained until the completed study database was locked and passed over to an independent study statistician".

Double-blinding. Preparations were identical liquids in appearance and taste, provided in identical packaging supplied by the manufacturers, identified by a trial batch and code number only

\begin{tabular}{lll}
\hline $\begin{array}{l}\text { Blinding of outcome as- } \\
\text { sessment (detection bias) } \\
\text { All outcomes }\end{array}$ & Low risk & $\begin{array}{l}\text { Quote: "Blinding of allocation to treatment was maintained until the complet- } \\
\text { ed study database was locked and passed over to an independent study statis- } \\
\text { tician" }\end{array}$ \\
\hline $\begin{array}{l}\text { Incomplete outcome data } \\
\begin{array}{l}\text { (attrition bias) } \\
\text { All outcomes }\end{array}\end{array}$ & Low risk & All reported \\
\hline
\end{tabular}

Selective reporting (re- $\quad$ Low risk $\quad$ All reported
porting bias)


Bjarnason 2019 (Continued)

$\begin{array}{ll}\text { Other bias } & \text { The study wask funded by the manufacturers of the probiotics product studied } \\ \text { in this article and the lead author has received financial support from the same } \\ \text { company. }\end{array}$

Copaci 2014

\begin{tabular}{|c|c|}
\hline Methods & $\begin{array}{l}\text { Open-label, parallel group, randomised clinical trial (abstract only) } \\
\text { Setting: not stated, however authors' affiliation - Fundini clinical institute, Bucharest, Romania } \\
\text { Study period: not stated }\end{array}$ \\
\hline Participants & $\begin{array}{l}\text { Inclusion criteria: people with UC in remission for over } 3 \text { months } \\
\text { Exclusion criteria: not stated } \\
\text { Age (range): } 18 \text { to } 65 \text { years } \\
\text { Sex: not stated } \\
\text { Site of disease: ? (total colitis), ? (left-sided colitis) } \\
\text { Use of medication: not stated } \\
\text { Length of time remission at study entry: not stated } \\
\text { Number randomised ( } \mathbf{n}=\mathbf{3 6}): ? \text { (probiotic }+ \text { mesalamine)/? (mesalamine + prebiotic) }{ }^{\star} / \text { ? (mesalamine) } \\
\text { Number assessed: ? (probiotic + mesalamine)/? (mesalamine + prebiotic) }{ }^{\star} / \text { ? (mesalamine) } \\
\text { Postrandomisation exclusion: not stated }\end{array}$ \\
\hline Interventions & $\begin{array}{l}\text { - Mesalazine plus probiotic (Bifidobacterium longum W11) } \\
\text { - Mesalazine plus prebiotic (Plantago Ovata) }{ }^{\star} \\
\text { - Mesalazine }\end{array}$ \\
\hline
\end{tabular}

$\begin{array}{ll}\text { Outcomes } & \text { Duration of follow-up: } 24 \text { weeks } \\ \text { - Relapse } \\ \text { - Continued remission. Remission - not defined } \\ \text { tom) }\end{array}$

Risk of bias

\begin{tabular}{lll}
\hline Bias & Authors' judgement & Support for judgement \\
\hline $\begin{array}{l}\text { Random sequence genera- } \\
\text { tion (selection bias) }\end{array}$ & Unclear risk & Quote: "Open-label, parallel group, randomized clinical trial". \\
& & Comment: not adequately described \\
\hline
\end{tabular}


Copaci 2014 (Continued)

Allocation concealment Unclear risk Not adequately described
(selection bias)

\begin{tabular}{|c|c|c|}
\hline $\begin{array}{l}\text { Blinding of participants } \\
\text { and personnel (perfor- } \\
\text { mance bias) }\end{array}$ & High risk & $\begin{array}{l}\text { Quote: "Open-label, parallel group, randomized clinical trial" } \\
\text { Comment: there was no blinding of participants and personnel }\end{array}$ \\
\hline
\end{tabular}

All outcomes

\begin{tabular}{|c|c|c|}
\hline $\begin{array}{l}\text { Blinding of outcome as- } \\
\text { sessment (detection bias) } \\
\text { All outcomes }\end{array}$ & High risk & $\begin{array}{l}\text { Quote: "Open-label, parallel group, randomized clinical trial" } \\
\text { Comment: no blinding }\end{array}$ \\
\hline
\end{tabular}

\begin{tabular}{lll}
\hline $\begin{array}{l}\text { Incomplete outcome data } \\
\text { (attrition bias) }\end{array}$ & Unclear risk & Not adequately reported \\
All outcomes & \\
\hline $\begin{array}{l}\text { Selective reporting (re- } \\
\text { porting bias) }\end{array}$ & Unclear risk & $\begin{array}{l}\text { Symptoms were monitored using a gastrointestinal symptom rating scale, } \\
\text { however, the results were not fully reported }\end{array}$ \\
\hline
\end{tabular}

\begin{tabular}{lll}
\hline Other bias & Unclear risk & Not adequately described \\
\hline
\end{tabular}

\section{Kruis 1997}

\begin{tabular}{|c|c|}
\hline Methods & $\begin{array}{l}\text { Double-blind, multicentre RCT } \\
\text { Setting: outpatient hospitals and private practices in Germany, the Czech Republic and Austria } \\
\text { Study period: not stated }\end{array}$ \\
\hline Participants & $\begin{array}{l}\text { Inclusion: age > } 17 \text { years; presence of chronic UC currently in remission (defined by CAI score) } \\
\text { Exclusion: active UC, infectious colitis, existing or intended pregnancy, any other medication for UC } \\
\text { besides the study drugs, antibiotics or suphonamides, substantial cardiac, hepatic or renal disease, } \\
\text { major operations on the bowels, and known intolerance to salicylates } \\
\text { Age* (range): } 19 \text { to } 88 \text { years } \\
\text { Sex (M/F): } 55 / 48 \\
\text { Site of disease*: } 28 \text { (proctitis); } 40 \text { (proctosigmoiditis); } 19 \text { (left-sided colitis); } 18 \text { (total/subtotal colitis) } \\
\text { Use of medication*: } 82 \text { (salicylates); } 25 \text { (corticosteroids) } \\
\text { Length of time remission at study entry: } 14 \text { ( } 1 \text { to } 147 \text { (probiotic)/12 (1 to } 60 \text { ) months (mesalazine) } \\
\text { Number randomised ( } \mathbf{n}=\mathbf{1 2 0}): 60 \text { ? (probiotics)/60? (mesalazine) } \\
\text { Number assessed: } 50 \text { (probiotics)/53 (mesalazine) } \\
\text { Postrandomisation exclusion: } 2 \text { - not started taking study medication, } 15 \text { - had CAl of }>4 \text { ( } 8 \text { versus } 7 \text { ) }\end{array}$ \\
\hline Interventions & $\begin{array}{l}\text { - Probiotics + mesalazine placebo: oral preparation containing } E \text { coli strain Nissle } 1917.200 \mathrm{mg} / \text { day } \\
\text { (day } 1 \text { to } 4 \text {, only } 100 \mathrm{mg} \text { /day) of a preparation of viable } E \text { coli strain Nissle } 1917 \text { (Mutaflor, Ardeypharm } \\
\mathrm{GmbH} \text {, Herdecke, Germany) taken as a single dose during breakfast. Mutaflor } 100 \mathrm{mg} \text { contains } 25 \mathrm{X} \\
10^{9} \text { viable } E \text { coli bacteria } \\
\text { - Mesalazine + placebo: } 500 \mathrm{mg} \text { mesalazine three times a day (Salofalk, Dr Falk Pharma GmbH, Freiburg, } \\
\text { Germany) plus placebo indistinguishable from the } E \text { coli preparation }\end{array}$ \\
\hline
\end{tabular}


Kruis 1997 (Continued)

- Relapse defined as CAI > 4

- Relapse-free time

- Adverse events

- Withdrawal due to adverse events

Notes

Funding source: supported by Ardeypharm GmbH, Herdecke, Germany

Declaration of interest: not reported.

*Baseline characteristics reported do not account for participants who were excluded postrandomisation

\section{Risk of bias}

\begin{tabular}{|c|c|c|}
\hline Bias & Authors' judgement & Support for judgement \\
\hline $\begin{array}{l}\text { Random sequence genera- } \\
\text { tion (selection bias) }\end{array}$ & Unclear risk & $\begin{array}{l}\text { Participants were reportedly randomised, however, the method of randomisa- } \\
\text { tion was not adequately described }\end{array}$ \\
\hline $\begin{array}{l}\text { Allocation concealment } \\
\text { (selection bias) }\end{array}$ & Unclear risk & Not stated \\
\hline $\begin{array}{l}\text { Blinding of participants } \\
\text { and personnel (perfor- } \\
\text { mance bias) } \\
\text { All outcomes }\end{array}$ & Low risk & $\begin{array}{l}\text { Described as double-blind double-dummy. Both intervention arms included } \\
\text { placebos. }\end{array}$ \\
\hline $\begin{array}{l}\text { Blinding of outcome as- } \\
\text { sessment (detection bias) } \\
\text { All outcomes }\end{array}$ & Unclear risk & $\begin{array}{l}\text { Described as double-blind double-dummy, however, there was no specific in- } \\
\text { formation as to whether outcome assessment was blinded }\end{array}$ \\
\hline $\begin{array}{l}\text { Incomplete outcome data } \\
\text { (attrition bias) } \\
\text { All outcomes }\end{array}$ & Low risk & $\begin{array}{l}\text { ITT analysis (modified ITT) was partially applied as it failed to account for } \\
\text { participants who were excluded postrandomisation. However, number and } \\
\text { reasons for postrandomisation exclusion appear to have been equal across } \\
\text { groups ( } 16 \% \text { versus } 11 \%)\end{array}$ \\
\hline $\begin{array}{l}\text { Selective reporting (re- } \\
\text { porting bias) }\end{array}$ & Low risk & $\begin{array}{l}\text { Trial registration was not available, however, all expected outcomes were re- } \\
\text { ported }\end{array}$ \\
\hline Other bias & Low risk & No other apparent biases \\
\hline
\end{tabular}

\section{Kruis 2004}

\begin{tabular}{ll}
\hline Methods & Double-blind, multicentre RCT \\
& Setting: 60 hospitals and private settings in 10 European countries (Austria, Czech Republic, Estonia, \\
& Germany, Latvia, Lithuania, Slovak Republic, Sweden, Switzerland, UK)
\end{tabular}

Study period: not stated

Participants

Inclusion: age 18 to 70 ; UC in remission (CAI $\leq 4$, endoscopic index $\leq 4$ and no sign of acute inflammation on histological examination); at least two acute attacks of UC prior to study; time since last relapse: $<12$ months

Exclusion: active UC; proctitis with up to $10 \mathrm{~cm}$ proximal spread; Crohn's disease, infectious colitis; severe accompanying illnesses or major colonic surgery; use of antibiotics, sulphonamides, steroids or 
Kruis 2004 (Continued)

other therapies for UC at entry into trial; administration of study intervention drug within the previous six months before trial entry; known intolerance to salicylates

Age: 19 to 82 years

$\operatorname{Sex}(M / F): 179 / 148$

Site of disease: 61 (sub/total); 62 (left-sided); 190 (distal)

Use of medication: 235 (oral salicylates - partly combined with steroids)

Length of time remission at study entry: $<4$ (probiotic)/ $<3$ months (mesalazine)

Number randomised ( $\mathbf{n}=\mathbf{3 2 7}): 162$ (probiotic)/165 (mesalazine)

Number assessed: 162 (probiotic)/165 (mesalazine)

Postrandomisation exclusion*: 2 - deterioration of disease excluding relapse; 6 - newly emerged exclusion criterion during study; 22 - patient's request; 9 - adverse events; 12 - insufficient patient compliance; 9 - insufficient patient co-operation; 7 - dropped out; 3 - other; premature discontinuation - 39

Interventions

- Probiotic + placebo: oral preparation containing E coli strain Nissle 1917. Capsules contained 2.5 to 25 X $10^{9}$ viable bacteria (Mutaflor 100 mg; Ardeypharm GmbH, Herdecke, Germany). Participants received one capsule of Mutaflor $100 \mathrm{mg}$ once daily and one tablet of placebo $3 \times$ daily for 4 days and 2 capsules of Mutaflor $100 \mathrm{mg}$ once daily and one tablet of placebo $3 \mathrm{x}$ daily from day 5 to the end of the study

- Mesalazine + placebo: 5-aminosalicylic acid (Salofalk, Dr Falk Pharma GmbH, Freiburg, Germany). Participants received one capsule of placebo once daily and one tablet of Salofalk $500 \mathrm{mg} 3 \times$ daily for 4 days and two capsules of placebo once daily and one tablet of Salofalk $500 \mathrm{mg} 3 \times$ daily from day 5 to the end of the study

No concomitant medication for UC was allowed throughout the study

\section{Outcomes Duration of follow-up: 12 months}

- Relapse defined as presence of all of the following: CAI > 6 (or an increase in CAI of at least 3 points with CAI = 4 being exceeded at the same time); endoscopic index $>4$; histological signs of acute inflammation

- Quality of life at 12 months

- Serious adverse events

- Adverse events requiring withdrawal of therapy

Notes Funding source: not stated

Declaration of interest: not reported

*some participants may have had multiple reasons for being excluded

\section{Risk of bias}

Bias Authors' judgement Support for judgement

Random sequence genera- Low risk tion (selection bias)
Quote: "Randomisation was carried out in a double blind manner in blocks of four patients using 1:1 allocation to the two treatment groups. Only complete blocks of random numbers were used for each centre. If patients were eligible for study entry, they were assigned to random numbers ( = patient numbers) in ascending order within each centre according to the chronological order of their randomisation and were given the corresponding study medication."

Comment: adequately described

\begin{tabular}{lll}
$\begin{array}{l}\text { Allocation concealment } \\
\text { (selection bias) }\end{array}$ & Unclear risk & $\begin{array}{l}\text { Confirmed via correspondence (quote): "Since Mutaflor and Mesalazine have } \\
\text { a different dosage form (capsule vs. tablet), the double-dummy method was } \\
\text { used to ensure double-blindness, i.e. a patient allocated to the test group was }\end{array}$ \\
\hline
\end{tabular}

Probiotics for maintenance of remission in ulcerative colitis (Review) 
Kruis 2004 (Continued)

given Mutaflor verum and Mesalazine placebo, whereas a patient allocated to the control group was given Mesalazine verum and Mutaflor placebo)"

Comment: unclear whether study interventions were provided in identical sequentially numbered containers

Blinding of participants Low risk Described as double-blind and double-dummy
and personnel (perfor-
mance bias)
All outcomes

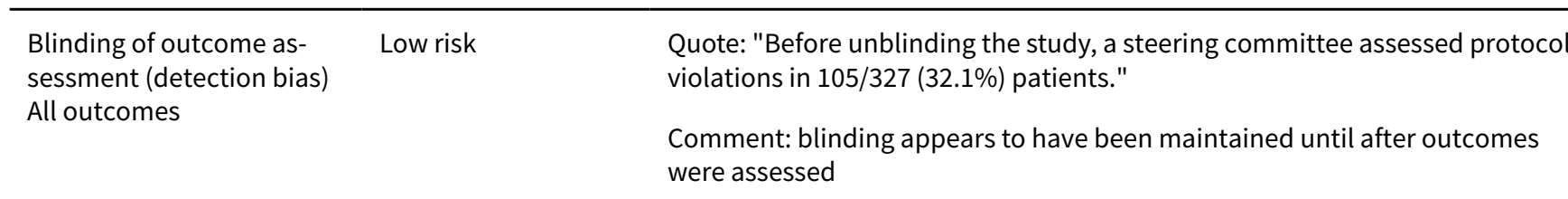

\begin{tabular}{lll}
\hline $\begin{array}{l}\text { Incomplete outcome data } \\
\text { (attrition bias) } \\
\text { All outcomes }\end{array}$ & Low risk & High attrition, but balanced between the two groups. \\
\hline $\begin{array}{l}\text { Selective reporting (re- } \\
\text { porting bias) }\end{array}$ & Low risk & $\begin{array}{l}\text { Trial registration not available, however, all measured outcomes were report- } \\
\text { ed }\end{array}$ \\
\hline $\begin{array}{ll}\text { Other bias } \\
\text { Low risk }\end{array}$ & $\begin{array}{l}\text { Quote: "The two patient groups were matched with regard to demographic, } \\
\text { clinical, and pretreatment characteristics" } \\
\text { Comment: no other apparent biases }\end{array}$ \\
\hline
\end{tabular}

\section{Matsuoka 2018}

\begin{tabular}{ll}
\hline Methods & Double-blind, parallel group, Multicentre RCT \\
& Setting: Keio University School of Medicine; Tokyo Yamate Medical Center, Center for Infammatory \\
Bowel Disease; Toho University Medical Center, Sakura Hospital; Kitasato University Hospital; Yoko- \\
hama City University Medical Center, Infammatory Bowel Disease Center; Kannai-Suzuki Clinic; and \\
Matsushima Clinic, Japan
\end{tabular}

Study period: April 2012 to September 2013

\section{Participants}

Inclusion: diagnosed with UC, in remission, age 20 to 70 , worsening symptoms within 2 years, defined as one or more of the following criteria:

- persistent bloody stool $>1$ week

- initiation of 5-ASA treatment, dose escalation, change in medication type for worsening symptoms

- initiation or dose escalation of cytapheresis or glucocorticoids

- initiation or dose escalation of immuno modulators, immunosuppressants, anti-tumour necrosis factor

\section{Exclusion:}

- Diagnosed with proctitis-type UC

- Visible bloody stools detected < 4 weeks before enrolment

- Dose modification of 5-ASA, or change in medication for worsened UC $<4$ weeks before enrolment

- Local administration of 5-ASA

- Administration of cytapheresis $<4$ weeks before enrolment

- Administration of immunomodulators (azathioprine, mercaptopurine) immunosuppressants (tacrolimus, cyclosporin) or anti-tumour necrosis factor (infliximab) $<12$ weeks before enrolment 
- Unable to stop regular consumption of probiotic products other than the study beverage, or food products using lactic acid bacteria during the study period

- Regular consumption of $B$ breve strain Yakult used in the study $<10$ days before enrolment

Age: 20 to 70 years

$\operatorname{Sex}(M / F): 100 / 92$

Site of disease: 100 (pancolitis); 92 (left-sided colitis)

Use of medication: 190 (5-ASA)

Length of time remission at study entry (mean/range): 362.7 (54 to 750 ) - probiotic/378.6 (41 to 846) days - placebo

Number randomised $(\mathbf{n}=\mathbf{1 9 5})^{\star}: 98$ (probiotics) $/ 97$ (placebo)

Number assessed: 97 (probiotics)/95 (placebo)

Postrandomisation exclusion ${ }^{\star \star}: 67$ - discontinuation of protocol specified treatment, 10 - prohibited concomitant treatment, 2 - adverse events, 13 - discontinuation of study beverage, 1 - other

Interventions

- Probiotic: one pack of $B$ breve strain Yakult fermented milk (Mil-Mil) (10 billion bacteria) and Lactobacillus acidophilus (1 billion bacteria) per day

- Placebo: one pack of energy beverage per day

All participants received their allocated treatment for 48 Weeks

Duration of follow-up: 48 weeks
Outcomes Incidence of relapse. Relapse defined as: persistence of a rectal bleeding score of greater or equal than
2 on Sutherland DAI score for 3 consecutive days and/or initiation of remission induction therapy for
worsening of UC (as judged by investigator)
- Maintence of remission. Remission defined as: Sutherland disease activity index (DAI) scale with rectal
bleeding score of 0 and an endoscopic score of 0 or 1
- Serious adverse events

Notes

Funding source: "This work was supported by Yakult Honsha Co., Ltd."

Declaration of interest: reported; Takanori Kanai received a financial donation from Yakult. Yasuo Suzuki, Toshifumi Hibi, Yukari Uemura, Kaoru Yokoyama, Naoki Yoshimura, Reiko Kunisaki, and Katsuyoshi Matsuoka have no conflicts of interest to declare

* Statistical power calculated 300 in each intervention arm needed. However, study split into Period 1 and Period 2. Only period 1 conducted - this used 97 in intervention and 95 in control

${ }^{\star \star}$ Some participants discontinued for multiple reasons

\section{Risk of bias}

\begin{tabular}{lll}
\hline Bias & Authors' judgement & Support for judgement \\
\hline $\begin{array}{l}\text { Random sequence genera- } \\
\text { tion (selection bias) }\end{array}$ & Unclear risk & $\begin{array}{l}\text { Quote: "Patient data were sent to the registration center via facsimile, where } \\
\text { randomization was implemented by the central registration method. A statis- } \\
\text { tician determined the algorithm of allocation. Patients were randomly allocat- } \\
\text { ed to the BFM group or placebo group at a ratio of } 1: 1 \text { by dynamic allocation } \\
\text { with the following randomization factors: age ( } \geq 40 \text { years/12 weeks), study site } \\
\text { (each study site), and compliance with 5-ASA" }\end{array}$ \\
& $\begin{array}{l}\text { Comment: algorithm was determined by a statistician based on age, study site } \\
\text { and compliance with 5-ASA as opposed to a computer }\end{array}$ \\
\hline
\end{tabular}


Matsuoka 2018 (Continued)

Allocation concealment (selection bias)
Low risk

Quote: "The study beverage and placebo beverage were packaged to be indistinguishable in appearance from each other and were delivered from the distribution center based on the allocation results at the time of enrolment. The distribution center, which was not informed of the groups to which patients were allocated, delivered the study beverage according to the provided numbers; this maintained blindness of the study."

Comment: participants and personnel could not foresee assignment
Blinding of participants Low risk and personnel (perfor-

mance bias)

All outcomes
Quote: "BFM and placebo consisted of $100 \mathrm{~mL}$ of an opaque white liquid that were identical"

Comment: similar opaque liquid used
Blinding of outcome assessment (detection bias)

All outcomes
Unclear risk

The trial was described as double-blinded, however, it is not clear if this includes blind outcome assessment. Though there was an independent data monitoring committee, the trial did not specifically report that they were blinded.

\begin{tabular}{ll}
$\begin{array}{l}\text { Incomplete outcome data } \\
\text { (attrition bias) }\end{array}$ & $\begin{array}{l}\text { Data analysed based on the "full study set". This full study set does not include } \\
\text { all participants who were randomised, however, the difference (1 versus } 1) \\
\text { all outcomes }\end{array}$ \\
\hline
\end{tabular}

High risk

Trial registration available (UMIN000007593), however, there were more outcomes reported in the trial than prespecified

Selective reporting (re- High risk comes reported in the trial than prespecified
porting bias)

Other bias High risk

\begin{abstract}
Quote: "The interim analysis results showed that the Bayesian predictive power was 3.7\%, which was markedly lower than the reference range for study continuation (20-25\%). Based on this, the Independent Data Monitoring Committee recommended discontinuation of the study, so the study was discontinued"
\end{abstract}

Comment: a posthoc decision was made to discontinue the study. This was not prespecified in the protocol.

\section{NCT02361957}

Methods Double-blind, single centre RCT

Setting: Hospital Gelderse Valei (Ede, The Netherlands)

Study period: not stated

Participants

Inclusion: age 18 to 65; left-sided UC or pancolitis in clinical remission (serum concentrations of C-reactive protein of $<10 \mathrm{mg} / \mathrm{L}$, which was checked with a point-of-care CRP test, and calprotectin of $<100$ $\mu \mathrm{g} / \mathrm{g}$ during their last medical check-up)

Exclusion: history of GI surgery, diabetes mellitus, cancer; use of antibiotics during the last 3 months; current use of corticosteroids; alcohol consumption $\geq 21$ servings a week for men and $\geq 14$ for women; hypersensitivity to milk protein, gluten, or soy protein; currently pregnant or breastfeeding

Age (mean \pm SD): $51.5 \pm 12.4$ years

$\operatorname{Sex}(M / F): 13 / 12$

Site of disease: ? (left-sided), ? (pancolitis)

Use of medication: not stated 
NCT02361957 (Continued)

\section{Length of time remission at study entry: not stated}

Number randomised ( $\mathbf{n}=\mathbf{2 5}): 13$ (probiotic)/12 (placebo)

Number analysed: 13 (probiotic)/12 (placebo); ITT principle applied

Postrandomisation exclusion: 1 - prednisone prescribed for a flare-up; 1 - personal reasons

Duration of follow-up: 12 weeks
Interventions
Probiotic: patients used 2 sachets per day of 3 grams of the multi species probiotic food supplement
Ecologic 825 . The supplement contained nine bacterial strains: Bifidobacterium bifidum W23, Bifi-
dobacterium lactis W51, Bifidobacterium lactis W52, Lactobacillus acidophilus W22, Lactobacillus casei
W56, Lactobacillus paracasei W20, Lactobacillus plantarum W62, Lactobacillus salivarius W24 and Lac-
tococcus lactis W19, in a concentration of $2.5 \times 10^{9}$ colony forming units per gram for 12 weeks with a
total concentration of $1.5 \times 1010 \mathrm{cfu} /$ day
- Placebo for 12 weeks

Mesalazine with a maximum dose of $2.4 \mathrm{~g} /$ day was the only medication for UC that was permitted during the study

Duration of follow-up:
- Relapse. Reported in the discussion section as a flare-up. However, no further description provided
- Quality of life (IBD-Q: 1 to 7 , higher score = better quality of life)

Notes

Funding source: funding was provided by the Dutch Ministry of Economy Affairs (IPCSFV2900) and Winclove Probiotics BV

Declaration of interest: IBvdV is employee of Winclove Probiotics. Winclove develops, researches and markets probiotic food supplements

\section{Risk of bias}

\begin{tabular}{lll}
\hline Bias & Authors' judgement & Support for judgement \\
\hline $\begin{array}{ll}\text { Random sequence genera- } \\
\text { tion (selection bias) }\end{array}$ & Low risk & $\begin{array}{l}\text { Quote: "The randomization scheme was computer generated by Winclove us- } \\
\text { ing permuted blocks with block size equal to 4" }\end{array}$ \\
& & Comment: adequate randomisation
\end{tabular}

Allocation concealment Unclear risk
(selection bias)

Quote: "It was impossible for research personnel involved with participants to adjust randomization or discern what product participants were receiving, ensuring true allocation concealment"

Comment: method of allocation concealment was not adequately described

\begin{tabular}{|c|c|c|}
\hline $\begin{array}{l}\text { Blinding of participants } \\
\text { and personnel (perfor- } \\
\text { mance bias) }\end{array}$ & Low risk & $\begin{array}{l}\text { Quote: "It was impossible for research personnel involved with participants to } \\
\text { adjust randomization or discern what product participants were receiving..." }\end{array}$ \\
\hline All outcomes & & Comment: study was referred to as double-blinded. \\
\hline
\end{tabular}

\begin{tabular}{|c|c|c|}
\hline $\begin{array}{l}\text { Blinding of outcome as- } \\
\text { sessment (detection bias) } \\
\text { All outcomes }\end{array}$ & Low risk & $\begin{array}{l}\text { Quote: "It was impossible for research personnel involved with participants to } \\
\text { adjust randomization or discern what product participants were receiving..." } \\
\text { Comment: study was placebo-blinded and quality of life data were recorded } \\
\text { by the participants }\end{array}$ \\
\hline
\end{tabular}

\begin{tabular}{|c|c|}
\hline $\begin{array}{l}\text { Incomplete outcome data } \\
\text { (attrition bias) }\end{array}$ & Low risk \\
\hline
\end{tabular}


NCT02361957 (Continued)

All outcomes

\begin{tabular}{|c|c|c|}
\hline $\begin{array}{l}\text { Selective reporting (re- } \\
\text { porting bias) }\end{array}$ & Low risk & $\begin{array}{l}\text { Trial registration is available (NCT02361957) and all prespecified outcomes } \\
\text { were reported }\end{array}$ \\
\hline
\end{tabular}

Other bias Low risk No other apparent biases

Shanahan 2006

$\begin{array}{ll}\text { Methods } & \text { Double-blind, single centre RCT (abstract only) } \\ \text { Setting: not stated } \\ \text { Study period: not stated }\end{array}$

Participants Inclusion: within one month of achieving clinical remission of UC following a documented relapse that required steroids to induce remission. Remission was defined as $<3$ bowel movements/day (without frank/gross blood) out of 7 , while off all steroids

Exclusion: not stated

Age: not stated, however, patients' demographic characteristics were similar across the three treatment groups

Sex: not stated, however, patients' demographic characteristics were similar across the three treatment groups

Site of disease: not stated, however, the extent of colitis which was similar across the groups was leftsided in about one-third, limited (proctitis) in one-third and pancolitis in one-third

Use of medication: not stated, however, patients' demographic characteristics were similar across the three treatment groups

\section{Length of time remission at study entry: not stated}

Number randomised ( $\mathbf{n}=\mathbf{1 5 7})$ : not stated $(52 / 52 / 53$ ?), however, there were similar numbers (52 to 53 ) per group

\section{Number analysed: not stated}

Postrandomisation exclusion: not stated

- Probiotic: Lactobacillus salivarius subsp. Salivarius UCC118

- Probiotic: Bifidobacterium infantis 35624

- Placebo

Each intervention was administered as a rehydrated blended yogurt powder ( $10^{9}$ daily for one year). A stable dose of aminosalicylate was the only permitted concomitant medication for colitis

Duration of follow-up: 1 year
- Relapse. Defined as $<3$ bowel movements per day (without frank/gross blood) out of 7
- Time to relapse
- Adverse events

Notes

Funding source: University College Cork

Declaration of interest: not stated 
Shanahan 2006 (Continued)

Emailed on 7 March 2018 - awaiting reply

\section{Risk of bias}

Bias Authors' judgement Support for judgement

Random sequence genera- Unclear risk tion (selection bias)

Quote: "a prospective, balanced, randomised, parallel group, double blind, placebo-controlled trial..."

Comment: not adequately described

\begin{tabular}{|c|c|c|}
\hline $\begin{array}{l}\text { Allocation concealment } \\
\text { (selection bias) }\end{array}$ & Unclear risk & Not adequately described \\
\hline $\begin{array}{l}\text { Blinding of participants } \\
\text { and personnel (perfor- } \\
\text { mance bias) } \\
\text { All outcomes }\end{array}$ & Low risk & Quote: "...double blind, placebo-controlled trial" \\
\hline $\begin{array}{l}\text { Blinding of outcome as- } \\
\text { sessment (detection bias) } \\
\text { All outcomes }\end{array}$ & Unclear risk & Not adequately described \\
\hline $\begin{array}{l}\text { Incomplete outcome data } \\
\text { (attrition bias) } \\
\text { All outcomes }\end{array}$ & Unclear risk & Insufficient information to make a judgement \\
\hline $\begin{array}{l}\text { Selective reporting (re- } \\
\text { porting bias) }\end{array}$ & High risk & $\begin{array}{l}\text { Not adequately described; adverse events mentioned but not gone into detail. } \\
\text { Trial registration was available (NCT00510978) }\end{array}$ \\
\hline Other bias & Unclear risk & $\begin{array}{l}\text { Insufficient information to support judgement as study was published as an } \\
\text { abstract. }\end{array}$ \\
\hline
\end{tabular}

Vejdani 2017

Methods Multicentre, double-blind, randomised, placebo-controlled trial

Setting: Multicentre, Iran, private practices

Study period: not stated

Participants

Inclusion criteria: between 15 and 65 years of age, newly diagnosed or recently relapsed UC, based on clinical, endoscopic, and histological findings and had a mild to moderately active UC according to Truelove and Witts criteria and $\mathrm{CAI} \geq 4$ and $\leq 12$. Additional external participants included in the maintenance of remission phase had to be in remission for less than 3 months.

Exclusion criteria: substantial cardiac, renal or hepatic diseases, severe immunocompromised patients, existing or intended pregnancy or breastfeeding, regular treatment with NSAID drugs, intestinal major operation, steroid dependency, known intolerance to sulphate free preparations of mesalazine, UC exacerbated by infectious colitis, toxic megacolon, use of antibiotic within 14 days prior to first visit for more than 1 week, use of corticosteroid injection within the last 30 days, use of immunosuppressive treatment within the last 90 days and use of mesalazine enema or corton enema within the last 14 days

Age (mean \pm SD): not stated

Sex (M/F): not stated

Site of disease: not stated 
Use of concurrent medication: conventional medical treatment for active UC

Treatment before study: not stated

Length of time remission at study entry: less than three months

Number randomised: 14 (probiotic), 15 (placebo)

Number analysed: 14 (probiotic), 15 (placebo)

Postrandomisation exclusion: 2 - lost to follow-up, 1 - concurrent illness, 1 - poor compliance, 1 - taking antibiotics

- Probiotic: $L$ Casei strain ATCC PTA-3945, $5 \times 10^{5}$ live active cells. Oral, 1 capsule twice daily
- Placebo: no detail
Participants also received conventional medical treatment for active UC according to the severity and
extension of their disease. Participants with mild proctitis, received mesalazine or sulfasalazine tablets
after remission. In participants with moderate proctitis, mesalazine suppositories were stopped after
remission. The rest of the drugs and their doses were kept unchanged.

$\begin{array}{ll}\text { Outcomes } & \text { Duration of follow-up: } 4 \text { months } \\ \text { - Relapse (defined as an increase in bowel frequency with blood for at least } 1 \text { week. A colonoscopy was } \\ \text { performed and biopsies were taken to confirm relapse) } \\ \text { - Withdrawals } \\ \text { - Serious adverse events }\end{array}$

Notes Funding source: not stated

Conflicts of interests: not reported

\section{Risk of bias}

\begin{tabular}{lll}
\hline Bias & Authors' judgement & Support for judgement \\
\hline $\begin{array}{ll}\text { Random sequence genera- } \\
\text { tion (selection bias) }\end{array}$ & Low risk & $\begin{array}{l}\text { Quote: "Randomisations were done using a random number table with odd } \\
\text { numbers for probiotic and even numbers for placebo; randomisation was } \\
\text { stratified according to the use of mesalazine or sulfasalazine and to the clinical } \\
\text { severity of disease (mild or moderate)" }\end{array}$ \\
& Comment: use of random number table
\end{tabular}

\begin{tabular}{lll}
\hline $\begin{array}{l}\text { Allocation concealment } \\
\text { (selection bias) }\end{array}$ & Unclear risk & No mention in the text \\
\hline $\begin{array}{l}\text { Blinding of participants } \\
\text { and personnel (perfor- } \\
\text { mance bias) }\end{array}$ & Low risk & Quote 'Placebos were indistinguishable from the L Casei preparation' \\
All outcomes & \\
\hline
\end{tabular}

\begin{tabular}{lll}
$\begin{array}{l}\text { Blinding of outcome as- } \\
\text { sessment (detection bias) } \\
\text { All outcomes }\end{array}$ & Unclear risk & $\begin{array}{l}\text { The study was reportedly double-blinded however, there is no indication that } \\
\text { outcome assessment was blinded }\end{array}$ \\
\hline $\begin{array}{l}\text { Incomplete outcome data } \\
\text { (attrition bias) }\end{array}$ & Low risk & Attrition rate was over 26\%, but balanced in both groups \\
All outcomes & \\
\hline
\end{tabular}


Vejdani 2017 (Continued)

Selective reporting (re- High risk Trial registration not available, however, biochemical tests were recorded both porting bias)

Other bias

Low risk at entry, remission and relapse, but not reported.
Quote: "There was not a significant difference between the two groups in fac-

Wildt 2011

\begin{tabular}{ll}
\hline Methods & Double-blinded, multicentre RCT \\
& Setting*: "two participating centers in Denmark" \\
& Study period: June 2004 to March 2006 \\
\hline Participants & Inclusion: age $\geq 18$ years; established diagnosis of UC left-sided disease (endoscopic changes distally to \\
the splenic flexure) - including proctitis; time since relapse $>4$ weeks during stable monotherapy with \\
5-ASA or no medication at all; $\geq 1$ relapse within the last year. \\
Exclusion: pregnancy (postive urine HCG) or breastfeeding; chronic liver or kidney disease; severe \\
chronic disease of vascular or cardiopulmonary aetiology, malignancies; immunosuppressive disease \\
or treatment; inflammatory bowel diseases besides UC, malabsorption syndromes, and former surgi- \\
cal procedures involving the gastrointestinal tract - with the exception of appendectomy. Treatment \\
with azathioprine, 6 -mercaptopurine, biological immunomodifiers, and treatment with steroids within \\
1 month of entry.
\end{tabular}
tors such as age, sex, disease duration and extent, smoking, education taken and clinical activity index"

Comment: baseline characteristics were balanced across groups and there were no other apparent risks of bias

$\operatorname{Sex}(M / F): 10 / 22$

Age (median/range): 37.5 (23 to 68 ) years

Site of disease (location from anal valve - $\mathbf{c m}$ ): 20 (5 to 70 ) - probiotic/22.5 (5 to 60 ) - placebo

Use of medication: 24 (5-ASA orally, rectally and both); 1 (salazopyrine)

Length of time remission at study entry: 4 (2 to 9) - probiotic/5 (2 to 11 ) months - placebo

Number randomised: 20 (probiotics)/12 (placebo)

Number analysed: 20 (probiotics)/ 12 (placebo)

Postrandomisation exclusion: 1 - pregnancy, however, ITT principle was applied

- Probiotics: oral preparation containing $L$ acidophilus strain La-5 and B animalis subsp. lactis strain BB-12

- Placebo. Two capsules taken three times daily for 52 weeks. No other medications for UC were allowed during the study period

Outcomes

Duration of follow-up: 52 weeks

- Number maintaining remission (1 year). Remission - presence of two out of three criteria:

* a simple clinical colitis activity index (SCCAI) score $\leq 4$

* endoscopically grade 0-1 (Baron 1964) and/or

* histologically grade 0-1 (Truelove 1956)

- Relapse (reported in the discussion section). Relapse was defined as SCCAI score $>4$ and/or endoscopic changes grade 2 to 3 
Wildt 2011 (Continued)

- Adverse events (flatulence, abdominal bloating and pain; changes in faecal consistency; musculoskeletal - arthralgia, sacroiliitis; various - tiredness, incontinence, stress, oral blisters, eye dryness; headache, dizziness; influenza, gastroenteritis, cystitis and pneumonia; serious adverse events)

- Serious adverse events

- Withdrawal due to serious adverse events

Notes $\quad$ Funding source: "The study was supported by grants from Chr. Hansen A/S, Hoersholm, Denmark and by grants received from P. Carl Petersens Foundation and The Danish Crohn Colitis Organisation."

Declaration of interest: "one of the authors (EB) is employed at the laboratory at Chr. Hansen A/S"

*Presumably Gentofte and Hvidovre Hospital, University of Copenhagen Denmark judging by authors' affiliation

\section{Risk of bias}

Bias Authors' judgement Support for judgement

Random sequence genera- Low risk tion (selection bias)

Quote: "...randomised in blocks of 6 according to a table-generated randomisation list to receive either Probio-Tec AB-25 (two capsules three times daily, resulting in a total delivery of $1.5 \times 1011$ CFU daily) or to receive placebo (two capsules three times daily) in a 2:1 ratio"

Comment: adequate randomisation

\begin{tabular}{|c|c|c|}
\hline $\begin{array}{l}\text { Allocation concealment } \\
\text { (selection bias) }\end{array}$ & Unclear risk & $\begin{array}{l}\text { Correspondence with author: "At inclusion in the study an enclosed envelope } \\
\text { was drawn from a batch of } 6 \text { envelopes - and the randomization revealed." } \\
\text { Comment: no information as to whether envelopes were opaque and num- } \\
\text { bered }\end{array}$ \\
\hline $\begin{array}{l}\text { Blinding of participants } \\
\text { and personnel (perfor- } \\
\text { mance bias) } \\
\text { All outcomes }\end{array}$ & Low risk & $\begin{array}{l}\text { Quote: "Placebo medication [...] was identical in appearance, size and taste" } \\
\text { Comment: adequate blinding }\end{array}$ \\
\hline
\end{tabular}

Blinding of outcome as- Unclear risk Trial was referred to as double-blinded placebo study, however, there were no sessment (detection bias) details on blind outcome assessment

All outcomes

\begin{tabular}{|c|c|c|}
\hline $\begin{array}{l}\text { Incomplete outcome data } \\
\text { (attrition bias) } \\
\text { All outcomes }\end{array}$ & Low risk & ITT analysis was applied \\
\hline $\begin{array}{l}\text { Selective reporting (re- } \\
\text { porting bias) }\end{array}$ & Low risk & $\begin{array}{l}\text { Study protocol available (NCT00268164) and all prespecified outcomes were } \\
\text { reported }\end{array}$ \\
\hline Other bias & High risk & $\begin{array}{l}\text { Comment: imbalance in baseline characteristics - there were more partici- } \\
\text { pants receiving medication at inclusion in the intervention group compared to } \\
\text { the control group (reported } \mathrm{P}=0.018 \text { ). }\end{array}$ \\
\hline
\end{tabular}

Yasushi 2015

Methods Double-blind, placebo-controlled, single centre RCT

Setting: Sakura Medical Center, Toho University, Japan 
Participants

Inclusion: patients with UC in remission who were receiving treatment on an outpatient basis (UC was diagnosed in accordance with the diagnostic criteria proposed by the Survey Research Group of Intractable Inflammatory Intestinal Disorders/Specified Diseases, Japanese Ministry of Health, Labour and Welfare); 13 years or older in whom the CAl was maintained at 5 or less while receiving drugs such as mesalazine, salazosulfapyridine, or steroids, with no change in treatment regimens within 4 weeks before study entry.

Exclusion: serious cardiac disease, serious renal disease, hypotension (systolic blood pressure, $\leq 80$ $\mathrm{mmHg}$ ), a history of shock during extracorporeal circulation, serious infections such as sepsis or pneumonia, or a serum haemoglobin concentration of less than $10 \mathrm{~g} / \mathrm{dL}$; newly began treatments such as leukocytapheresis, granulocyte adsorptive apheresis, or immunosuppressant therapy with drugs such as 6-mercaptopurine, azathioprine, and cyclosporine to improve symptoms, having milk allergy or a CAl of 6 or higher; pregnant women

Age (mean \pm SD): $43.9 \pm 14.8$ years*

$\operatorname{Sex}(M / F): 28 / 18$

Site of disease: 15 (left colon), 11 (proctosigmoiditis), 20 (total/subtotal)

Use of medication: 24 (pentasa), 19 (salazopyrin), 1 (pentasa + salazopyrin), 2 (nothing)

Length of time remission at study entry: unclear

Number randomised $(\mathbf{n}=\mathbf{6 0}): 30$ (probiotic)/30 (placebo)

Number analysed: 23 (probiotic)/23 (probiotic)

Postrandomisation exclusions: 14 (7 in each group) - prohibited use of drug and lack of consent

Interventions
- Probiotic: Bio-Three - 2 mg Streptococcus faecalis T-110 (lactomin) 10 mg Clostridium butyricum TOA, 10 mg Bacillus mesentericus TO-A

- Placebo prepared by substituting equivalent amounts of starch for the probiotic powder

All participants received 3 tablets $3 \times$ daily for 12 months. As concomitant medication, the use of mesalazine and salazosulfapyridine was unrestricted, but steroids could not be used as remission maintenance therapy. The use of drugs with similar effects as the study drug, potentially affecting the evaluation of effectiveness (i.e. other active live microbial preparations, laxatives, etc.) was prohibited from 1 week before study entry to the completion of the study. In principle, the use of oral antibiotics was also prohibited, but the use of topical antibiotics other than oral preparations was not particularly restricted. If a participant received a new treatment in addition to their basic therapy with drugs such as mesalazine or salazosulfapyridine, relapse was diagnosed, and the study treatment and faecal sample collection were discontinued.

- Relapse at 3, 6, 9 and 12 months. Relapse was defined as CAI $\leq 5$

- Remission maintenance at 12 months. Remission not absolutely defined

- Serious adverse events

Declaration of interest: partially reported (YY - none, other authors - not reported)

${ }^{\star *}$ Reported for the two intervention groups and pooled using an online calculator (www.statstodo.com/CombineMeansSDs_Pgm.php)

\section{Risk of bias}


Yasushi 2015 (Continued)

Bias Authors' judgement Support for judgement

Random sequence genera- Low risk tion (selection bias)
Quote: "At the start of the study, 30 outpatients were randomly assigned to the Bio-Three group and 30 to the placebo group by means of a computer-generated scheme."

Comment: adequately described

\begin{tabular}{|c|c|c|}
\hline $\begin{array}{l}\text { Allocation concealment } \\
\text { (selection bias) }\end{array}$ & Unclear risk & Not stated \\
\hline $\begin{array}{l}\text { Blinding of participants } \\
\text { and personnel (perfor- } \\
\text { mance bias) } \\
\text { All outcomes }\end{array}$ & Low risk & $\begin{array}{l}\text { Placebo tablets were identical to Bio-Three tablets and could not be distin- } \\
\text { guished from the active preparation on the basis of appearance. }\end{array}$ \\
\hline $\begin{array}{l}\text { Blinding of outcome as- } \\
\text { sessment (detection bias) } \\
\text { All outcomes }\end{array}$ & Unclear risk & Not stated \\
\hline $\begin{array}{l}\text { Incomplete outcome data } \\
\text { (attrition bias) } \\
\text { All outcomes }\end{array}$ & Low risk & Overall attrition rate was over $20 \%$, but balanced between the two groups \\
\hline $\begin{array}{l}\text { Selective reporting (re- } \\
\text { porting bias) }\end{array}$ & Low risk & $\begin{array}{l}\text { Trial registration not available, however, all expected outcomes appear to } \\
\text { have been reported }\end{array}$ \\
\hline Other bias & Low risk & $\begin{array}{l}\text { Quote: "After randomization, the baseline characteristics of sex, age, age at } \\
\text { disease onset, disease duration, disease extent, and concomitant treatment } \\
\text { did not differ between the groups" } \\
\text { Comment: no other apparent biases }\end{array}$ \\
\hline
\end{tabular}

Zocco 2003

\begin{tabular}{ll}
\hline Methods & RCT (abstract only) \\
Setting: not stated \\
Study period: not stated
\end{tabular}

Participants

Inclusion: inactive UC and quiescent Crohn's disease*

Exclusion: not stated

Age (mean): 32 years

$\operatorname{Sex}(M / F): 20 / 16$

Site of disease: not stated

Use of medication: not stated

Length of time remission at study entry: not stated

Number randomised $(\mathbf{n}=\mathbf{3 6}): 12$ (probiotic)/10 (mesalazine)/14 (probiotic + mesalazine)

Number assessed: 12 (probiotic)/10 (mesalazine)/14 (probiotic + mesalazine) 
Zocco 2003 (Continued)

\section{Postrandomisation exclusion: none}

$\begin{array}{ll}\text { - } & \text { Probiotic alone: Lactobacillus GG } 18 \times 10^{9} \text { viable bacteria per day (Giflorex, Errekappa, Euroterapic, } \\ & \text { SpA, Milan, Italy) } \\ \text { - } & \text { Probiotic + mesalazine: Lactobacillus } G G 18 \times 10^{9} \text { viable bacteria and mesalazine } 2.4 \mathrm{~g} \text { per day } \\ \text { - } & \text { Mesalazine } 2.4 \mathrm{~g} \text { per day }\end{array}$

\begin{tabular}{ll}
\hline Outcomes & Duration of follow-up: 12 months \\
- Relapse (defined by clinical and endoscopic features. No further details) \\
- Withdrawal due to adverse events
\end{tabular}

Notes

Funding source: not stated

Declaration of interest: not reported

Data from participants with CD were discarded due to the limited scope of the review.

\section{Risk of bias}

\begin{tabular}{|c|c|c|}
\hline Bias & Authors' judgement & Support for judgement \\
\hline $\begin{array}{l}\text { Random sequence genera- } \\
\text { tion (selection bias) }\end{array}$ & Unclear risk & $\begin{array}{l}\text { Participants were reportedly randomised, however, no further details were } \\
\text { available }\end{array}$ \\
\hline $\begin{array}{l}\text { Allocation concealment } \\
\text { (selection bias) }\end{array}$ & Unclear risk & Not stated \\
\hline $\begin{array}{l}\text { Blinding of participants } \\
\text { and personnel (perfor- } \\
\text { mance bias) } \\
\text { All outcomes }\end{array}$ & Unclear risk & Not stated \\
\hline $\begin{array}{l}\text { Blinding of outcome as- } \\
\text { sessment (detection bias) } \\
\text { All outcomes }\end{array}$ & Unclear risk & Not stated \\
\hline $\begin{array}{l}\text { Incomplete outcome data } \\
\text { (attrition bias) } \\
\text { All outcomes }\end{array}$ & Low risk & All participants appear to have been accounted for \\
\hline $\begin{array}{l}\text { Selective reporting (re- } \\
\text { porting bias) }\end{array}$ & Unclear risk & $\begin{array}{l}\text { The study was published as an abstract. Insufficient information to make a } \\
\text { judgement }\end{array}$ \\
\hline Other bias & Unclear risk & $\begin{array}{l}\text { The study was published as an abstract. Insufficient information to make a } \\
\text { judgement }\end{array}$ \\
\hline
\end{tabular}

Zocco 2006

Methods Open-label, single centre RCT

Setting: Inflammatory Bowel Diseases Centre of the Catholic University, Rome, Italy

Study period: June 2001 to December 2004

\begin{tabular}{ll}
\hline Participants & $\begin{array}{l}\text { Inclusion: } U C \text { in clinical }(\mathrm{CAI}<4) \text {, laboratory and endoscopic remission; time since last relapse: }<12 \\
\text { months }\end{array}$
\end{tabular}


Exclusion: patients with active disease or complications, severe accompanying illness or major colonic surgery, gastrointestinal infections, serious concomitant diseases (renal or hepatic failure, severe hypertension), diabetes mellitus, immunosuppressive treatment being administered currently or in the month before enrolment, mesalazine intolerance, and pregnant or lactating woman

Age (mean $\pm \mathbf{S D}): 33 \pm 5.8$ years $^{*}$

$\operatorname{Sex}(M / F): 104 / 83$

Site of disease: 35 (proctosigmoiditis), 25 (left colon), 12 (total/subtotal)

Use of medication: not stated

Length of time remission at study entry: $\leq 4$ weeks in $12 \%$ (probiotic) $11 \%$ (probiotic + mesalazine) $/ 10 \%$ (mesalazine); $\leq 3$ months in $26 \%$ (probiotic) $/ 25 \%$ (probiotic +mesalazine) $/ 26 \%$ (mesalazine)

Number randomised $(\mathbf{n}=\mathbf{1 8 7}): 65$ (probiotic) $/ 62$ (probiotic + mesalazine) $/ 60$ (mesalazine)

Number analysed: 65 (probiotic)/62 (probiotic + mesalazine)/60 (mesalazine)

Postrandomisation exclusion: none (premature discontinuation of the study for reasons other than relapse did not occur)

Interventions
- Probiotic: Lactobacillus GG treatment $18 \times 10^{9}$ viable bacteria/day divided into two oral administrations

- Mesalazine $800 \mathrm{mg}$ tablets (mesalazine Errekappa, Euroterapici SpA), three tablets (2400 mg) daily

- Probiotic + mesalazine: Lactobacillus GG $118 \times 10^{9}$ viable bacteria/day plus mesalazine $2400 \mathrm{mg}$ daily

Participants were treated for 12 months. Treatment was interrupted in case of disease relapse, occurrence of side effects, poor compliance and inability to attend follow-up visit. Oral or rectal treatment with antibiotic or steroid medications, apart from the study drugs, was not allowed during the trial. Full clinical evaluation with symptoms assessment and physical examination was performed at baseline and every 3 months for all the 12-month study period.
Outcomes
Duration of follow-up: 12 months
- Relapse (6 and 12 months). Relapse defined as the appearance of UC symptoms or an increase in CAI to more than 4 points.
- Maintenance of remission at 6 and 12 months
- Serious adverse events

Funding source: no external funding
Declaration of interests: not reported
* Reported for the three intervention groups and pooled using an online calculator (www.statsto-
do.com/CombineMeansSDs_Pgm.php)

\section{Risk of bias}

\begin{tabular}{lll}
\hline Bias & Authors' judgement & Support for judgement \\
\hline $\begin{array}{l}\text { Random sequence genera- } \\
\text { tion (selection bias) }\end{array}$ & Unclear risk & $\begin{array}{l}\text { Participants were reportedly randomised, however, no further details were } \\
\text { provided }\end{array}$ \\
\hline $\begin{array}{l}\text { Allocation concealment } \\
\text { (selection bias) }\end{array}$ & Unclear risk & Not stated \\
\hline
\end{tabular}


Zocco 2006 (Continued)

\begin{tabular}{|c|c|c|}
\hline $\begin{array}{l}\text { Blinding of participants } \\
\text { and personnel (perfor- } \\
\text { mance bias) } \\
\text { All outcomes }\end{array}$ & High risk & The study was an open-label study \\
\hline $\begin{array}{l}\text { Blinding of outcome as- } \\
\text { sessment (detection bias) } \\
\text { All outcomes }\end{array}$ & High risk & The study was an open-label study \\
\hline $\begin{array}{l}\text { Incomplete outcome data } \\
\text { (attrition bias) } \\
\text { All outcomes }\end{array}$ & Low risk & All participants were accounted for \\
\hline $\begin{array}{l}\text { Selective reporting (re- } \\
\text { porting bias) }\end{array}$ & Low risk & Trial registration not available, however, all participants were accounted for \\
\hline Other bias & Low risk & $\begin{array}{l}\text { Quote: "Demographic and prestudy clinical characteristics did not differ signif- } \\
\text { icantly among the three groups" }\end{array}$ \\
\hline & & Comment: no other apparent biases \\
\hline
\end{tabular}

5-ASA: 5-aminosalicylic acid; CAl: colitis activity Index; CD: crohn's disease; CFU: colony forming units; CRP; C-reactive protein; DAl: disease activity index; FCAL: fecal calprotectin; GI: gastrointestinal HCG: human chorionic gonadotropin; IBD: inflammatory bowel disease; IBDQ: inflammatory bowel disease questionnaire; ITT: intention to treat IV: intervention; NSAID: non steroidal ant-inflammatory drugs; QoL; quality of life; RCT: randomised controlled trial; SCCAI: simple clinical colitis activity index; SD: standard deviation; UC: ulcerative colitis

\section{Characteristics of excluded studies [ordered by study ID]}

\begin{tabular}{|c|c|}
\hline Study & Reason for exclusion \\
\hline Ahmed 2013 & $\begin{array}{l}\text { Insufficient duration of follow-up, i.e. less than } 3 \text { months; (quote): "if this could be altered with one } \\
\text { months treatment with synbiotics" }\end{array}$ \\
\hline Ballini 2019 & Wrong patient population and not maintenance study \\
\hline Bamba 2002 & Wrong intervention, i.e. uses prebiotic; (quote): "A new prebiotic from germinated barley..." \\
\hline Cui 2004 & $\begin{array}{l}\text { Insufficient duration of follow-up; (quote): "the patients were evaluated .....after } 2 \text { mo of treat- } \\
\text { ment..." }\end{array}$ \\
\hline Do 2010 & Wrong study design, i.e. review article \\
\hline Faubion 2000 & Wrong study design, i.e. commentary piece \\
\hline Folwaczny 2000 & Wrong study design, i.e. not randomised \\
\hline Fujimori 2009 & Wrong patient population, i.e. patients were not in remission, so not maintenance trial \\
\hline Henker 2008 & Wrong study design, i.e. not randomised \\
\hline IRCT20120415009475N5 & Wrong study type \\
\hline Ishikawa 2002 & Insufficient information: emailed author for clarification, no reply \\
\hline Ishikawa 2011 & $\begin{array}{l}\text { Wrong patient population: data from patients in remission presented together with those not in re- } \\
\text { mission, unable to differentiate data }\end{array}$ \\
\hline
\end{tabular}




\begin{tabular}{|c|c|}
\hline Study & Reason for exclusion \\
\hline Li 2013 & Wrong patient population: patients not in remission, so not maintenance trial \\
\hline Liu 2014 & Wrong patient population: translated from Chinese and confirmed not maintenance study \\
\hline Miele 2009 & Wrong patient population: patients not in remission, so not maintenance study \\
\hline NCT00268164 & Insufficinet information: university replied 26 February 2018 - no access to full paper \\
\hline NCT00374725 & Insufficient information: no reply from author - emailed 15 January 2018 \\
\hline NCT00803829 & Insufficient information: author passed away - no access to full paper \\
\hline NCT00951548 & $\begin{array}{l}\text { Insufficient information: emailed author for classification on } 15 \text { January } 2018 \text {, replied and con- } \\
\text { firmed not maintenance trial }\end{array}$ \\
\hline NCT01772615 & $\begin{array}{l}\text { Wrong patient population: author replied with full paper - patients not in remission so not mainte- } \\
\text { nance study }\end{array}$ \\
\hline Palumbo 2016 & Wrong patient population: patients being induced, so not maintenance study \\
\hline Pelech 1998 & Insufficient information: emailed author for classification, no reply \\
\hline Rembacken 1999 & $\begin{array}{l}\text { Includes both an induction and maintenance phase, however, participants were only randomised } \\
\text { for induction. The maintenance phase was an observational study. }\end{array}$ \\
\hline Rohatgi 2015 & Wrong patient population: patient cohort have microscopic colitis so not ulcerative colitis study \\
\hline Sanchez-Morales 2019 & Induction study \\
\hline Shadnoush 2013 & $\begin{array}{l}\text { Wrong patient population: study uses patients with inflammatory bowel disease - does not differ- } \\
\text { entiate between ulcerative colitis and Crohn's }\end{array}$ \\
\hline Solovyeva 2014 & Wrong patient population: patients being induced, so not maintenance trial \\
\hline Tursi 2010 & Wrong patient population: patients being induced, so not maintenance trial \\
\hline Venturi 1999 & Wrong study design: this study was not a randomised controlled trial \\
\hline Zhang 2018a & Induction study \\
\hline
\end{tabular}

Characteristics of studies awaiting assessment [ordered by study ID]

Fan 2019

Methods RCT, single centre

Setting: The First Affiliated Hospital of Fujian Medical University

Study duration: January 2015 to June 2016

Participants
40 with IBD randomised (19 control group, 21 observation group)
UC total: 31, CD total: $9 ;$ UC control 15, CD IV 4; CD control 4, CD IV 5


Fan 2019 (Continued)

Inclusion: confirmed IBD diagnosis with mild to moderate symptoms as per the current standards in China; no previous probiotic treatment; no allergy to drugs used in the present study; cognisance of the purpose of the present study and willingness to sign an informed consent

Exclusion: severe heart, liver, kidney and other systemic diseases; pregnancy or lactation; unresponsive to medical treatment and with complications; immune system disorders

Sex (M/F): 10/9 control group; 10/11 observation group

Age (mean +/- SD): $39.97+/-8.68$ control group; $42.56+/-7.58$ observation group

Site of disease: not specified

Use of medication: not specified

Length of time remission at study entry: not specified

Number randomised: 40

Number assessed: not specified

Postrandomisation exclusion: not specified

Follow-up: 40 days

Interventions

IV: pentasa (mesalazine extended action tablet) as in the control regimen + probiotics ( 2 tablets Bifico once and three times/day + "a largely liquid-based high nutrition diet"

Control: 1 to 2 pentasa tablets once and three times/day and a maintenance dose of 1 tablet once and three times/day

$\begin{array}{ll}\text { Outcomes } & \text { Microflora composition } \\ \text { - Biochemical indices } \\ \text { - Inflammatory markers } \\ \text { - Activity scores }\end{array}$

Notes

Mixed: contacted author for UC data

This work was supported by the Fujian Province Natural Science Fund Project

The authors declare that there are no conflicts of interest

Fang 2018

Methods RCT, multicentre

Setting: Chunan County First People's Hospital and Taizhou Hospital

Study duration: February 2016 to September 2017

Participants

84 patients with UC (42 control, 42 IV)

Control: 18 mild, 24 moderate; IV: 19 mild, 23 moderate

Inclusion: met the relevant diagnostic criteria for UC, confirmed by colonoscopy, barium enema, etc; course of disease $\geq 4$ weeks; accompanied by persistent or recurrent diarrhoea, haemorrhagic stool with abdominal pain, acute aftermath etc; age $\geq 18$ years; volunteer to participate in this study and sign informed consent

Exclusion: those with allergies; combined with infectious colitis such as amoebiasis, bacterial disease, intestinal tuberculosis, chronic schistosomiasis; severe intestinal perforation, intestinal ob- 
Fang 2018 (Continued)

struction, toxic colonic dilatation etc; people with unconsciousness, serious insufficiency of important organs such as heart and kidney; people with radiation colitis, ischaemic colitis, Crohn's disease, mental illnesses, history of drug and alcohol abuse; pregnant, lactating women

Sex (M/F): 26/16 control; 28/14 IV

Age: $45.12+/-6.21$ control; $45.13+/-6.2$ IV

Site of disease: control: whole colon 15, right half colon 19, left half colon 8; IV: whole colon 16, right half colon 17 , left half colon 9

Use of medication: not specified

Length of time remission at study entry: not specified

Number randomised: 84

Number assessed: not specified

Postrandomisation exclusion: not specified

Follow-up: 2 months

Interventions IV: mesalazine + gold bifid

Control: mesalazine only

$\begin{array}{ll}\text { Outcomes } & \text { Inflammation markers (IL-10, TNF- } \alpha \text {, IL-18, sIL-2R) } \\ \text { - Lesion activity scores (modified Mayo scores) } \\ \text { - Clinical efficacy } \\ \text { - Anorectal motility }\end{array}$

Notes

Disease activity to be clarified. 95 versus $76 \%$ effective rate

Main article in Chinese. Google translate was used for the translation.

Funding and conflict of interest were not discussed in the article.

Methods RCT, single centre

Study duration: May 2014 to February 2018

Setting: Bai'an Affiliation Sanxia Central Hospital of Chongqing

Participants

Abstract: 120 UC patients (control 60, IV 60)

Main text: 360 UC patients (control 180, IV 180) ???

Inclusion: not specified

Exclusion: not specified

Sex (M/F): 81/99 control; 90/90 IV

Age (mean +/- SD): $41.5+/-8.3$ control; $42.2+/-9.4$ IV

Site of disease: not specified

Use of medication: not specified 
Huang 2018 (Continued)

Length of time remission at study entry: not specified

Number randomised: 120 or 360

Number assessed: not stated

Postrandomisation exclusion: not stated

Follow-up: 8 weeks

\section{Control: mesalazine only}

IV: mesalazine + bifid triple viable capsules enteric-coated tablet of mesalazine (Sunflower Group Jiamusi Luling Pharmaceutical Co, Ltd, $0.25 \mathrm{~g} /$ tablet, batch No.: 13001830), four tablets oral administration before meal, 3 times/day. Those in the research group would additionally take two bifid triple viable capsules (Jincheng Haisi Pharmaceutical Co, Ltd, 0.21 g/capsule,

Batch No.: 13012365) prior to meal, 3 times/day

\begin{tabular}{ll}
\hline Outcomes & Evaluation of clinical efficacy \\
- DAl of UC \\
- Score of clinical symptoms \\
- Changes in inflammatory factors (TNF- $\alpha$, IL-8 and IL-10)
\end{tabular}

Notes

Unclear whether active or inactive UC - emailed authors. Effectiveness rate $=90$ versus $72 \%$

Funding and conflict of interest not discussed in the article.

Study duration: August 2014 to November 2016

Inclusion criteria: all who met the diagnosis of ulcerative colitis in the "Consensus Opinions on the Diagnosis and Treatment of Inflammatory Bowel Diseases in China" formulated by the Collaborative Group of Inflammatory Bowel Diseases of the Chinese Medical Association Gastroenterology Branch Criterion, with typical clinical manifestations (diarrhoea, mucus, pus, blood, stool, etc.) and colonoscopy (continuous, diffuse distribution of ulcer surface); Patients agreed to the study and signed informed consent

Exclusion: those who used contraindications to the study; those who had poor compliance during treatment; other reasons were not suitable for inclusion in the study

Sex (M/F): IV: 14/27; control: 17/24

Age (mean +/- SD): IV: 47.1+/- 4.9; control: $47.3+/-6.2$

Site of disease: not specified

Use of medication: not specified

Length of time remission at study entry: not specified

Number randomised: 86 
Shi 2018 (Continued)

Number assessed: not specified

Postrandomisation exclusion: not specified

Follow-up: treatment 2 months +6 months

IV: Bacillus subtilis and Enterococcus faecium + mesalazine
Control: mesalazine only
Mesalazine enteric-coated tablets (Sunflower Pharmacy, Chinese Medicine
(specification: $0.25 \mathrm{~g} /$ tablet), oral, $1 \mathrm{~g} /$ time, $6 \mathrm{~h} /$ time; the observation grou
the Bacillus subtilis double live enteric-coated capsules (trade name: Mei C
mei Pharmaceutical Co, Ltd. based on the control group). Company, Natio
S20030087, specification: $250 \mathrm{mg} /$ capsule), $500 \mathrm{mg}$, orally, 3 times/day; two
were continuously taking medication for 2 months.
- Inflammation markers (IL-6, IL-8, IL-10, TNF- $\alpha$, MDA, SOD, COX-2, NF-kB)
- Clinical curative effect
- Time to symptom relief
- Rachmitewitz and Sutherland scores

Notes

Disease activity to be clarified. $93 \%$ versus $76 \%$ effective rate

Article in Chinese. Google Translate was used for the translation.

Funding and conflict of interest were not discussed in the article.

Yilmaz 2019

Methods $\quad$ RCT, single centre, prospective, open-label

Study duration: May 2015 to December 2016

Participants

45 IBD patients (25 IV, 20 control)

$U C=15, C D=10$

Inclusion/exclusion: "Patients with IBD participated in the study. In the trial, CD Activity Index for $C D$ and Truelove-Witts scoring systems for UC were used for disease assessment scores. If the score was $<450$, patients with $C D$ were admitted to the study. If the score was higher, patients with UC were not admitted to the study. Volunteers also had to be $>18$ years old. Patients with alcohol consumption $>20 \mathrm{~g} /$ day, allergies or intolerance to milk, antibiotic treatment within the last 1 month, column or bowel operation history up to 3 months before the start of the study, and the presence of active infection within 1 month prior to the start of the study or during the study were excluded from the study. In addition, if a patient requested to leave on his/her own will, or if kefir was not consumed continuously for 2 weeks, the trial protocol was assessed and was not approved."

Sex (M/F): IV: total 13/12, UC 9/6, CD: 4/6, control: total 10/10, UC: 4/6, CD: 6/4

Age (median): IV: 33, control: 43

Site of disease: IV: UC colon 15, CD colon 1, Ileum 6, colon + Ileum 3; control: UC colon 10, CD Ileum 10

Use of medication: not specified

Length of time remission at study entry: not specified

Number randomised: 45 ? 
Yilmaz 2019 (Continued)

\section{Number assessed: 45}

Postrandomisation exclusion: either 0 or 3 . Authors mention 3 patients left the trial willingly, however participant and completers number are the same $(n=45)$

Follow-up: 4 weeks

Interventions

IV: $400 \mathrm{~mL} /$ day kefir $\times 2$ day

Control: ???

"The control group did not consume placebo because it was not possible to prepare a control product with a similar flavor, texture, and taste as those of kefir. Ayran and yogurt were similar to kefir, but they also have Lactobacillus and can affect the microbiota results."

Outcomes Symptoms diary questionnaire

- Effects on Lactobacillus flora and their biochemical properties

Notes Disease activity not clear. $96 \%$ versus $85 \%$ effective rate

The authors declare no conflict of interest and that this study has received no financial support.

Methods RCT, single centre

Setting: Department of Gastroenterology, Longyou County People's Hospital, Luzhou, Zhejiang Province

Study duration: October 2016 to November 2017

Participants

110 UC patients ( 55 control (38 UC, 17 CD); 55 observation (36 UC, 19 CD))

Inclusion: in accordance with the diagnostic criteria of the "Consensus on the diagnosis and treatment of inflammatory bowel disease in China" formulated by the Chinese Medical Association; no significant abnormalities in liver and kidney function; no other severe chronic diseases; informed consent

Exclusion: severe liver and kidney diseases; intestinal diseases such as intestinal tuberculosis, Crohn's disease, intestinal tumours; hormones, 5-aminosalicylic acid, and intestinal probiotics for nearly 4 weeks; patients taking other drugs; patients who are allergic to drugs such as mesalazine, Bifidobacterium quadruplex, etc.; pregnant and lactating women; patients with mental illness; patients who do not co-operate with treatment; younger than 18 years old

Sex (M/F): IV 29/26; control 32/23

Age (mean +/- SD): IV: $44.6+/-5.8$; control $45.3+/-5.5$

Site of disease: not specified

Use of medication: not specified

Length of time remission at study entry: not specified

Number randomised: 110

Number assessed: not specified

Postrandomisation exclusion: not specified

Follow-up: 2 months 
Zhang 2018b (Continued)

Interventions

\section{IV: Bifidobacterium quadruplex bacteria tablets + mesalazine}

\section{Control: mesalazine}

Both groups were given mesalazine enteric-coated tablets (trade name: Huidi, Manufacturer: Sunflower Pharmaceutical Group Jiamusi Luling Pharmaceutical Co, Ltd, National Medicine Standard $\mathrm{H} 19980148,0.25 \mathrm{~g} /$ tablet), oral, $1 \mathrm{~g} / 3$ times/day. The observation group was given a Bifidobacterium quadruple live bacteria tablets (brand name: Siliankang, manufacturer: Hangzhou Longda Xinke Biopharmaceutical Co, Ltd, National Medicine Standard)

S20060010, $0.5 \mathrm{~g} /$ tablet), oral, $1.5 \mathrm{~g} / 3$ times/day

Notes

Article in Chinese. Google Translate was used for the translation.

Funding and conflict of interest were not discussed in the article.

CD: crohn's disease; COX-2: cyclooxygenase-2; DAl: disease activity index; IBD: inflammatory bowel disease; IL: interleukin; IV: intervention; MDA: malondialdehyde; NF-k $\beta$ : nuclear factor kappa beta; RCT; randomised controlled trial; sIL-2R: soluble interleukin 2 receptor; SOD: superoxide dismutase; TNF- $\alpha$ : tumor necrosis factor alpha; UC: ulcerative colitis

Characteristics of ongoing studies [ordered by study ID]

\section{NCT03415711}

Trial name or title

(PROREM UC)

\begin{tabular}{|c|c|}
\hline Methods & RCT, double-blind, parallel assignment \\
\hline Participants & 39 UC participants \\
\hline Interventions & $\begin{array}{l}\text { - Group A: } 13 \text { participants will receive mesalamine } 2.4 \mathrm{~g} / \text { day in once daily administration plus } \\
\text { VSL\#3 } 450 \text { billion sachet, two sachets per day for } 12 \text { months ( } 900 \text { billion of bacteria per day) } \\
\text { - Group B: } 13 \text { participants will receive mesalamine } 2.4 \mathrm{~g} / \text { day in once daily administration plus } \\
\text { VSL\#3 } 450 \text { billion sachet, two sachets twice a day ( } 1800 \text { billion of bacteria per day) for } 12 \text { months } \\
\text { - Group C: } 13 \text { patients will receive mesalamine } 2.4 \mathrm{~g} / \text { day in once daily administration plus placebo } \\
\text { for } 12 \text { months }\end{array}$ \\
\hline Outcomes & $\begin{array}{l}\text { - To characterise the efficacy of VSL\# } 3^{\circledR} \text { plus standard therapy (5-ASA) in maintaining clinical and } \\
\text { endoscopic remission in patients with UC in remission (time frame: } 12 \text { months) } \\
\text { - Proportion of subjects in clinical and endoscopic remission at } 12 \text { months, as defined by Total Mayo } \\
\text { Score } \leq 2 \text { with no individual subscore }>1 \text { and rectal bleed subscore of } 0\end{array}$ \\
\hline Starting date & April 2017 \\
\hline Contact information & Antonino Amato clinicaltrialcentre@policlinicogemelli.it \\
\hline Notes & Sponsors and collaborators: VSL pharmaceuticals, Actial Farmaceutica S.r.l. \\
\hline
\end{tabular}


NCT03565939

\begin{tabular}{ll}
\hline Trial name or title & Probiotic Treatment of Ulcerative Colitis with Trichuris Suis Ova (PROCTO) \\
\hline Methods & RCT, parallel assignment, double-blind, comparative, exploratory phase II proof of concept trial \\
\hline Participants & 120 UC participants \\
\hline Interventions & IV: trichuris suis ova \\
& Control: placebo \\
\hline
\end{tabular}

Outcomes

\section{Primary outcome measures}

- Response (full Mayo) (time frame: 24 weeks). The proportion of TSO participants, compared with placebo participants (i.e. a proportional difference), who obtain a reduction of 3 or more full Mayo score steps between the baseline visit and the end of trial visit (week 24). The full Mayo score (range 0-12) is the sum of 4 clinical scores (stool frequency, rectal bleeding, findings on endoscopy, physician's global assessment) each scored with a value 0 (normal), 1, 2, or 3 (worst).

\section{Secondary outcome measures}

- Remission (full Mayo) (time frame: 24 weeks). Proportion of TSO participants, compared with placebo participants (i.e.. a proportional difference), who obtain a full Mayo score $\leq 2$ at the end of trial visit (week 24) (remission).

- Reduction in use of steroid (time frame: 24 weeks). Mean value of total accumulated sum of milligram oral and rectal glucocorticosteroids taken by TSO participants during the trial compared with the corresponding mean value among placebo participants.

\begin{tabular}{ll}
\hline Starting date & May 2018 \\
\hline Contact information & Contact: Michelle V Prosberg, MD, \\
& michelle.vernstroem.prosberg@regionh.dk \\
& Contact: Andreas M Petersen, MD, Ph.D \\
& andreas.munk.petersen@regionh.dk \\
\hline
\end{tabular}

Notes Sponsors and collaborators: ParaTech A/S

NCT03798210

\begin{tabular}{ll}
\hline Trial name or title & Lactobacillus reuteri ATCC PTA 4659 in ulcerative colitis (COLUS) \\
\hline Methods & RCT, triple-blind, parallel assignment \\
\hline Participants & 40 UC patients \\
\hline Interventions & Lactobacillus reuteri versus placebo \\
\hline
\end{tabular}

Outcomes

\section{Primary outcome measures}

- Rectal bleeding with Mayo score $\geq 5$ (time frame: 12 months). Rectal bleeding as sign of increased inflammatory activity as determined by the Mayor Clinic Score for evaluation of disease activity in ulcerative colitis

\section{Secondary outcome measures}

- Increased faecal calprotectin (time frame: 12 months) 
NCT03798210 (Continued)

- Gut inflammatory biomarker

- Increased CRP (time frame: 12 months)

- General inflammatory biomarker

\section{Other outcome measures}

- Serum zonulin (time frame: 12 months)

- Gut permeability biomarker. Gut permeability (time frame: 12 months). Recovery of sugar molecules in urine as marker of increased permeability

\begin{tabular}{ll}
\hline Starting date & January 2017 \\
\hline Contact information & $\begin{array}{l}\text { Contact: Per M Hellström, Prof }+46703727423 \text { per.hellstrom@medsci.uu.se; Peter Benno, MD, PhD } \\
+46705795554 \text { peter.benno@endoskopienheten.se }\end{array}$ \\
\hline Notes & Sponsors and collaborators: Uppsala University \\
\hline
\end{tabular}

\section{NCT04006977}

\begin{tabular}{ll}
\hline Trial name or title & Multistrain probiotics reduces UC depression and anxiety scores \\
\hline Methods & RCT, double-blind, parallel assignment \\
\hline Participants & 60 UC patients \\
\hline Interventions & IV: multistrain probiotic product (DSF) \\
& Control: placebo \\
\hline
\end{tabular}

\section{Outcomes}

\section{Primary outcome measures}

- Reduction of anxiety and depression scores (time frame: 0 week, 8 weeks, 12 weeks, 16 weeks)

- Reduction of anxiety and depression scores (with points as standard units) using HADS at 8 weeks and 16 weeks after randomised treatment

\section{Secondary outcome measures}

- Clinical response (time frame: 4 weeks, 8 weeks, 12 weeks, 16 weeks) measured by a $\geq 1.5$ (3) points reduction in Simple Clinical Colitis Activity Index score at week 8 and 16

- Clinical remission (time frame: 4 weeks, 8 weeks, 12 weeks, 16 weeks) measured by Simple Clinical Colitis Activity Index score $\leq 5(2)$ points at week 8 and 16

- Endoscopic remission/response (time frame: 0 week, 16 weeks) measured by a Mayo endoscopic subscore of $<1$ point, or at least a 1-point reduction from baseline in the endoscopy subscore at week 16

- Changes in faecal-associated microbiota following probiotic therapy (time frame: 0 week, 16 weeks). Changes in faecal-associated microbiota using 16S ribosomal RNA sequencing and changes in the metabolomic profile of the faeces following probiotic therapy (at baseline and 16 weeks) will be assessed, stratified by both change in Simple Clinical Colitis Activity Index score following probiotic therapy and randomization

- Identification of potential stressors (time frame: 0 weeks, 16 weeks). Participants will be asked to complete a modified practical and family problem list to identify 13 potential stressors

Adverse events (time frame: 4 weeks, 8 weeks, 12 weeks, 16 weeks). Adverse events were assessed at weeks 8 and 16 by participant survey. 
NCT04006977 (Continued)

Contact information

Prof Jie Liang liangjie@fmmu.edu.cn

Notes

Sponsors and collaborators: Xijing Hospital of Digestive Diseases, MENDES SA

5-ASA: 5-aminosalicylic acid; CRP; C-reactive protein; DSF: Disulfiram HADS: hospital anxiety and depression scale; TSO: trichuris suis ova; UC: ulcerative colitis

\section{DATA AND ANALYSES}

Comparison 1. Probiotics versus placebo

\begin{tabular}{llllll}
\hline Outcome or subgroup title & $\begin{array}{l}\text { No. of } \\
\text { studies }\end{array}$ & $\begin{array}{l}\text { No. of } \\
\text { partici- } \\
\text { pants }\end{array}$ & Statistical method & Effect size \\
\hline 1 Clinical relapse & 4 & 361 & Risk Ratio (M-H, Random, 95\% Cl) & $0.87[0.63,1.18]$ \\
\hline 2 Maintenance of clinical remission & 2 & 141 & Risk Ratio (M-H, Fixed, 95\% Cl) & $1.16[0.98,1.37]$ \\
\hline 3 Serious adverse events & 4 & 351 & Risk Ratio (M-H, Fixed, 95\% Cl) & $0.0[0.0,0.0]$ \\
\hline 4 Withdrawal due to adverse events & 2 & 113 & Risk Ratio (M-H, Fixed, 95\% Cl) & $0.0[0.0,0.0]$ \\
\hline 5 Health-related quality of life & 1 & 25 & $\begin{array}{l}\text { Mean Difference (IV, Fixed, 95\% } \\
\text { Cl) }\end{array}$ & $-0.70[-1.63,0.23]$ \\
\hline
\end{tabular}

Analysis 1.1. Comparison 1 Probiotics versus placebo, Outcome 1 Clinical relapse.

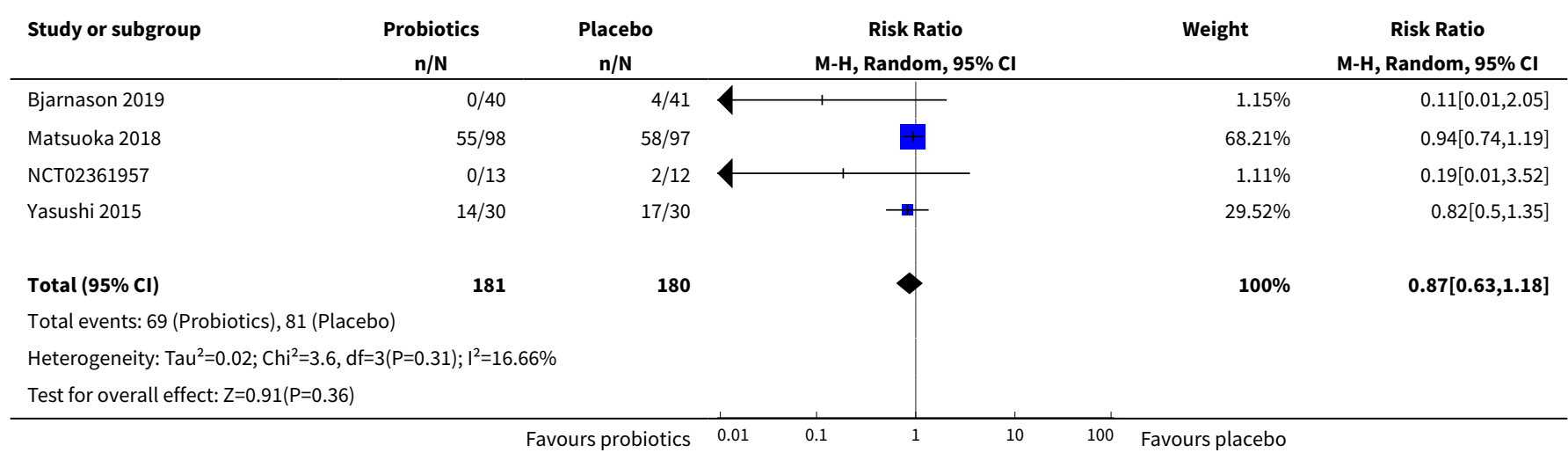

Analysis 1.2. Comparison 1 Probiotics versus placebo, Outcome 2 Maintenance of clinical remission.

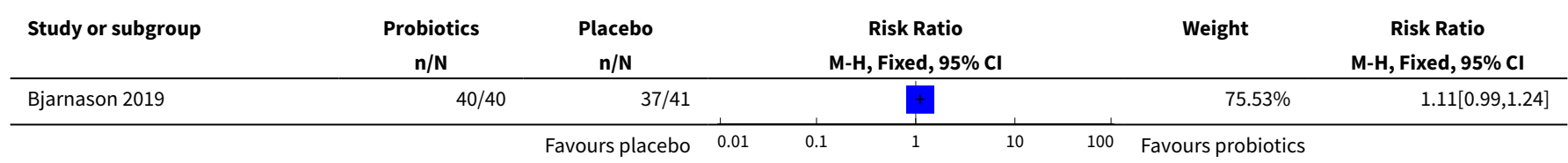




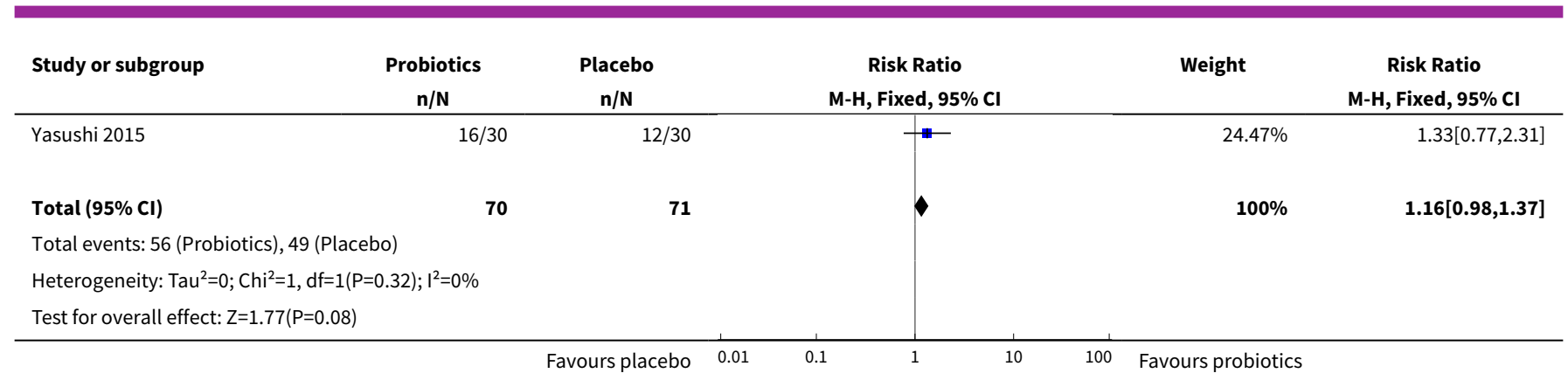

Analysis 1.3. Comparison 1 Probiotics versus placebo, Outcome 3 Serious adverse events.

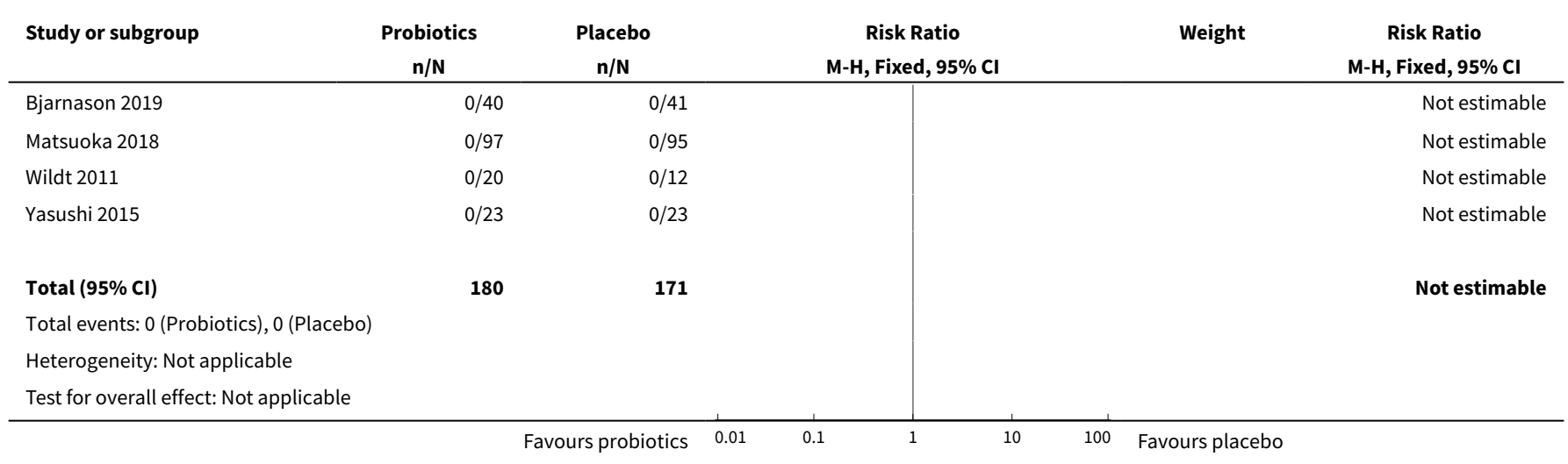

Analysis 1.4. Comparison 1 Probiotics versus placebo, Outcome 4 Withdrawal due to adverse events.

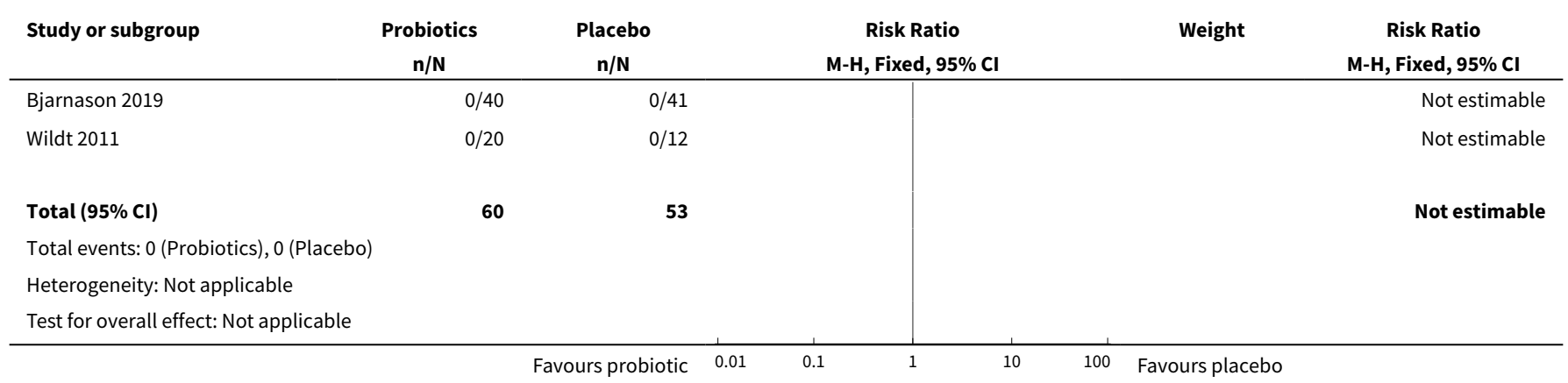

Analysis 1.5. Comparison 1 Probiotics versus placebo, Outcome 5 Health-related quality of life.

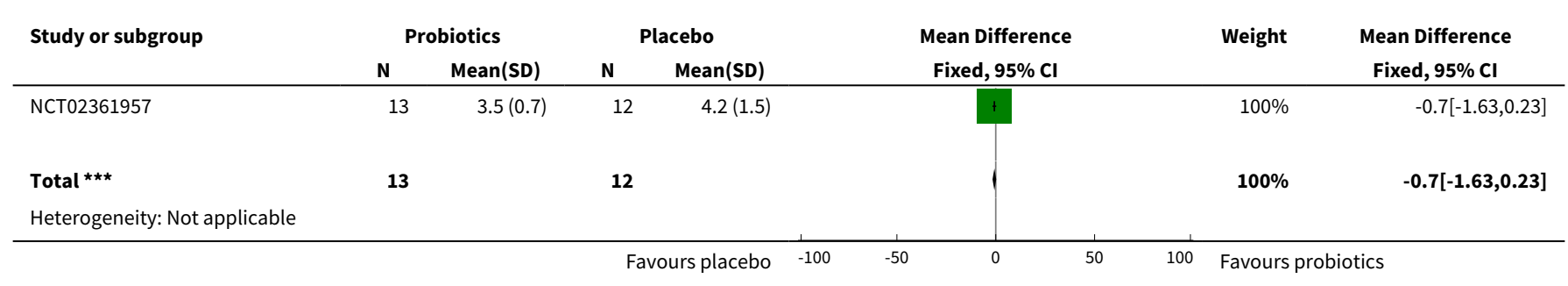




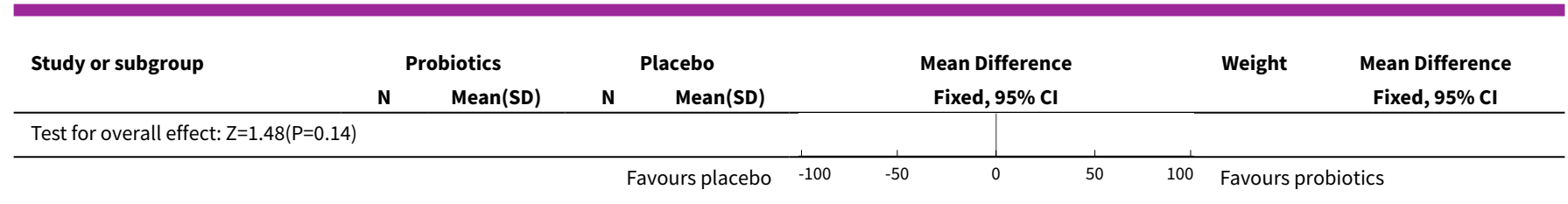

Comparison 2. Probiotics versus 5-aminosalicylic acid (5-ASA) (mesalazine)

\begin{tabular}{lllll}
\hline Outcome or subgroup title & $\begin{array}{l}\text { No. of } \\
\text { studies }\end{array}$ & $\begin{array}{l}\text { No. of } \\
\text { partici- } \\
\text { pants }\end{array}$ & Statistical method & Effect size \\
\hline 1 Clinical relapse & 2 & 452 & $\begin{array}{l}\text { Risk Ratio (M-H, Random, 95\% } \\
\text { Cl) }\end{array}$ & $1.01[0.84,1.22]$ \\
\hline 2 Maintenance of clinical remission & 1 & 125 & Risk Ratio (M-H, Fixed, 95\% Cl) & $1.06[0.90,1.25]$ \\
\hline 3 Serious adverse events & 1 & 327 & Risk Ratio (M-H, Fixed, 95\% Cl) & $1.19[0.41,3.46]$ \\
\hline 4 Withdrawal due to adverse events & 1 & 222 & Risk Ratio (M-H, Fixed, 95\% Cl) & $1.02[0.46,2.25]$ \\
\hline 5 Health-related quality of life & 1 & 222 & $\begin{array}{l}\text { Mean Difference (IV, Fixed, 95\% } \\
\text { Cl) }\end{array}$ & $-0.80[-2.01,0.41]$ \\
\hline
\end{tabular}

Analysis 2.1. Comparison 2 Probiotics versus 5-aminosalicylic acid (5-ASA) (mesalazine), Outcome 1 Clinical relapse.

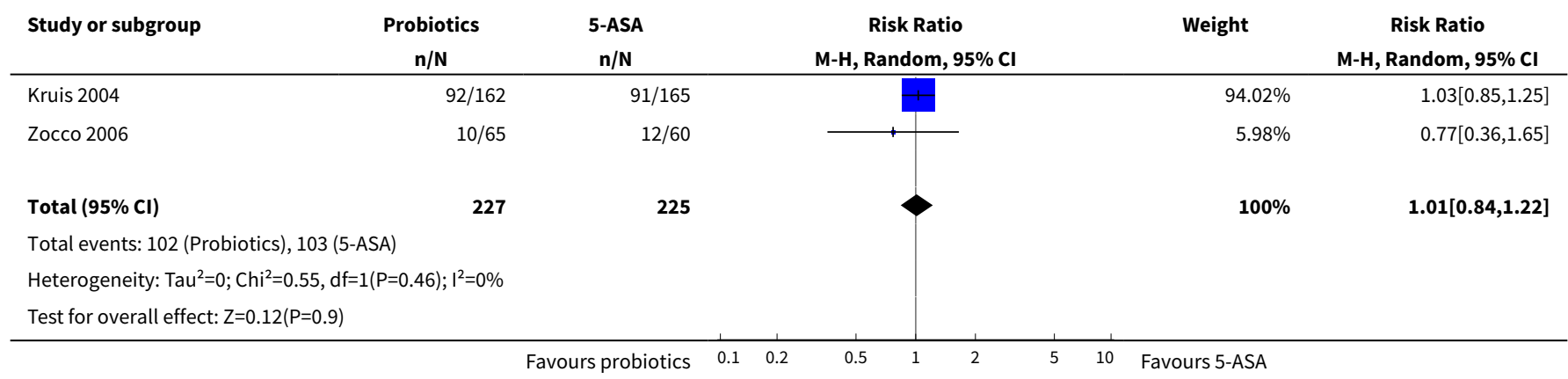

Analysis 2.2. Comparison 2 Probiotics versus 5-aminosalicylic acid (5ASA) (mesalazine), Outcome 2 Maintenance of clinical remission.

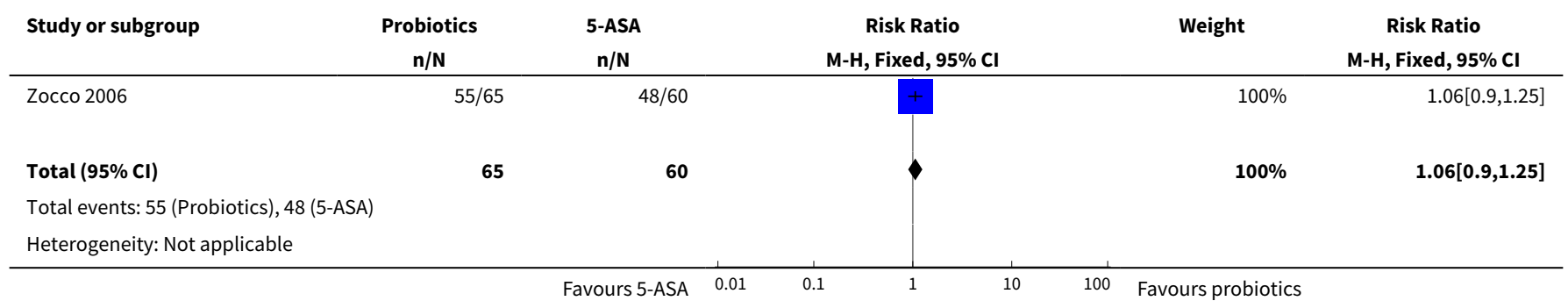




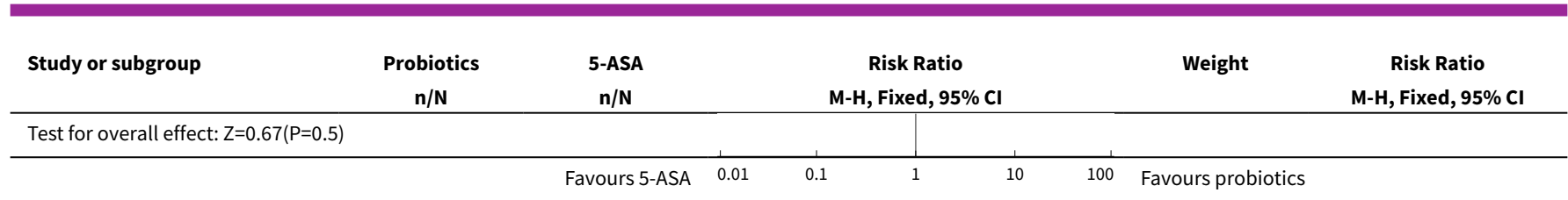

Analysis 2.3. Comparison 2 Probiotics versus 5-aminosalicylic acid (5-ASA) (mesalazine), Outcome 3 Serious adverse events.

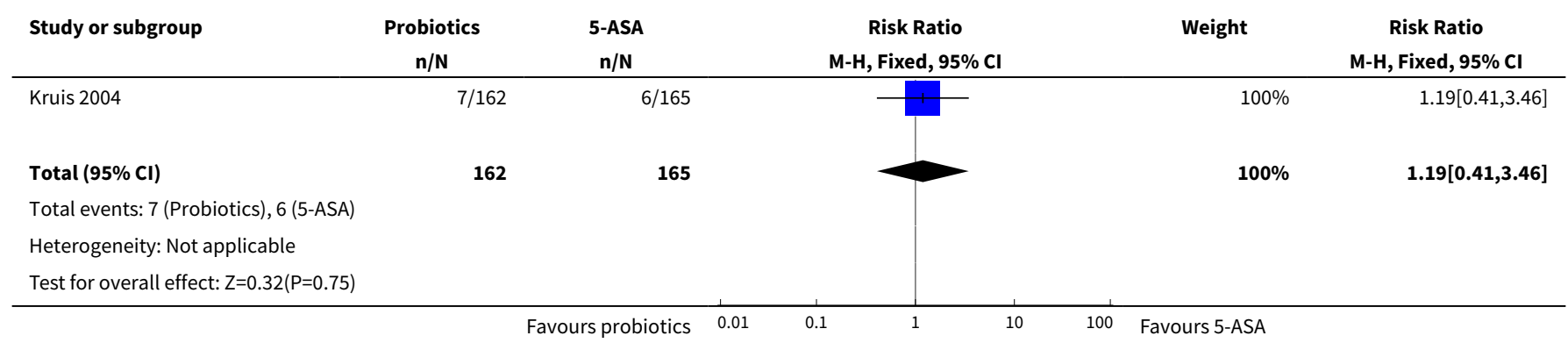

Analysis 2.4. Comparison 2 Probiotics versus 5-aminosalicylic acid (5-

ASA) (mesalazine), Outcome 4 Withdrawal due to adverse events.

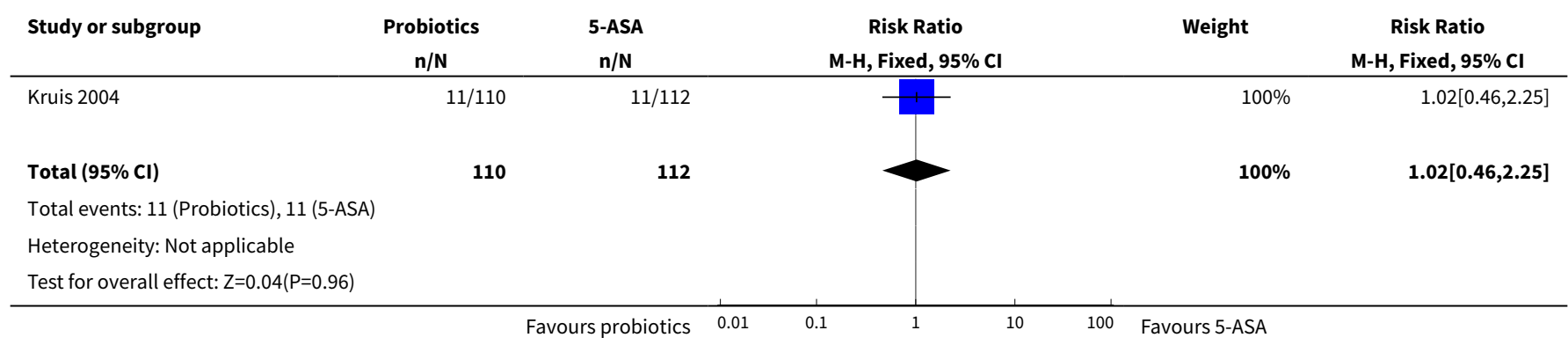

Analysis 2.5. Comparison 2 Probiotics versus 5-aminosalicylic acid (5-ASA) (mesalazine), Outcome 5 Health-related quality of life.

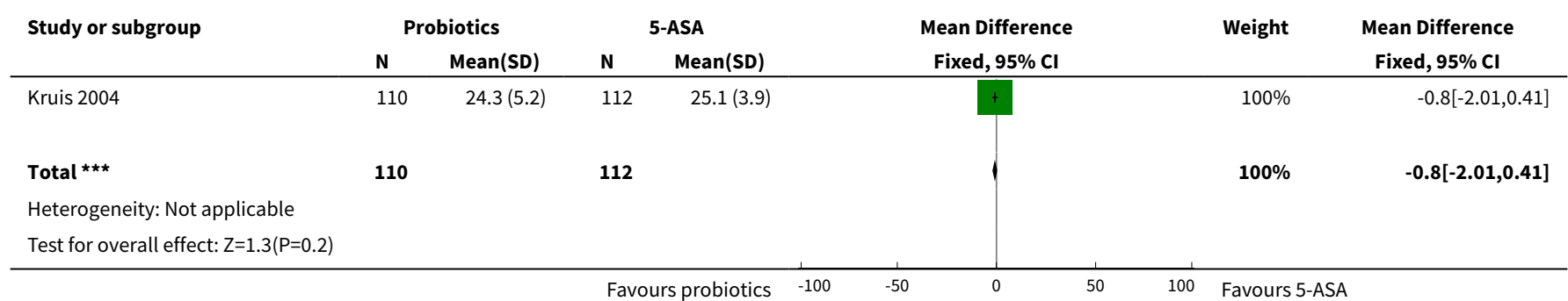


Comparison 3. Probiotic + 5-aminosalicylic acid (5-ASA) (mesalazine) versus 5-ASA (mesalazine)

\begin{tabular}{lllll}
\hline Outcome or subgroup title & $\begin{array}{l}\text { No. of } \\
\text { studies }\end{array}$ & $\begin{array}{l}\text { No. of } \\
\text { partici- } \\
\text { pants }\end{array}$ & Statistical method & Effect size \\
\hline 1 Clinical relapse & 2 & 242 & Risk Ratio (M-H, Random, 95\% Cl) & $1.11[0.66,1.87]$ \\
\hline 2 Maintenance of clinical remission & 1 & 122 & Risk Ratio (M-H, Random, 95\% Cl) & $1.05[0.89,1.24]$ \\
\hline $\begin{array}{l}3 \text { Withdrawal due to serious ad- } \\
\text { verse events }\end{array}$ & 2 & 127 & Risk Ratio (M-H, Fixed, 95\% Cl) & $5.29[0.26,107.63]$ \\
\hline
\end{tabular}

Analysis 3.1. Comparison 3 Probiotic + 5-aminosalicylic acid (5-ASA)

(mesalazine) versus 5-ASA (mesalazine), Outcome 1 Clinical relapse.

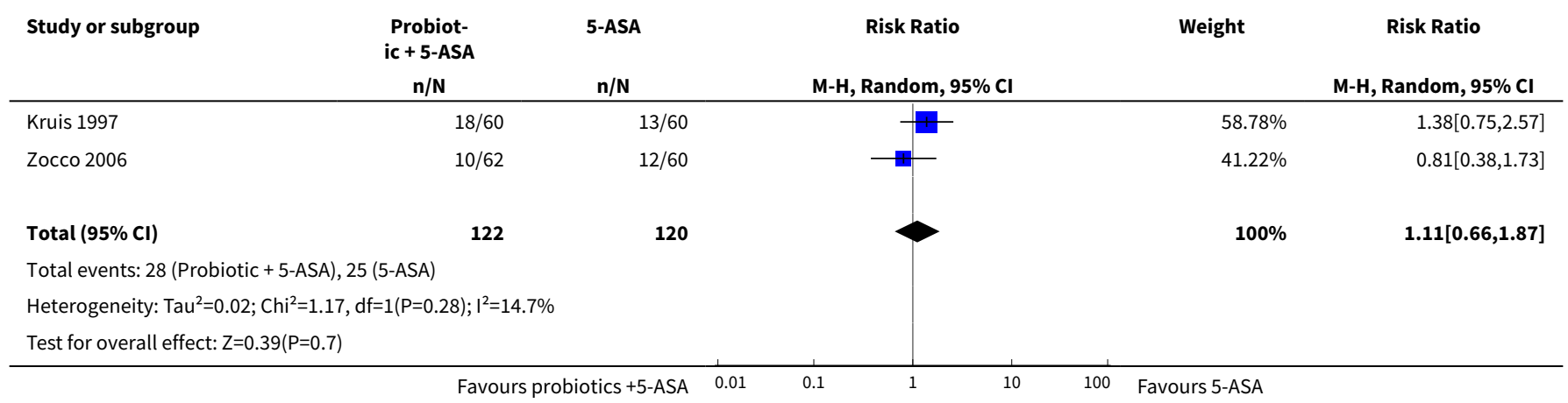

Analysis 3.2. Comparison 3 Probiotic + 5-aminosalicylic acid (5-ASA) (mesalazine) versus 5-ASA (mesalazine), Outcome 2 Maintenance of clinical remission.

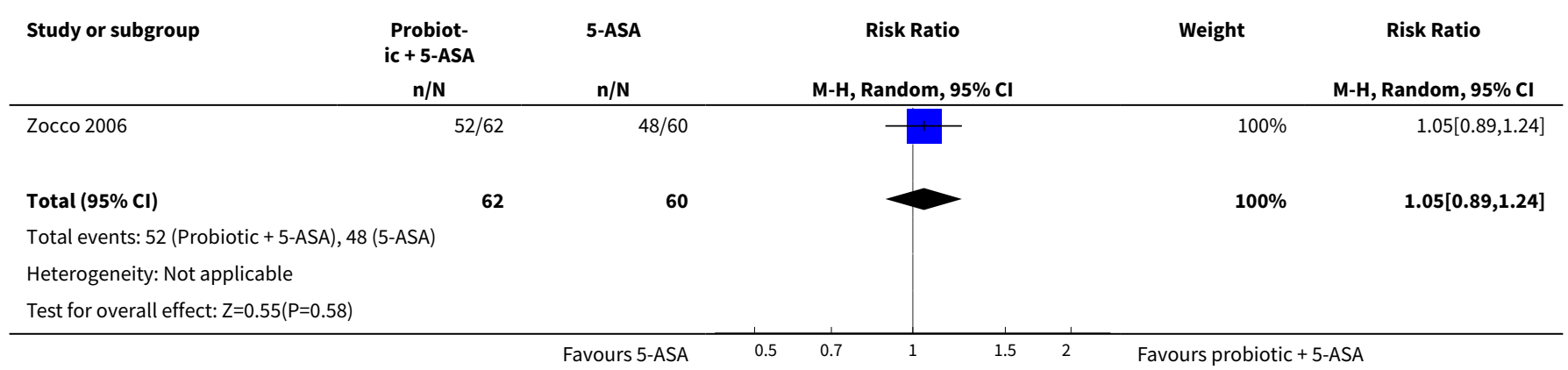


Analysis 3.3. Comparison 3 Probiotic + 5-aminosalicylic acid (5-ASA) (mesalazine) versus 5-ASA (mesalazine), Outcome 3 Withdrawal due to serious adverse events.

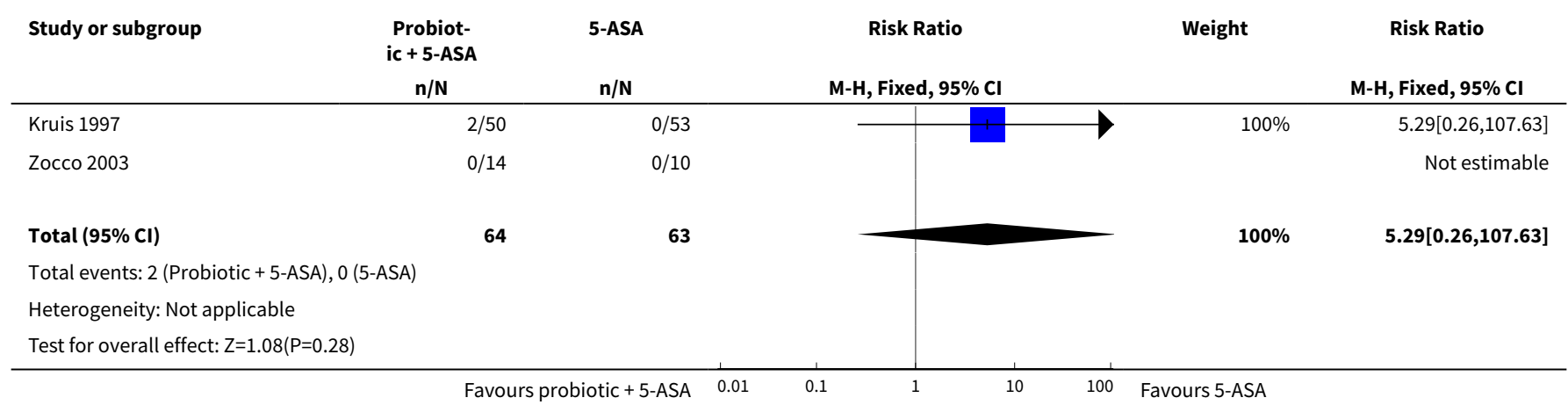

\section{ADDITIONAL TABLES}

Table 1. Outcome data table

\begin{tabular}{|c|c|c|c|c|c|c|}
\hline Study ID & Number of relapses & Definition of relapse & $\begin{array}{l}\text { Mainte- } \\
\text { nance of } \\
\text { remission }\end{array}$ & $\begin{array}{l}\text { Quality of } \\
\text { life }\end{array}$ & $\begin{array}{l}\text { Serious } \\
\text { adverse } \\
\text { events }\end{array}$ & $\begin{array}{l}\text { With- } \\
\text { drawal } \\
\text { due to } \\
\text { adverse } \\
\text { events }\end{array}$ \\
\hline $\begin{array}{l}\text { Bjarnason } \\
2019\end{array}$ & 0 versus 4 & NR & NR & $\begin{array}{l}7.9+/-2.8 \\
\text { versus } 8.0 \\
+/-2.5\end{array}$ & None & None \\
\hline NCT0236195 & $\begin{array}{l}70 / 13 \text { versus } 1 / 12 \\
0 / 13 \text { versus } 2 / 12\end{array}$ & Relapse was defined as a flare-up & NR & $\begin{array}{l}3.5+/-0.7 \\
\text { versus } 4.2 \\
+/-1.5\end{array}$ & NR & NR \\
\hline $\begin{array}{l}\text { Copaci } \\
2014\end{array}$ & $30 \%$ versus $28 \%$ & NR & $\begin{array}{l}77 \% \text { ver- } \\
\text { sus } 90 \%\end{array}$ & NR & NR & NR \\
\hline Kruis 1997 & $\begin{array}{l}8 / 50 \text { versus } 6 / 53 ; \\
18 / 60 \text { versus } 13 / 60\end{array}$ & $\mathrm{CAl}>4$ & NR & NR & NR & $\begin{array}{l}2 / 50 \text { ver- } \\
\text { sus } 1 / 53\end{array}$ \\
\hline Kruis 2004 & $\begin{array}{l}40 / 110 \text { versus } 38 / 112 ; \\
92 / 162 \text { versus } 91 / 165\end{array}$ & $\begin{array}{l}\text { The presence of all of the follow- } \\
\text { ing: } \mathrm{CAI}>6 \text { (or an increase in CAI of } \\
\text { at least } 3 \text { points with } \mathrm{CAI}=4 \text { being } \\
\text { exceeded at the same time); endo- } \\
\text { scopic index }>4 \text {; histological signs of } \\
\text { acute inflammation }\end{array}$ & NR & $\begin{array}{l}24.3+/- \\
5.2 \text { versus } \\
25.1+/- \\
3.9\end{array}$ & $\begin{array}{l}7 / 162 \text { ver- } \\
\text { sus } 6 / 165\end{array}$ & $\begin{array}{l}11 / 110 \\
\text { ver- } \\
\text { sus } 11 / 112 \\
63 / 162 \\
\text { versus } \\
64 / 165\end{array}$ \\
\hline $\begin{array}{l}\text { Matsuoka } \\
2018\end{array}$ & $\begin{array}{l}22 / 97 \text { versus } 19 / 95 \\
55 / 98 \text { versus } 58 / 97\end{array}$ & $\begin{array}{l}\text { The persistence of a rectal bleeding } \\
\text { score of } \geq 2 \text { on Sutherland DAI score } \\
\text { for } 3 \text { consecutive days and/or initia- } \\
\text { tion of remission induction therapy } \\
\text { for worsening of UC }\end{array}$ & $\begin{array}{l}\text { Reported } \\
P=0.643\end{array}$ & NR & $0^{*}$ & $\begin{array}{l}0 / 97 \text { ver- } \\
\text { sus } 2 / 95\end{array}$ \\
\hline $\begin{array}{l}\text { Shanahan } \\
2006\end{array}$ & NR & $\begin{array}{l}\text { Defined as }<3 \text { bowel movements per } \\
\text { day (without frank/gross blood) out } \\
\text { of } 7\end{array}$ & NR & NR & NR & NR \\
\hline
\end{tabular}


Table 1. Outcome data table (Continued)

\begin{tabular}{|c|c|c|c|c|c|c|}
\hline $\begin{array}{l}\text { Vejdani } \\
2017\end{array}$ & $\begin{array}{l}2 / 14 \text { versus } 4 / 15 \\
4 / 14 \text { versus } 7 / 15\end{array}$ & $\begin{array}{l}\text { An increase in bowel frequency } \\
\text { with blood for at least } 1 \text { week. A } \\
\text { colonoscopy was performed and } \\
\text { biopsies were taken to confirm re- } \\
\text { lapse }\end{array}$ & NR & NR & 0 & NR \\
\hline Wildt 2011 & $15 / 20$ versus $11 / 12$ & $\begin{array}{l}\text { SCCAI score }>4 \text { and/or endoscopic } \\
\text { changes grade } 2-3\end{array}$ & $\begin{array}{l}5 / 20 \text { ver- } \\
\text { sus } 1 / 12\end{array}$ & NR & $\begin{array}{l}0 / 20 \text { ver- } \\
\text { sus } 0 / 12\end{array}$ & $\begin{array}{l}0 / 20 \text { ver- } \\
\text { sus } 0 / 12\end{array}$ \\
\hline $\begin{array}{l}\text { Yasushi } \\
2015\end{array}$ & $\begin{array}{l}7 / 23 \text { versus } 10 / 23 \\
14 / 30 \text { versus } 17 / 30\end{array}$ & $\mathrm{CAI} \leq 5$ & $\begin{array}{l}16 / 23 \text { ver- } \\
\text { sus } 13 / 23 \\
16 / 30 \text { ver- } \\
\text { sus } 13 / 30\end{array}$ & NR & $\begin{array}{l}0 / 23 \text { ver- } \\
\text { sus } 0 / 23\end{array}$ & NR \\
\hline $\begin{array}{l}\text { Zocco } \\
2006\end{array}$ & $\begin{array}{l}\text { 10/65 (Probiotic) ver- } \\
\text { sus } 12 / 60 \text { (Mesalazine) } \\
\text { versus } 10 / 62 \text { (Probiot- } \\
\text { ic+Mesalazine) }\end{array}$ & $\begin{array}{l}\text { The appearance of UC symptoms } \\
\text { or an increase in CAI to more than } 4 \\
\text { points }\end{array}$ & $\begin{array}{l}55 / 65 \text { ver- } \\
\text { sus } 48 / 60 \\
\text { versus } \\
52 / 62\end{array}$ & NR & $\begin{array}{l}0 / 65 \text { ver- } \\
\text { sus } 0 / 60 \\
\text { versus } \\
0 / 62\end{array}$ & NR \\
\hline
\end{tabular}

*Serious adverse events which occurred were reportedly not related to the intervention (avascular necrosis of bilateral femoral head and pulmonary thromboembolism)

CAl: colitis activity index; DAl: disease activity index; NR: not reported; SCCAI: simple clinical colitis activity index UC: ulcerative colitis

Table 2. Sensitivity analysis

\begin{tabular}{lll}
\hline Outcome & Fixed-effect & Random-effects \\
\hline Probiotics versus placebo & & \\
\hline Clinical relapse & RR $0.85,95 \% \mathrm{Cl} 0.68$ to 1.05 & $\mathrm{RR} 0.87,95 \% \mathrm{Cl} 0.63$ to 1.18 \\
\hline Maintenace of clinical remission & $\mathrm{RR} 1.16,95 \% \mathrm{Cl} 0.98$ to 1.37 & $\mathrm{RR} 1.11,95 \% \mathrm{Cl} 0.99$ to 1.24 \\
\hline Probiotics versus 5-ASA & & $\mathrm{RR} 1.01,95 \% \mathrm{Cl} 0.84$ to 1.22 \\
\hline Clinical relapse & $\mathrm{RR} 1.00,95 \% \mathrm{Cl} 0.83$ to 1.21 & $\mathrm{RR} 1.06,95 \% \mathrm{Cl} 0.90$ to 1.25 \\
\hline Maintenace of clinical remission & $\mathrm{RR} 1.06,95 \% \mathrm{Cl} 0.90$ to 1.25 & \\
\hline Probiotics + 5-ASA versus 5-ASA & & $\mathrm{RR} 1.11,95 \% \mathrm{Cl} 0.66$ to 1.87 \\
\hline Clinical relapse & $\mathrm{RR} 1.10,95 \% \mathrm{Cl} 0.69$ to 1.78 & $\mathrm{RR} 1.05,95 \% \mathrm{Cl} 0.89$ to 1.24 \\
\hline Maintenance of clinical remission & $\mathrm{RR} 1.05,95 \% \mathrm{Cl} 0.89$ to 1.24 & \\
\hline
\end{tabular}

5-ASA: 5-aminosalicylic acid; CI: confidence interval; RR: risk ratio 


\section{A P P E N D I CES}

\section{Appendix 1. Search strategies}

\section{EMBASE}

1. random\$.tw.

2. factorial\$.tw.

3. (crossover\$ or cross over\$ or cross-over\$).tw.

4. placebo\$.tw.

5. single blind.mp.

6. double blind.mp.

7. triple blind.mp.

8. (singl\$ adj blind\$).tw.

9. (double\$ adj blind\$).tw.

10. (tripl\$ adj blind\$).tw.

11. assign\$.tw.

12. allocat\$.tw.

13. crossover procedure/

14. double blind procedure/

15. single blind procedure/

16. triple blind procedure/

17. randomized controlled trial/

18. or/1-17

19. exp ulcerative colitis/

20. colitis.mp.

21. inflammatory bowel disease.mp.

22. IBD.mp.

23. UC.mp.

24. $0 r / 19-23$

25. exp Probiotics/

26. exp Synbiotics/

27. probiotic*.tw.

28. synbiotic ${ }^{\star} . t w$.

29. exp Lactobacillus/

30. lactobacill*.tw.

31. bacill*.tw.

32. exp Bifidobacterium/ 
33. (bifidus or bifidobacter ${ }^{\star}$ ).tw.

34. exp Streptococcus thermophilus/

35. streptococcus thermophilus.tw.

36. streptococc ${ }^{\star} . t w$.

37. exp Lactococcus/

38. lactococc ${ }^{\star}$.tw.

39. Bacillus subtilis/

40. bacillus subtilis.tw.

41. exp Enterococcus/

42. exp Enterococcus faecium/ or Enterococcus faecalis/

43. exp Saccharomyces/

44. saccharomyc*.tw.

45. leuconostoc.tw.

46. pediococc ${ }^{\star}$. tw.

47. bulgarian bacillus.tw.

48. (beneficial adj3 bacter $^{\star}$ ).tw.

49. (Escherichia coli or "E. coli").tw.

50. Yeast.tw.

51. (fungus or fungi).tw.

52. (VSL\# 3 or VSL 3).tw.

53. $\mathrm{Or} / 25-52$

54. 18 and 24 and 53

\section{Medline}

1. random\$.tw.

2. factorial\$.tw.

3. (crossover\$ or cross over $\$$ or cross-over\$).tw.

4. placebo\$.tw.

5. single blind.mp.

6. double blind.mp.

7. triple blind.mp.

8. (singl\$ adj blind\$).tw.

9. (double $\$$ adj blind\$).tw.

10.(tripl\$ adj blind\$).tw.

11.assign\$.tw.

12.allocat\$.tw.

13.randomized controlled trial/

14.or/1-13

15.exp ulcerative colitis/

16.colitis.mp.

17.inflammatory bowel disease.mp.

18.IBD.mp.

Probiotics for maintenance of remission in ulcerative colitis (Review) 
19.UC.mp.

20.0r/15-19

21.exp Probiotics/

22.exp Synbiotics/

23. probiotic ${ }^{*}$.tw.

24. synbiotic ${ }^{\star}$.tw.

25.exp Lactobacillus/

26.lactobacill*.tw.

27. bacill ${ }^{\star}$. tw.

28.exp Bifidobacterium/

29. (bifidus or bifidobacter ${ }^{\star}$ ).tw.

30.exp Streptococcus thermophilus/

31.streptococcus thermophilus.tw.

32. streptococc ${ }^{\star}$. tw.

33.exp Lactococcus/

34. lactococc ${ }^{\star}$.tw.

35. Bacillus subtilis/

36. bacillus subtilis.tw.

37.exp Enterococcus/

38. exp Enterococcus faecium/ or Enterococcus faecalis/

39.exp Saccharomyces/

40. saccharomyc ${ }^{\star}$. tw.

41.leuconostoc.tw.

42. pediococc ${ }^{\star} . t w$.

43. bulgarian bacillus.tw.

44. (beneficial adj3 bacter $^{\star}$ ).tw.

45.(Escherichia coli or "E. coli").tw.

46. Yeast.tw.

47. (fungus or fungi).tw.

48. (VSL\# 3 or VSL 3).tw.

49. Or/21-48

50.14 and 20 and 49

\section{Cochrane CENTRAL}

\#1 MeSH descriptor: [Probiotics] explode all trees

\#2 MeSH descriptor: [Synbiotics] explode all trees

\#3 probiotic*

\#4 synbiotic*

\#5 MeSH descriptor: [Lactobacillus] explode all trees

\#6 lactobacill*

\#7 bacill ${ }^{\star}$

\#8 MeSH descriptor: [Bifidobacterium] explode all trees

\#9 (bifidus or bifidobacter ${ }^{\star}$ )

\#10 MeSH descriptor: [Streptococcus thermophilus] explode all trees

\#11 streptococcus thermophilus

\#12 streptococc*

Probiotics for maintenance of remission in ulcerative colitis (Review) 
\#13 MeSH descriptor: [Lactococcus] explode all tree

\#14 lactococc*

\#15 MeSH descriptor: [Bacillus subtilis] explode all trees

\#16 bacillus subtilis

\#17 MeSH descriptor: [Enterococcus] explode all trees

$\# 18$ enterococcus faec ${ }^{*}$

\#19 MeSH descriptor: [Saccharomyces] explode all trees

\#20 saccharomyc*

\#21 leuconostoc*

\#22 pediococc ${ }^{\star}$

\#23 bulgarian bacillus

\#24 (Escherichia coli or "E. coli").tw.

\#25 Yeast.tw.

\#26 (fungus or fungi).tw.

\#27 Or/\#1-\#26

\#28 MeSH: [Ulcerative colitis] explode all trees

\#29 UC

\#30 Inflammatory bowel disease

\#31 IBD

\#32 \#28 or \#29 \#30 and \#31

\#33 \#27 and \#32

The Cochrane IBD/FBD Review Specialised Trials Register

1. Probiotics and Inflammatory bowel disease

2. Probiotics and Ulcerative colitis

3. Synbiotics and Inflammatory bowel disease

4. Synbiotics and Ulcerative colitis

\section{CINAHL}

1. (TI probiotic* or $A B$ probiotic $)$ OR ( $T$ I synbiotic* or $A B$ synbiotic $\left.{ }^{\star}\right)$ OR (TI probiotics ${ }^{\star}$ or $A B$ probiotics $\left.{ }^{\star}\right)$ OR $(T I$ lactobacill* or $A B$ lactobacill*) OR (TI bacill* or AB bacill*) OR (TI bifidobacter ${ }^{\star}$ or AB bifidobacter ${ }^{\star}$ ) OR (TI bifidus ${ }^{\star}$ or AB bifidus ${ }^{\star}$ ) OR (TI streptococc or $^{\star}$ AB

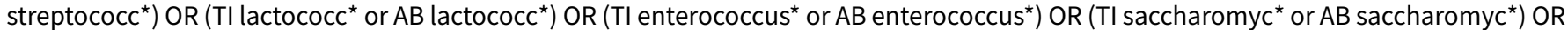

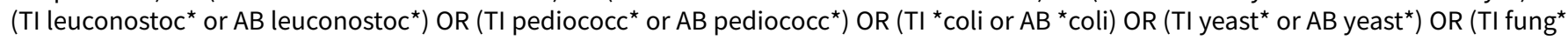
or $A B$ fung $\left.{ }^{\star}\right) O R\left(T I V S L^{\star}\right.$ or $\left.A B V S L^{\star}\right)$

2. (TI Inflammatory bowel disease or AB Inflammatory bowel disease) OR ( $T I$ Ulcerative colitis or AB Ulcerative colitis) OR (TI UC or AB UC) $\mathrm{OR}(\mathrm{TI}$ IBD or AB IBD)

\section{1 and 2}

\section{Clinical trials.gov}

1. Probiotics and inflammatory bowel disease (37) 
2. Probiotics and Ulcerative colitis (23)

3. Synbiotic and inflammatory bowel disease (3)

4. Synbiotic and Ulcerative colitis (1)

WHAT'S NEW

\begin{tabular}{lll}
\hline Date & Event & Description \\
\hline 29 November 2019 & $\begin{array}{l}\text { New citation required but conclusions } \\
\text { have not changed }\end{array}$ & $\begin{array}{l}\text { There remains insufficient evidence for the use of probiotics } \\
\text { in maintaining remission in ulcerative colitis. Further research } \\
\text { against placebo is unlikely to provide useful data, and instead } \\
\text { comparisons to other therapies is proposed. }\end{array}$ \\
\hline 31 October 2019 & New search has been performed & $\begin{array}{l}\text { We updated the searches in December 2017 and reran them in } \\
\text { October 2019; we added eight new studies to this update. }\end{array}$ \\
\hline
\end{tabular}

\section{H I S T ORY}

Protocol first published: Issue 4, 2008

Review first published: Issue 12, 2011

\begin{tabular}{lll}
\hline Date & Event & Description \\
\hline 8 May 2018 & Amended & ZIE, LK and PB were added to the author team \\
\hline
\end{tabular}

\section{CONTRIBUTIONS OF AUTHORS}

Zipporah Iheozor-Ejiofor co-ordinated the review; extracted data and contacted authors; checked the quality of data extraction; analysed and interpreted data; undertook and checked quality assessment; performed statistical analysis; checked the quality of the statistical analysis; produced the first draft of the review; contributed to writing and editing the review; made an intellectual contribution to the review; and approved the final review prior to submission.

Lakhbir Kaur performed screening of titles and abstracts and full-text articles, extracted data and contacted authors; contributed to writing and editing the review; made an intellectual contribution to the review; and approved the final review prior to submission.

Morris Gordon performed screening of titles and abstracts and full-text articles, extracted data and contacted authors, analysed and interpreted data; contributed to writing and editing the review; made an intellectual contribution to the review; contributed to previous versions of the review; made final changes to the review, including the update search prior to publication and peer review changes; and approved the final review prior to submission.

Patricia Baines contributed to writing and editing the review; made an intellectual contribution to the review; approved the final review prior to submission

Vasiliki Sinopoulou made update changes to all sections of the review following peer review and repeated searches; and approved the final review.

Anthony Akobeng initiated and conceptualised the review; contributed to previous versions of the review; and approved the final review prior to submission.

\section{DECLARATIONS OF INTEREST}

Zipporah Iheozor-Ejiofor: my employment at the University of Central Lancashire is funded by the National Institute for Health Research (NIHR) UK and focuses on high priority Cochrane Reviews in Inflammatory Bowel Disease.

Lakhbir Kaur: none known 
Morris Gordon: received travel grants from various companies to attend scientific meetings in the last three years, including Biogaia, Synergy, Tillots, Ferring and Allergan. None of these companies have had any involvement in the planning, completion, analysis or write up of this or any other reviews. This review has been completed as part of a UK funded National Institute for Health Research (NIHR) Cochrane Programme grant, with some time funded.

Patricia Baines: none known

Vasiliki Sinopoulou: none known

Anthony Akobeng: none known

\section{SOURCES OF SUPPORT}

\section{Internal sources}

- School of Medicine, University of Central Lancashire, UK.

\section{External sources}

- National Institute for Health Research, UK.

This project was supported by the National institute for Health Research, via Cochrane Infrastructure and Cochrane Programme Grant funding (NIHR Cochrane Program Grant 16/114/13 - A programme of Cochrane systematic reviews to investigate optimal treatment strategies using emerging pharmacological interventions, dietary therapies and interventions to manage pain in inflammatory bowel disease) to the University of Central Lancashire (UCLAN). The views and opinions expressed therein are those of the authors and do not necessarily reflect those of the Systematic Reviews Programme, NIHR, National Health Service (NHS) or the Department of Health.

\section{DIFFERENCES BETWEEN PROTOCOL AND REVIEW}

We made a posthoc decision not to collect data on biochemical markers of inflammation as an outcome. Biochemical markers as surrogate endpoints are unlikely to provide results which are helpful to clinicians or patients.

Since the previous review, we have updated the search strategy, 'Risk of bias' reporting and use of GRADE to current Cochrane standards.

\section{INDEX TERMS}

\section{Medical Subject Headings (MeSH)}

Colitis, Ulcerative [*therapy]; Probiotics [adverse effects] [ ${ }^{\star}$ therapeutic use]; Randomized Controlled Trials as Topic; Remission Induction

\section{MeSH check words}

Humans 